\title{
PRIOR LEARNING ASSESSMENT FOR CREDIT AT THE UNIVERSITY OF CENTRAL MISSOURI: A PROGRAM EVALUATION
}

A Dissertation
presented to the
Faculty of the Graduate School
University of Missouri - Columbia
In Partial Fulfillment
of the Requirements for the Degree of
Doctor of Education
br. Sandy Hutchinson, Dissertation Supervisor
MAY 2018


The undersigned, appointed by the dean of the Graduate School, have examined the dissertation entitled

\section{PRIOR LEARNING ASSESSMENT PROCESS FOR CREDIT AT THE UNIVERSITY OF CENTRAL MISSOURI: A PROGRAM EVALUATION}

presented by Vicki M. Orcutt, a candidate for the degree of Doctor of Education, and hereby certify that, in their opinion, it is worthy of acceptance

Dr. Sandra Hutchinson, Dissertation Advisor

Dr. Barbara N. Martin

Dr. Douglas Thomas

Dr. Steve Ritter 
There is no way I would have completed this journey without a lot of divine intervention from being accepted into the program to the completion of this dissertation. While God has been with me, so has my family. John, you have always been my biggest advocate for the last 32 years and without your subtle and not so subtle nudges to keep going I would not have accomplished this goal. Samantha, Daniele, and Taylor Mae thank you for understanding that sometimes I could not be there when you needed me. I am so proud of each of you and thanks for being my biggest fans...love you. 


\section{ACKNOWLEDGEMENTS}

I would never have applied for this doctoral program if not for my former boss, Dr. Gersham Nelson. Every time I would take a class he would counsel me on my educational goals and encourage me to get my doctorate. I am so glad he cared enough to push me in this direction and that I listened.

I also would not have made it through if not for my program coordinator, Dr. Sandy Hutchinson who provided encouragement and direction throughout this degree program. Thank you to my dissertation committee: Dr. Sandy Hutchinson, Dr. Barbara Martin, Dr. Douglas Thomas, and Dr. Steven Ritter for your insight and support. I realize being on a dissertation committee takes a great deal of time out of your already busy schedules.

My classmates, Dr. Tammy Allen, Mr. Scott Ammon, Dr. Aime Breshears, Mr. Brad Drace, Dr. Jennifer Huseman, and Dr. Dan Jensen, made Wednesdays nights class something I looked forward to. I learned so much from each of you about higher education and K-12 education. I also want to say thank you to Dr. Dan Jensen for reaching out to me and keeping me focused on completing my dissertation.

Dr. Laurel Hogue, thank you for allowing me to complete this program evaluation and for being a good friend and boss. Your ability to complete your Ed.D. while raising two small children and accepting a Vice Provost position was motivation and encouragement for me. You are a great role model.

Thank you, Ms. Marcia Clemens, for taking the time to review and edit my dissertation. I am not sure I would have completed this daunting task without your assistance. 


\section{TABLE OF CONTENTS}

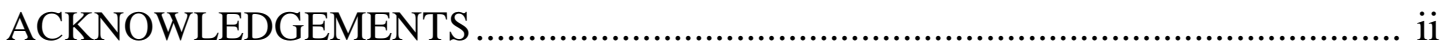

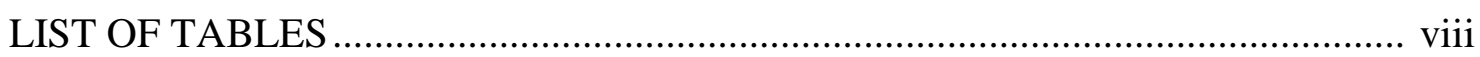

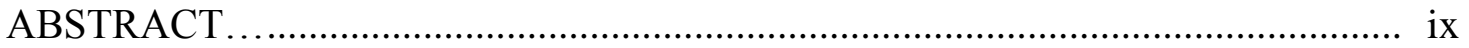

CHAPTER ONE: INTRODUCTION TO THE STUDY …................................ 1

Statement of the Problem ..................................................................... 8

Purpose of the Study .................................................................... 9

Research Questions .................................................................. 10

Conceptual Framework ...................................................................... 10

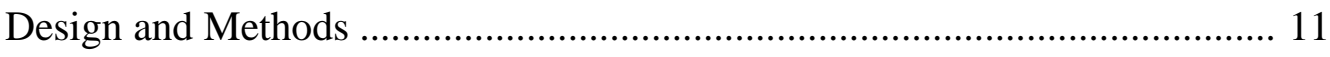

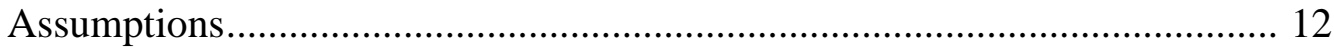

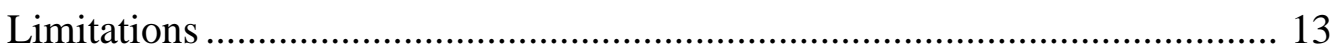

Definition of Key Terms ................................................................ 14

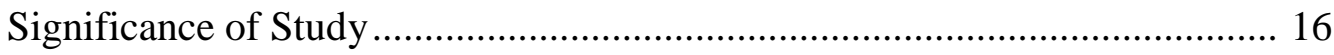

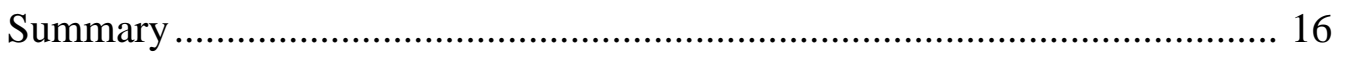

CHAPTER TWO: REVIEW OF RELATED LITERATURE................................. 19

The Learning Process............................................................................ 19

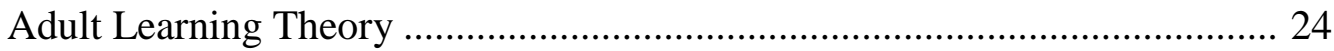

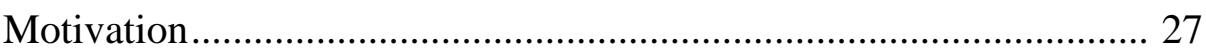

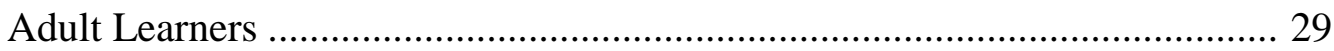

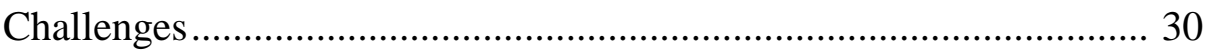

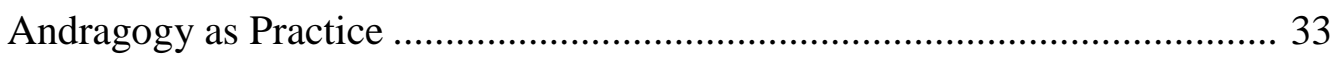

Transformative Learning .......................................................... 36 
Experiential Learning...................................................................... 38

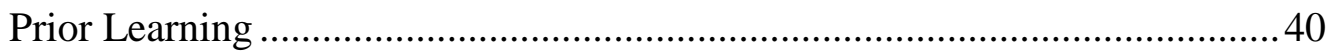

Advanced Placement Exams ............................................................ 42

College Level Examination Programs (CLEP) .................................... 43

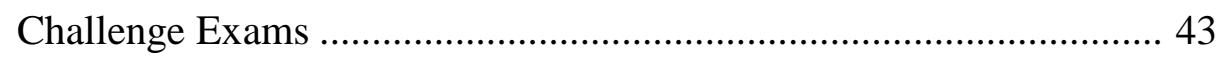

Evaluative Training, Certifications, and Licenses ............................... 44

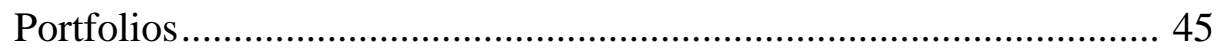

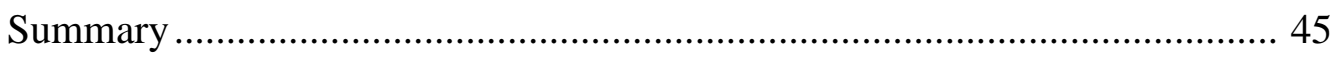

CHAPTER THREE: OVERVIEW OF THE STUDY …………………................... 47

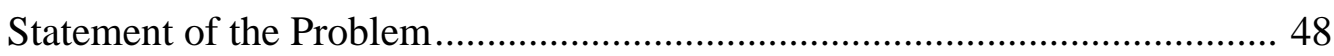

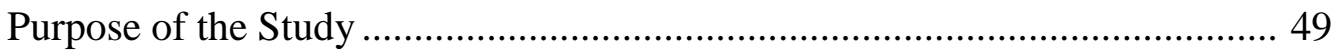

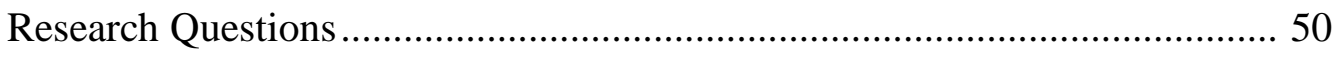

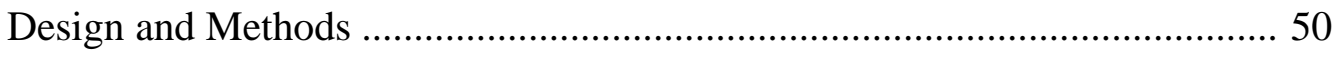

Participation and Sampling Procedures ........................................................ 51

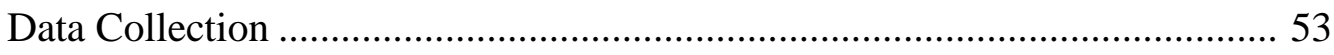

Data Collection Procedures................................................................. 53

Human Subjects Protection and Other Ethical Consideration .............. 55

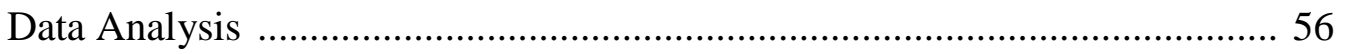

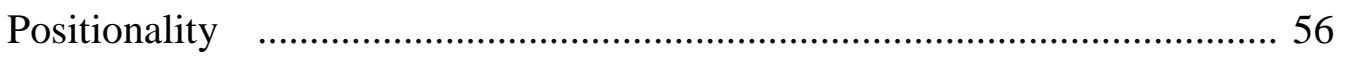

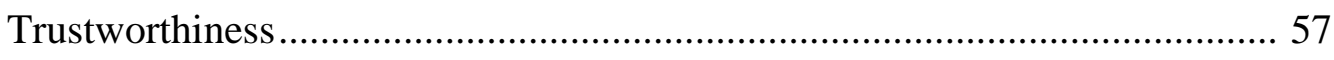

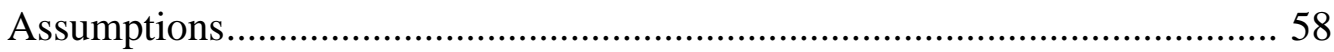

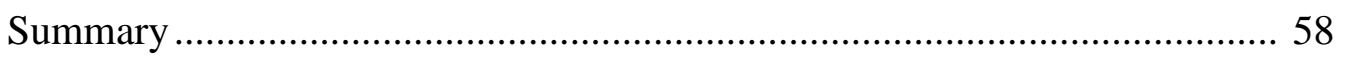

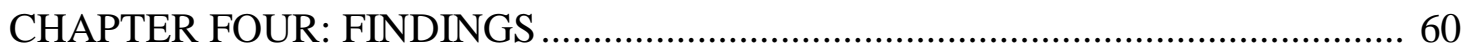




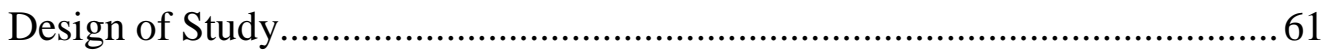

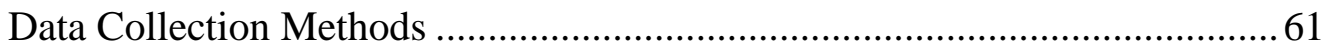

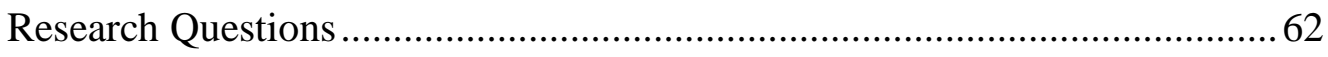

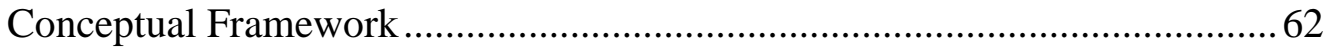

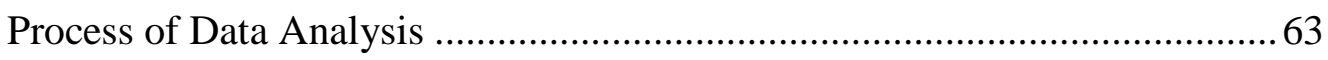

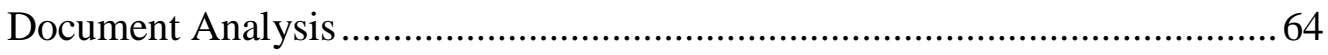

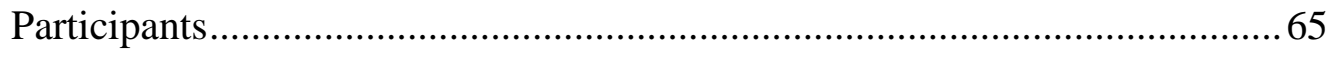

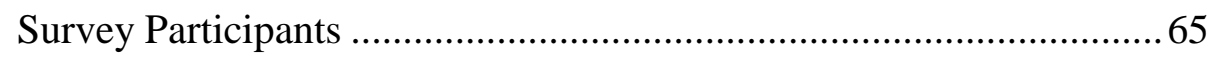

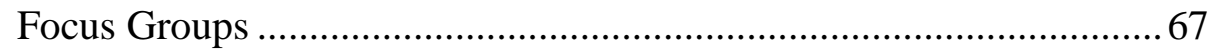

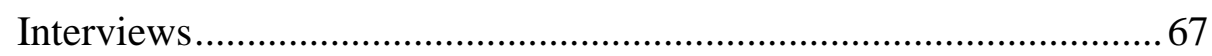

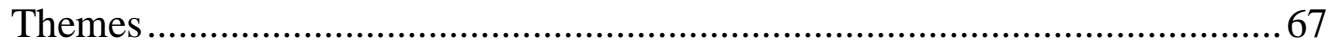

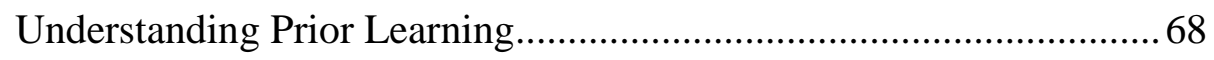

Initiation of the PLA Process .................................................. 71

Determining Credit Approval/Disapproval.................................... 73

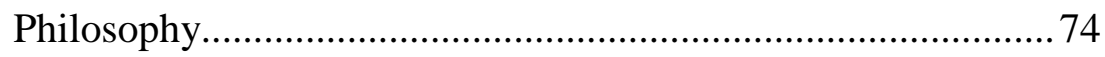

Policy …........................................................................ 75

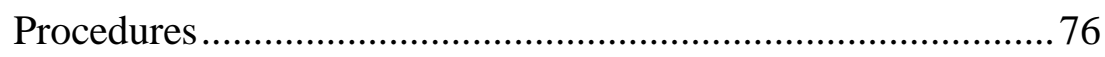

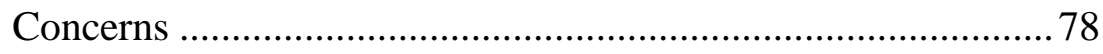

Impact on Student Success .................................................... 80

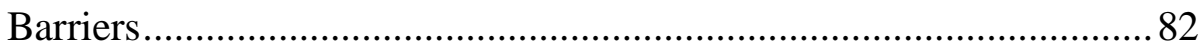

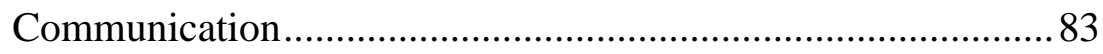

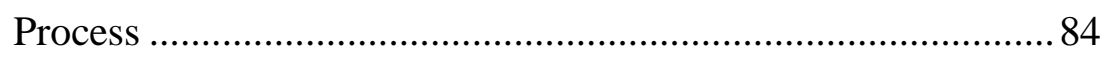

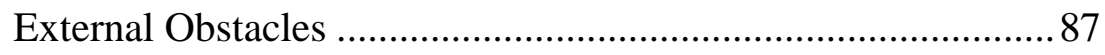


Summary

CHAPTER 5: SUMMARY, RECOMMENDATIONS, AND CONCLUSIONS .......91

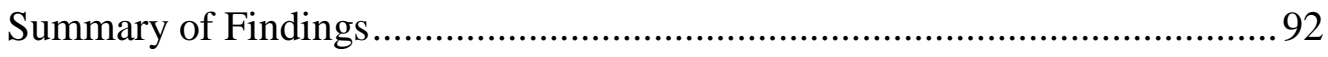

What Do Faculty Assessors Perceive as Barriers to Accepting

Credit for Prior Learning at UCM? ............................................. 93

What Type of Process do Faculty Assessors Use to Determine

Credit or Noncredit for Prior Learning? ....................................... 98

How Recognizable is UCM's PLA Program to Faculty, Administrators,

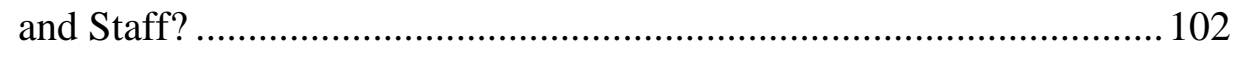

How Important Do Administrators and Faculty Assessors Perceive PLA in regards to Retention and Persistence Efforts of Nontraditional

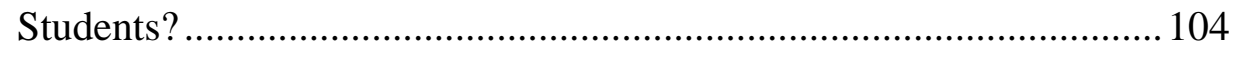

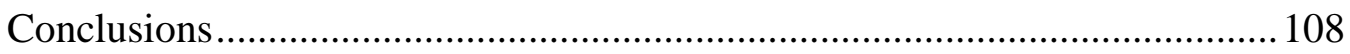

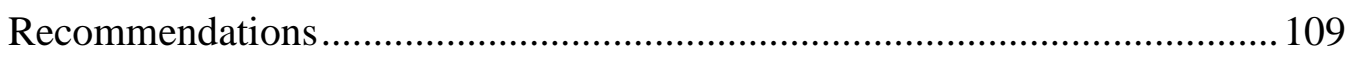

Understanding Prior Learning.................................................. 109

Initiation of the PLA Process ...................................................... 111

Determining Credit Approval/Disapproval...................................... 111

Impact of Student Success ...................................................... 113

The Future of PLA .................................................................. 114

Limitations for Practice.................................................................... 115

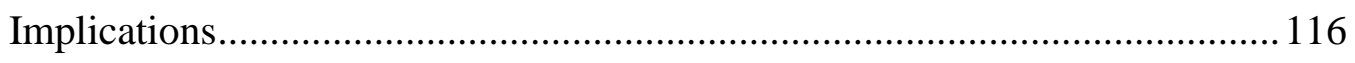

Recommendations for Future Studies ................................................. 120 


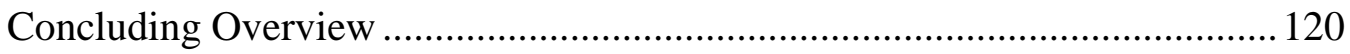

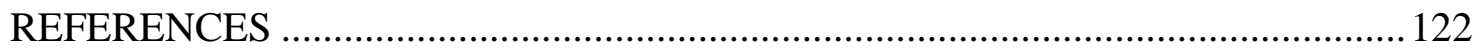

Appendix A Electronic Letters to Participant Groups ................................. 131

Appendix B Prior Learning Program Evaluation Survey ............................. 133

Appendix C Processing Staff Interview Protocol ...................................... 137

Appendix D Administration Interview Protocol ....................................... 138

Appendix E Focus Group Protocol ....................................................... 140

Appendix F Informed Consent Form-Academic Advisors ........................... 141

Appendix G Informed Consent Form-Administrators and Staff ................... 143

Appendix H Human Subjects Approval to Collect Research........................145

Appendix I University of Missouri IRB Review.........................147

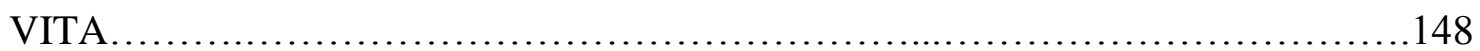




\section{LIST OF TABLES}

Table

Page

4.1 Prior Learning Assessment for Credit Logic Map ............................................ 60

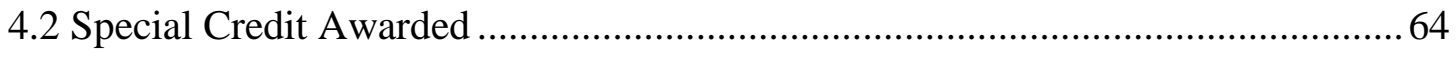

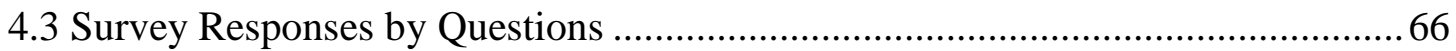




\title{
PRIOR LEARNING ASSESSMENT FOR CREDIT AT THE UNIVERSITY OF CENTRAL MISSOURI: A PROGRAM EVALUATION
}

Vicki M. Orcutt

Dr. Sandy Hutchinson, Dissertation Supervisor

\begin{abstract}
Institutions of higher learning have focused recruiting, retention, and persistence efforts on the "traditional" student. In doing so, the retention and persistence rates of the highest growing population in higher education (the nontraditional student) is even lower than traditional students. Tinto (2012) described the relationship between the student and the institution as a moral contract in which the institution is obligated to provide an environment for success, particularly in the classroom so those students who are willing can achieve their goals. Unfortunately, the lack of specific policy or recognition of adult learning in higher education has resulted in the breaking of this contract for many adult students. This is validated through their decision not to return.

Knowles' (1973) adult learning theory addressed the differences between traditional and nontraditional students. His focus was on how to enhance the learning environment for adult learners. One of the key aspects of his theory was the importance of the experiences the nontraditional or adult learner brings with them to the classroom. One way to improve adult student retention is through the recognition of their life/work experiences. Prior Learning Assessment (PLA) for credit consideration provides this opportunity.
\end{abstract}

The focus of this research was to determine the effectiveness of the University of Central Missouri's PLA program. To accomplish this task, Patton's (2008) utilization focused evaluation method was selected. The intended purpose of this evaluation was 
"formative improvement and learning" (p. 139). To accomplish this task, the participant's perceptions and understandings of the policies and practices were essential, making a qualitative design the preferred approach.

Four research questions were developed in coordination with the key stakeholder: 1) What do faculty assessors perceive as the barriers to accepting credit for prior learning; 2) What type of process do faculty assessors use to determine credit or non-credit for prior learning; 3) How visible is UCM's PLA program to faculty, administrators, and staff; and, 4) How important do administrators and faculty assessors perceive PLA to be in retention and persistence efforts of nontraditional students? For this program assessment, 330 faculty were contacted through survey, with 67 respondents. Eleven academic advisors participated in two focus groups, and 19 interviews were held with department chairs and staff directly involved in the prior learning assessment process.

Through multiple participant data collection methods, several themes emerged: 1) understanding prior learning; 2) initiation of the PLA process; 3) determining credit approval/disapproval; 4) impact on student success; 5) program barriers; and 6) the future of PLA. These themes highlight key aspects of the PLA program and addressed the research questions for the program evaluation. The following recommendations for program improvement were presented to the key stakeholder for consideration: 1) A purposeful information campaign providing university policy and procedures, as well as, the types of prior learning are necessary for faculty assessors; 2) Improve the visibility of the PLA on the university webpage; 3) Recommend a committee be established to address faculty, staff, and administrators to address policy and procedures for a more systematic approval process; 4) Recognize the impact PLA has on student success and 
the cost savings associated with PLA to the student; and 5) Evaluate the amount of special credit is being awarded each academic year.

The purpose of this qualitative utilization focused evaluation was to determine the understanding, perceptions, and experiences with prior learning assessment at UCM. This was accomplished through data collection and analysis with an opportunity for the key stakeholder to improve the program based on the suggested recommendations. 


\section{CHAPTER ONE}

\section{INTRODUCTION TO THE STUDY}

On Tuesday, February 24, 2009, President Barack Obama addressed the Joint Session of Congress. A significant portion of his address focused on education-its importance, where we are, and where we need to be:

In a global economy where the most valuable skill you can sell is your knowledge, a good education is no longer just a pathway to opportunity - it is a pre-requisite. Right now, three quarters of the fastest-growing occupations require more than a high school diploma. And yet, just over half of our citizens have that level of education. We have one of the highest high school dropout rates of any industrialized nation. And half of the students who begin college never finish. This is a prescription for economic decline, because we know the countries that out-teach us today will out-compete us tomorrow. ("www.whitehouse.gov," n.d.) At the conclusion of this portion of his address, the President set an aggressive goal for the country - by the year 2020, the United States of America would regain the distinction of having the highest number of college graduates in the world. So, just how well is this country doing to meet the President's mandate?

To reduce the impact of the recession on the states, the federal government passed the American Recovery and Reinvestment Act (ARRA). This act provided stimulus dollars to the states which could be used to support the shortfalls in public higher education. In its first year, 2009, 3\% of the total support from the states for higher education came from ARRA. In 2010, the amount subsidized by ARRA rose to 5\%, with 43 states using a portion of the ARRA funding for higher education. ARRA funding 
stopped after 2011. With the decrease in federal support, state support for higher education dropped by $7.9 \%$, bringing educational appropriations for a full-time equivalent enrollment (FTE) to a 25 -year low of $\$ 5,906$, in inflation adjusted terms (State of Higher Education Finance, 2012). Oliff, Palacios, Johnson, and Leachman (2013) purport a significant reason for the funding reduction in education is tied to state government's decision to solve the economic downturn, almost exclusively through spending cuts. For example, the New Hampshire legislature voted to decrease state support for higher education by nearly $50 \%$ (Huddeleston, n.d.). While this reduction in state funding is the largest reduction out of all of the states, it is policy decisions like these that have pushed institutions of higher education to find ways to cover the shortfall. To reduce a funding shortfall an organization of any type must increase revenue and/or cut spending.

Reductions in operating expenditures within higher education are usually tied to program elimination and personnel cuts. At the University of Nevada-Las Vegas (UNLV) there has been a $30 \%$ drop in state funding from 2007-2010. The administration addressed this shortfall by eliminating 200 state funded positions, with a total of 406 positions cut during the FY08-FY11 period. Additionally, UNLV eliminated 8 departments and reduced 1,000 class sections ("www.unlv.edu/news/article/budget-cutscontinue-unlv,"2010).

Increasing revenue is also a strategy to cover a deficit. Within higher education the primary source for revenue generation is tuition. For an institution to bring in more revenue, the current revenue stream (returning students) must increase. In just one year, from FY2011-FY2012, there was a 9.5\% increase in tuition rates across the United 
States. Forty-seven percent of the total educational revenue for FY 2012 is from net tuition. Almost half of the educational burden is being covered by student tuition, when in 2007 only $36.4 \%$ of the revenue generated for education came from tuition ("State Higher Education Finance FY 2012," n.d.). The University of California has seen a 48\% increase in tuition rates since the fall semester of 2010, resulting in students covering $49 \%$ of the educational costs for the university ("The Facts: UC Budget Basics," 2011).

With the dismal rates of graduation (less than 50\%), as mentioned by the President (www.whitehouse.gov, n.d.), universities cannot rely solely on repeat business. Kanter's (2011) statistics suggest little has changed in the last few years. Twenty-one percent of students who enter two-year colleges receive a degree or certificate within three years; 55\% who attend four-year public colleges obtain a bachelor's degree within six years. While graduation rates are certainly below what is required to meet former President Obama's mandate, the real challenge is with retention and persistence. Institutions spend a great deal of time and effort tracking and reporting first time, full time (FTFT) freshmen return rates. The National Center for Higher Education Management Systems (2013) identified retention rates for FTFT college freshmen attending four-year public universities to be $78.4 \%$ for 2010 . This $21.6 \%$ drop in attendance is a significant reduction in available revenue. With this drop in projected revenues and the loss of state support, universities must increase admissions to help mitigate the educational shortfall. Finch (2016) highlighted institutions of higher education access and completion policies remain focused on the traditional FTFT student customer segment while ignoring the needs of the largest growing population in higher 
education - the adult learner. Ross-Gordon (2011) posited 73\% of college students could be viewed as nontraditional students when considering factors other than age alone.

Oliff et al. (2013) described a type of "perfect storm" based on state fiscal decisions from 2008 to 2013 which may ultimately harm students and the economy. Specifically, many institutions have not only increased tuition rates, but also cut programs and personnel to cover shortfalls. This indicates a student, traditional or nontraditional, considering college will pay more for less. Where once sat a fully tenured faculty member with a $\mathrm{PhD}$ in the field, now an adjunct or graduate student provides instruction. Additionally, complete programs have been eliminated, reducing the options available to the student. This is just part of the storm that lies ahead. Unless there is significant change in retention and persistence policies, students will drop out before obtaining a college degree. This scenario not only affects the student but, even more importantly, our economic growth as a country.

The U.S. Bureau of Labor Statistics (2016) identified the unemployment rate for individuals with a high school diploma at $5.1 \%$ as compared to $2.5 \%$ for individuals with bachelor's degrees. Additionally, the weekly earnings for an individual with a bachelor's degree are over $\$ 500$ more than an individual with a high school diploma. Education improves an individual's quality of life, while enhancing the overall economic outlook for the country.

Has anything changed within higher education to avert the "perfect storm?" As Finch (2016) mentioned, many colleges and universities have continued with the same policies with respect to student retention and persistence while the student demographics have changed significantly. Specifically, the nontraditional student is becoming the 
majority and, as such, course delivery and design needs to be addressed to accommodate this growing population.

In admitting a student, a college enters into a contract — indeed, takes on a moral obligation - to establish those conditions on campus, especially in the classroom, that enhance the likelihood that students who are willing to expend the effort will succeed. (Tinto, 2012, p.120)

It is this moral obligation described by Tinto (2012) that requires higher education to focus more effort on the adult learner or nontraditional student. The reason for a more focused approach is two-fold — admissions continue to rise but retention and persistence is even lower than the traditional student. Ruffalo Noel-Levitz (2015) reported 27\% of the nontraditional students did not succeed in completing their degree. However, there is one group of adult learners who have been successful—students who have been awarded credit for prior learning.

The Council for Adult and Experiential Learning (CAEL) (2010) conducted a study which consisted of 48 institutions of higher learning and 62,475 student responses. The data highlighted higher graduation rates at both the associate and bachelor level and a reduced time to degree completion in comparison to adult learners without credit for prior learning (CPL). Specifically, 56\% of students with prior learning credit received a post-secondary degree within seven years as compared to the $21 \%$ graduation rate for the adult students without CPL. Depending on the amount of CPL awarded, students were able to save between 2.5 and 10.1 months of time to complete their degree.

For credit to be awarded for prior learning there must be an assessment of the student's learning experience. Prior Learning Assessment (PLA) is the process used to 
award credit for prior learning (CPL). Starr-Glass (2016) identified three types of learning: formal, informal, and incidental. Formal learning is planned and occurs in a structured environment and results in recognition of the learning through badges, certificates, or degrees. While informal learning is also intentional it is less structured and focuses more on training and development programs provided by an employer. Incidental learning is unintentional and occurs often though it may not be recognized.

For adult learners, especially for those who have delayed college entrance, the submerged iceberg of informal and incidental learning can be considerable, but it is usually unrecognized - by the individual and by others. PLA is based on the understanding that: (a) this massive, submerged and taken for granted of knowledge exists; (b) that it is often of considerable value for the learner and for others; and (c) that with sufficient care it can be rendered visible. (Starr-Glass, 2016, pp. 3-4)

The concept of PLA is not new; however, the expansion into non-academic experiences being evaluated for academic credit has broadened the opportunity for institutions to recognize the value adult learners bring with them to the classroom.

Dewey (1938) recognized the importance of experience in education and his work was the foundation of experiential learning. Dewey's primary focus was on the development of a philosophy of experience that was based on determining what education is—not advocating for the "new" or "old" education.

I am not, I hope and believe, in favor of any ends or any methods simply because the name progressive may be applied to them. The basic question concerns the nature of education with no qualifying adjectives prefixed. What we want, and 
need is education pure and simple, and we shall make surer and faster progress when we devote ourselves to finding out just what education is and what conditions have to be satisfied in order that education may be a reality and not a name or a slogan. It is for this reason alone that I have emphasized the need for a sound philosophy of experience. (Dewey, 1938, pp. 90-91)

Dewey suggested a need for a theory of experience to help guide the process from traditional education to the new progressive movement and while there was little structure for the new education philosophy there was a common understanding that there is a natural connection between education and personal experience. However, Dewey was quick to point out that not all experiences are educative and, in fact, some experiences hinder the education process (Dewey, 1938). While Dewey's recognition of the varying types of experiences was based primarily on whether the experiences would hinder or assist in the education process, today institutions are evaluating individuals' experiences for college credit through PLA.

PLA is the method adopted by institutions of higher learning to determine if the knowledge, skills, and experiences individuals have obtained outside of a formal academic setting should be granted college level credit. PLA is the overarching theme which encompasses several types of assessments used to evaluate prior learning. Specifically, there are standardized tests, credit evaluation for military and corporate training, program evaluations by colleges and universities, customized or challenge exams, and the student portfolio. CAEL (2010) conducted a study of prior learning assessment in which 48 institutions participated. The results showed:

- $94 \%$ acknowledged standardized exams 
- $77 \%$ considered the American Council on Education (ACE) evaluated corporate training

- $81 \%$ accepted ACE evaluated military training

- $63 \%$ used institutionally developed training programs

- $65 \%$ of the institutions surveyed used institutional challenge exams, and

- $88 \%$ accepted portfolio assessments for credit consideration (p. 20)

In addition to determining what type of PLA was accepted by the universities surveyed, the study also addressed how or where the credit was applied. The majority of institutions applied PLA credit to required elective credit, general education requirements, and to meet major requirements.

\section{Statement of the Problem}

Institutions of higher learning have focused recruiting, retention, and persistence effort on the "traditional" student. In doing so, the retention and persistence rates of the highest growing population in higher education (the nontraditional student) is even lower than traditional students and needs to be addressed. Tinto (2012) described the relationship between the student and the institution as a moral contract in which the institution is obligated to provide an environment for success, particularly in the classroom, so those students who are willing can achieve their goals. Unfortunately, the lack of specific policy or recognition of adult learning in higher education has resulted in the breaking of this contract for many adult students. This is validated through their decision not to return. One way to improve adult student retention is through the recognition of their life/work experiences. While PLA provides this opportunity, the approval process varies between colleges because the credit assessment is determined by 
different faculty. Understanding the reasons for approval or disapproval between departments will enhance the communication process between the student, the processor of PLA, and the faculty assessor.

\section{Purpose of the Study}

The purpose of this qualitative utilization focused evaluation was to determine the understanding, perceptions, and experiences with prior learning assessment at the University of Central Missouri (UCM). UCM has accepted many types of prior learning; however, there is an inconsistency within colleges and schools. There was also a need to determine the value faculty assessors place on adult students' prior learning experiences.

The CAEL (2010) study identified higher retention and persistence for adult learners who were awarded credit for prior learning. Specifically, graduation rates for adult students earning a bachelor's degree were $28 \%$ higher than adult students who did not receive prior learning credit. Adult students working towards an associate's degree graduated 7\% higher than their non-PLA counterparts.

The University of Central Missouri is dedicated to student success with the goals of access, affordability, completion, and student success after degree obtainment. PLA can be a key contributor to the university's strategic governance (https://www.ucmo.edu/about/identity, n.d). Allowing prior learning to be considered reduces barriers for student access by recognizing the adult learners' contribution to the classroom and their desire to obtain a degree. PLA reduces the financial burden by allowing credit for past experiences and the CAEL (2010) study validated degree completion is higher when PLA is assigned. Understanding how the university's practices 
and acceptance of prior learning enhance/detract from the administration's student success model is a necessary part of this evaluation.

\section{Research Questions}

This program evaluation will examine the faculty assessors' understanding of PLA and the assessment processes developed to support UCM's strategic goals for student success. To accomplish this objective, the following research questions will guide this study.

1. What do faculty assessors perceive as barriers to accepting credit for prior learning at UCM?

2. What type of processes do faculty assessors use to determine credit or noncredit for prior learning?

3. How recognizable is UCM's PLA program to faculty, administrators, and students?

4. How do administrators and faculty assessors perceive PLA to be in regards to retention and persistence efforts of adult learners?

\section{Conceptual Framework}

The conceptual framework for this research begins with Knowles' (1973) adult learning theory. Through his work key differences were identified between the traditional and nontraditional student. Knowles' focus was on how to enhance the learning environment for adult learners. One of the key aspects of his theory was the importance of the experiences the nontraditional or adult learners bring with them to the classroom. Understanding the importance of experience in an educational setting was not something new; in fact, Dewey (1938) placed experience as a critical component of the educational 
experience. "I assume that amid all uncertainties there is one permanent frame of reference: namely, the organic connection between education and personal experience; or, that the new philosophy of education is committed to some kind of empirical and experimental philosophy" (Dewey, 1938, p. 25).

Knowles' (1973) study of the adult learner has evolved into identifiable policies and practices within higher education. One specific area that has gained momentum over the years is prior learning assessment (PLA). In today's data driven environment it is important for institutions of higher learning to determine program successes and vulnerabilities. To that end, this researcher with the support of the PLA administrator implemented a program review of the University of Central Missouri's PLA process with Patton's (2008) Utilization Focused Evaluation framework as the guide.

\section{Design and Methods}

The focus of this research is on determining the effectiveness of UCM's PLA program. To accomplish this task, the participants' perceptions and understanding of the policies and practices is essential, making a qualitative design the preferred approach.

Qualitative research is a means for exploring and understanding the meaning individuals or groups ascribe to a social or human problem. The process of research involves emerging questions and procedures, data typically collected in the participant's setting, data analysis inductively building from particulars to general themes, and the researcher making interpretations of the meaning of the data. (Creswell, 2009, p. 4)

The intended purpose of this evaluation was "formative improvement and learning" (Patton, 2008, p.139). Upon completion of this evaluation key stakeholders will be given 
the opportunity to make adjustments and improvements as identified by research participants. The research participants are individuals involved in the process (Patton, 2008).

Unobtrusive data (Hatch, 2002) were examined; surveys were disseminated to 330 faculty members. The survey questions focused on providing answers to the research questions already identified. Interviews were conducted with 19 key constituents on a voluntary basis. A focus group was conducted with 11 academic advisors. These tools provided the necessary breadth and depth of information required for a proper program assessment.

\section{Assumptions}

To determine research validity, Denzin's (1978) methodological triangulation was the primary method used. This type of triangulation takes different methods of research (e.g., surveys, interviews, focus groups, and archival data) and compares the results. While time consuming, it does provide multiple opportunities to confirm the consistency or incongruities of the data collected. The survey was a cross-sectional design administered once to the selected participants (Fink, 2009). Participants were selected based on their participation in and connection with prior learning assessments. Before actual data collection, survey questions were developed through consultation with the PLA administrator and pilot tested (Fink, 2009).

Hatch (2009) described how an individual's view of the world affects the selection of data collection methods and research designs. Hatch described the world view of a constructivist as one who places a great deal of importance on the participants being researched. The products created by researchers with a constructivist view may be 
case studies, reconstructions, and narratives (Hatch, 2009). A constructivist lens also supports a utilization focused evaluation due to the importance placed on the participants' views. It is this type of characterizations that led the researcher to a constructivist positionality. This research is concerned with PLA participants' perception of the program's effectiveness and importance as it relates to retention and persistence of the adult learner. Obtaining an individual's perspective requires getting to know and understand different viewpoints. While the data being collected were qualitative in nature, the researcher's inclination to look at data from a methodological perspective assisted in providing a balanced program evaluation.

\section{Limitations}

The primary limitation of this program evaluation was the participants were all part of the University of Central Missouri community. Individuals may feel pressured to be less than candid for fear of being recognized during the data gathering phase of this research. While there are varying research collection methods, the number of individuals involved in the prior learning assessment process was limited and this small sample size could create a false positive or negative impression based on the potentially low response rates. Also, since the researcher had a significant role in the PLA process, participants were made aware of the researcher's involvement.

To minimize these potential limitations, pseudonyms were used for individuals participating in interviews or focus groups. Additionally, the basic construct of a utilization focused evaluation is to highlight areas of improvement. With the key stakeholder in this evaluation being part of the strategic leadership team this should support candid comments from participants. 


\section{Definition of Key Terms}

For the purpose of this research, the following terms are defined:

American Council on Education (ACE). An external organization to universities or colleges which provides credit recommendations for prior learning.

Adult Learner. From a chronological view, an adult learner is someone 24 years of age or older (Jinkens, 2009). Additional characteristics that further define the adult learner are: delayed entry into college, having dependents, being a single parent, working full time, not financially supported by family, and attending part time (Ross-Gordon, 2011, p. 1). To be an adult learner does not require for the student to be identified in each category. Additionally, for purposes of this research, adult learner and nontraditional student are used interchangeably.

Council for Adult and Experiential Learning (CAEL). "The Council for Adult and Experiential Learning got its start in the 1970s as part of a movement to provide access to higher education by recognizing the prior learning of adults and valuing their experiential learning" (CAEL, 2016, A Letter from the Editors).

First Time Full Time (FTFT). A student who is attending an institution of higher learning, two or four year, for the first time and who is attending full-time enrolled in 12 or more credit hours is considered first time, full time. This is the category of student that is counted when determining retention rates for freshmen returning their sophomore year.

Full-Time-Equivalent Enrollment (FTE). A measure of enrollment equal to one student enrolled full-time for one academic year, based on all credit hours (including summer sessions) (State Higher Finance, 2012). 
Institution of Higher Learning. This phrase is used throughout this research paper and is used interchangeably with college and university and refers to a four-year public state institution.

Nontraditional Student. From a chronological view a nontraditional student is someone 24 years of age or older (Jinkens, 2009). Additional characteristics that further define the nontraditional student are: delayed entry into college, having dependents, being a single parent, working full time, not financial supported by family, and attending part time (Ross-Gordon, 2011, p. 1). To be an adult learner does not require for the student to be identified in each category. Additionally, for purposes of this research, nontraditional student and adult learner are used interchangeably.

Persistence. "...the rate at which students who begin higher education at a given point in time continue in higher education and eventually complete their degree" (Tinto, 2012, Appendix A).

Primary Stakeholder. This term is used to identify the individual the researcher works with throughout the program evaluation. This term is used interchangeably with key stakeholder and program coordinator.

Prior Learning Assessment (PLA). The process institutions of higher learning use to offer credit to students based on experiences either personal or professional and can include work, non-credit education and training that are applicable to a specific course or program of study (Design2Learn, 2016, p. 5).

Retention. “...the rate at which an institution retains and graduates' students who first enter the institution as freshman at a given point in time" (Tinto, 2012, Appendix A). 
Utilization-Focused Program Evaluation. "An evaluation done for and with specific intended primary users for specific, intended uses" (Patton, 2008, p. 37).

\section{Significance of Study}

The largest growing group in higher education is the nontraditional or adult learner (Klein-Collins, 2011) and yet most, if not all, of the focus with respect to marketing and retention efforts is applied to the traditional student. Understanding the needs of the adult learner and applying that knowledge to institutional policies and procedures will assist in reversing the current retention trends. One area that can assist adult learners is a strong prior learning assessment (PLA) program. PLA can reduce time to degree and cost associated with returning to college.

This program evaluation provides the necessary data to highlight program strengths and weaknesses, along with faculty and administrators' perceptions of the current PLA program. With this program evaluation being utilization-focused there is commitment from university leadership to not only review the data collected but to also facilitate the necessary changes.

\section{Summary}

In 2009, President Obama described an educational system in crisis with over half of the students who attend a four-year institution failing to complete their degrees ("www.whitehouse.gov," n.d.). Even more important than the personal failure is the economic impact to our country. In a knowledge-based economy, human capital is of the utmost importance. To stimulate a sluggish economy, during the recession the federal government provided additional funding to the states through the American Recovery and Reinvestment Act (ARRA) which could be used for education. In 2011, ARRA funding 
expired, and higher education support dropped to a twenty-five-year low, after adjusting for inflation.

To compensate for the shortfall, institutions of higher learning not only raised tuition rates, but also cut programs and personnel. In 2012, 49\% of the overall educational costs were covered by net tuition ("State of Higher Education Finance," 2012). New students are not only paying more to attend college, they are also getting less. There are fewer programs to choose from and tenured faculty have been replaced by adjuncts or graduate students. While this is important, what is even more important is trying to keep the students who are already attending. Most university administrators are primarily focused on the first-time full-time student when, in fact, the largest growing population attending institutions is the adult learner, and retention of these students is even lower than the traditional student. However, adult learners who are awarded credit for prior learning experiences are persisting and graduating sooner and with less debt (CAEL, 2010).

CAEL (2010) conducted a 48-institution study whereby 62,475 student records were examined, and the study followed their academic progress for seven years. The published findings found " $56 \%$ of PLA students earned a postsecondary degree within seven years, while only $21 \%$ of non-PLA students did so" (CAEL, 2010, p.7).

Additionally, time to degree completion was reduced for students awarded credit for prior learning.

PLA students earning bachelor's degrees saved an average of between 2.5 and 10.1 months of time in earning their degrees, compared to non-PLA students earning degrees. PLA students earning 13-24 PLA credits saved an average of 6.6 
months, and those earning 49 or more PLA credits saved an average of 10.1 months. (CAEL, 2010, p.8)

As public institutions of higher learning continue to receive lower state and federal funding, there needs to be a shift in policies and procedures to not only attract but also to retain the largest growing student population - the adult learner. 


\section{CHAPTER TWO}

\section{REVIEW OF RELATED LITERATURE}

This literature review focused primarily on the impact of prior learning assessment in higher education with respect to the types of prior learning and benefits for both the individual and the institution. To fully understand the emergence of prior learning assessment it was necessary to obtain a deeper understanding of the learning process from the broadest of concepts to specific types of learning methodologies and assessments for prior learning.

\section{The Learning Process}

In today's fast paced result-oriented world, little attention, if any, is paid to "how" the result was achieved. The "how" is the learning process. Csikszentmihalyi (2014) defined learning as "an increase in complexity in the information-processing capacity of an organism" (p. 153). This information-processing capacity was the foundation for Bloom's (1956) taxonomy. Bloom and a group of educators' primary focus was on the nature of thinking (information-processing) which led to a hierarchical order of thinking with varying levels of complexity for the purpose of classifying thinking behaviors they believed were important to the learning process. History has proven this to be correct with its wide application among educators. Bloom's Taxonomy provided educators with a classification process of thinking and learning (Forehand, 2005). Bloom's Taxonomy was published in 1956 and remained the primary tool for educators until Anderson and Krathwohl (2001) led a group of researchers to update the taxonomy to the 21 th century. While the basic intent of taxonomy remained, the revised version provided two 
dimensions to the cognitive (knowledge) domain and recognized the connectedness between knowledge and thought (Hess, Jones, Carlock, \& Walkup, 2009).

Although Bloom's Taxonomy has provided a tool for measuring thinking, the use of similar verbs at different levels lacked the clarity to differentiate the complexity between levels; however, Webb's $(1997,1999)$ Depth of Knowledge (DOK) levels fills the gap (Hess, et al., 2009). This cognitive classification system changed the way many states assessed test questions providing an opportunity for both the complexity of the content and the task required to achieve a specific Depth of Knowledge. There are four levels of knowledge: DOK-1, Recall and Reproduction; DOK-2, Basic Application of Skills/Concepts; DOK-3, Strategic Thinking; and DOK-4, Extended Thinking (Hess, et al., 2009). Paige, Sizemore, and Neace (2013) found Webb's classification system easier to distinguish the levels of complexity when observing instruction. Additionally, teachers found using DOK levels when developing curriculum ensured the appropriate level of cognitive rigor was incorporated in the lessons. Bloom's Taxonomy identifies how individuals think; whereas, Webb's DOKs categorize the level of thinking.

While Bloom's Taxonomy provides a tool for measuring thinking and Webb's DOKs focus on levels of knowledge, neither address the creation of knowledge. Nonaka and Konno (1998) used the Japanese concept called " $b a$ " as the foundation for knowledge creation. This foundation is made possible by providing a shared space for developing relationships. The "space" could be physical, virtual, mental or any combination of the three.

Knowledge is embedded in $b a$ (in these shared spaces), where it is then acquired through one's own experience or reflections on the experience of others. If 
knowledge is separated from $b a$, it turns into information which can then be communicated independently from $b a$. Information resides in media and networks, it is tangible. In contrast, knowledge resides in $b a$. It is intangible. (pp. 53-54)

Since knowledge is intangible, its value is dependent on the purposeful union of the tangible (shared spaces) and the intangible (knowledge) to come together at a specific point in time. It is this purposeful merging of the tangible and intangible which creates the foundation for knowledge creation.

Nonaka and Konno (1998) further described knowledge creation as a selftranscendental process which begins with two types of knowledge: explicit and tacit. Explicit knowledge is considered to be easily shared with others through the use of directions, instructions (verbal or written), symbols, or numbers. Nonaka and Konno posit explicit knowledge is widely emphasized in the West. This seems to be confirmed based on Bloom's Taxonomy (1956) and to a certain degree Webb's DOKs $(1997,1999)$ since both look for students to remember and recall information as a measurement of cognitive levels. On the other hand, the Japanese view knowledge primarily at the tacit level. Tacit knowledge is considered to be difficult to describe, making communication with others difficult. Tacit knowledge is also based on deeply personal ideas, thoughts, and experiences. Tacit knowledge is further broken down into two areas: technical and cognitive. The technical focuses on an individual's know-how, whereas the cognitive is an individual's ideals, thoughts, and beliefs which are deeply rooted and frame our world view (Nonaka \& Konno, 1998). "Knowledge creation is a spiraling process of interactions between explicit and tacit knowledge. The interactions 
between these types of knowledge lead to the creation of new knowledge" (p.55).

Illeris' (2015) development of the Learning Triangle added a third element to the learning process which he describes as incentive. Prior to Illeris there had been an understanding of the need for interaction with contact (Nonaka \& Konno, 1998), but the inclusion of incentive focused on the motivation or energy to drive the learning process. Within the learning process there are two distinctive kinds of learning (addition and reconstruction) and four learning types (cumulation, assimilation, accommodation, and transformation).

Learning as additional includes cumulation: starting a new mental scheme, and assimilation: adding new elements to existing schemes. Learning as reconstruction includes accommodation: changing elements of schemes, and transformation: changing elements of the identity (which involves a multitude of schemes. These learning types refer to the character of the acquisition. (p. 29) The acquisition of content (information) is consumed differently for each individual and it is this diversity of consumption when delivered in a group setting that can, and many times does, result in different levels of learning.

In addition to describing the learning process, Illeris (2015) identified three main barriers to learning which are tied to the learning triangle. The first barrier is described as mislearning and is tied to content. This could be due to a lack of concentration or understanding or also an inability to learn because of the lack of prior knowledge to understanding the content. The second barrier, learning defense, is related to the incentive portion of the learning triangle. This can occur if the individual is ambivalent or rejects the learning opportunity. This type of learning defense is seen by many when parents 
force their children to attend college when their children have no desire to attend at that time. The third barrier to learning is called learning resistance which occurs in the interaction domain. This is manifested when learning is unwanted because it goes contrary to an individual's beliefs or perceptions. An example of this type of barrier could be the subject of evolution or any number of social issues.

The inclusion of incentive into the learning model is a key component particularly in a content driven environment. Csikszentmihalyi (2014) focused on deliberate learning and the associated types of motivation, intrinsic or extrinsic. Intrinsic motivation is further broken down into autotelic and exotelic. Autotelic is learning pursued for learning sake. Exotelic is learning which is focused on a goal. The goal is the motivation more so than the learning itself. Csikszentmihalyi provided the example of K-12 education as extrinsic motivation. "For most people, the thirteen-plus years spent in formal educational institutions involve learning that is experienced as forced rather than chosen, and over which one does not feel responsibility or ownership" (p.153). While the pursuit of higher education can be defined as "chosen," extrinsic motivators are still prevalent. From the insistent parent to the pressure from friends many first-time college students are motivated by outside influences.

Another area associated with an individual's commitment to learning is selfefficacy. Glynn, Aultman, and Owen (2005) described a positive self-efficacy as essential for learning. This positive self-efficacy will lead to higher goals, increased commitment, additional effort, and persistence (Yadin \& Or-Bach, 2010). However, Bandura (1986) suggested self-efficacy can only motivate individuals if their perception of self-efficacy is supported with actual skills and incentives. While a positive self-efficacy is preferred 
over a negative self-efficacy, what is truly needed is an accurate self-assessment of one's work. Zepke and Leach (2010) observed students' confidence in their own capabilities was a strong motivator for ongoing active learning. As such, the students stayed motivated and engaged. With accurate self-assessment individuals can appropriately evaluate learning capabilities, strengths, and weaknesses (Mosca, Agacer, Flaming \& Buzza, 2011).

\section{Adult Learning Theory}

Based upon current teaching principles in higher education one would assume the vast majority of students are traditional freshman, commonly referred to as full-time firsttime students. However, the adult student is growing in population at institutions of higher learning. It is predicted by the year 2019 adult students will rise to $61 \%$ of the undergraduate student population (Finch, 2016). While traditional teaching is often defined as machine-like and repetitive, the adult learner thrives in a more malleable and cooperative environment (Adamson \& Bailie, 2012). The idea that the adult learner is somehow different is nothing new. In fact, in 1926 the American Association for Adult Education (AAAE) was created. At that point in time the focus of adult education was community not formal education (Rose, 2008).

Kenner and Weinerman (2011) attributed the underpinnings of adult learning theory to the field of organizational development (OD). OD's primary focus is on providing the skills and tools necessary to increase employee productivity. "In the 1950s and 1960s, OD practitioners created new learning models because traditional higher education pedagogical models did not translate well into the workplace training environment" (p. 88). This lack of cohesion between academics and the workplace 
contributed to Argyris and Schön's (1978) organizational learning theory which identified types of organizational learning: single-loop and double-loop. Single-loop is described mainly as incorporating control systems to monitor processes. In contrast, double-loop learning identifies a problem and then there is an evaluation of the process to determine if there is a better way. Double-loop learning breaks the cycle of the routine to allow for creative ideas to be implemented. While organizational learning was important, adults were still entering college which produced a lot of the research from an academic perspective. At that time most of the academic research focused on why adults were entering college or was there a specific type of adult student? Knowles (1973) moved away from the "why" and the "who" and focused on the "how" adult students learn. We have finally really begun to absorb into our culture the ancient insight that the heart of edducation (sic) is learning, not teaching, and so our focus has started to shift from what the teacher does to what happens to the learners. (p. 41)

It was the concept of how individuals learn that brought to light the stark differences in the way adults and children learn. In fact, the differences were so vast that Knowles (1974) adopted the term andragogy to define adult learning and provided four main assumptions that differentiate andragogy from pedagogy.

The first assumption is the changes in self-concept. The basic premise is as individuals mature their self-concept changes on a continuum of dependency to varying levels of self-directedness. Individuals who have had professional training or are working tend to see themselves as self-directing and identify themselves psychologically as an adult. Placing self-directed individuals in an educational environment that they perceive to be treating them like children will impede learning (Knowles, 1974). 
Knowles' (1974) second assumption is the role of experience. Basically, as individuals mature their experiences increase. These experiences allow for a richer learning experience and provide a broader focus for new learning to occur. Because of this experience factor there is more emphasis placed on experiential learning opportunities. The use of traditional lectures and one-way communication tend to be less effective. Andragogy leans towards team projects, field experience, and group discussions (p. 46).

The third andragogical theory assumption is readiness to learn. “...andragogy assumes that learners are ready to learn those things they 'need' to because of the development phases they are approaching in their roles as workers, spouses, parents, organizational members and leaders, leisure time users, and the like" (Knowles, 1974, p. 47). There are many reasons why adult learners return to college; however, all adult learners want the education to focus on their specific needs. Instructors must find a way to ensure the instruction relates to the adult learner for there to be a successful learning experience.

The final assumption is orientation to learning. Adults have a problem-centered orientation towards learning. Children have a subject-centered orientation. Children learn the subjects required to move to the next grade, to enter college, and to complete college to get a job and hopefully become a productive adult in society. Adults come to learning more to solve a problem, whether that is to learn a new skill, to get a promotion, or to change their station in life. There is an urgency associated with the adult learner; there is a need for the adult student to be able to apply what has been learned right away. (Knowles, 1974) 
Csikszentmihalyi's (2014) concept of deliberate learning and its connection to intrinsic and extrinsic motivation is similar to the differences between traditional and nontraditional students. For example, traditional students are more extrinsically motivated with respect to attending college. Those external motivations could be parents, friends, social needs, or simply preparing for a job. The nontraditional student, as Knowles (1973) highlighted, is more intrinsically motivated because of life circumstances.

Motivation. Noel-Levitz (2016) reported on the motivation of first time freshmen adult learners, defined as 25 years of age or older, to complete a college degree. Overall, 98.4\% of men, women, first generation, and non-first-generation students were motivated to complete their degree. However, within the first year there is a significant drop in motivation with $22.4 \%$ wondering if the courses are worth their time, money, and effort. Deci and Ryan (2000) addressed the precepts of their Self-Determination Theory (SDT) with the basic foundation being individual needs.

...we define needs at the psychological rather than physiological level. Thus, in SDT, needs specify innate psychological nutriments that are essential for ongoing psychological growth, integrity, and well-being. As noted, we identified three, the needs for competence, relatedness, and autonomy. (p. 229)

Deci and Ryan (2000) acknowledged physiological needs must be satisfied. Getting warm is an individual's primary concern when they are cold and without shelter. However, SDT theory posits once balance has been established, with respect to need satisfaction, subsequent behavior is not driven by physiological needs, but it is more about doing what is of interest and importance to the individual. Fulfillment of the three 
needs (competence, relatedness, and autonomy) identified by Deci and Ryan are fulfilled through intrinsic motivation.

Intrinsic motivation, as it relates to the need for autonomy, can be observed when individuals are free to follow their inner interests and desires. For some this may be pursuing a lifelong goal or learning a new technology at work. The important aspect of this behavior is the individual is in control. Deci and Ryan (1980) posited some external motivational strategies actually reduce intrinsic motivation due to the perceived lack of autonomy. "Motivational strategies such as rewards and threats undermine autonomy and thus lead to nonoptimal outcomes such as decreased intrinsic motivation, less creative, and poorer problem solving” (Deci \& Ryan, 2000, p. 234). With higher education continuing to admit adult learners this particular need for autonomy should be recognized. As Knowles (1973) suggested, adult learners have a strong self-identity and are self-directed resulting in a higher sense of internal motivation than the more traditional college student. Failure of faculty to recognize the adult learner's motivation can, at the very least, produce a less than optimal learning experience, at its worst the adult student stops out.

Intrinsic motivation, as related to competence, is enhanced or reduced primarily by feedback. Basically, positive feedback enhances intrinsic motivation as related to competence, whereas negative feedback resulted in reduced motivation. However, Fischer (1978) suggested intrinsic motivation is only affected either positively or negatively if the individual feels responsible for competent performance or if the feedback is provided in such a way that does not over shadow the individual's feelings of autonomy (Ryan, 1982). When considering adult learning theory and the need for 
competence as a required psychological need to be filled, it is understandable how easily an adult student's intrinsic motivation could be thwarted by a bad grade.

While the final psychological need, relatedness, does not impact intrinsic motivations as readily as autonomy and competence there is connection that cannot be ignored. "People often engage in intrinsically motivated behaviors (e.g., playing solitaire, hiking) in isolation, suggesting that relational supports may not be necessary as proximal factors in maintaining intrinsic motivation” (Deci \& Ryan, 2000, p. 235). While Deci and Ryan placed less importance on relatedness with respect to the three psychological needs identified in SDT, they did recognize relatedness plays an important role throughout an individual's life from the connection made at birth to the relationships developed over time. From an adult learning perspective there seems to be a desire for a more multidirectional relationship instead of the one-direction often experienced by traditional students and their instructors (Kenner \& Weinerman, 2011).

\section{Adult Learners}

The National Center for Educational Statistics (NCES) provided statistical trends and projections in a number of different categories. However, the primary indicator identifying the adult learner is their chronological age when, in fact, there are several factors to be considered. Ross-Gordon (2011) posited the nontraditional student should no longer be identified as "nontraditional" because when the age of the student and the other psychosocial characteristics not usually considered when identifying student types (i.e., financial independence, full time employment) the nontraditional student actually becomes the majority becoming the new "traditional" student. Horn and Carroll (1996) 
described nontraditional students as students having one or more of the following seven characteristics:

- delayed enrollment into college,

- part time attendance,

- financial independence with respect to financial aid consideration,

- full time employment while attending college,

- dependents (other than a spouse),

- single parent, and/or

- did not receive a standard high school diploma. (NCES 97-578, highlights)

Jinkens (2009) described the nontraditional student by differing mindsets with age not necessarily the differentiator. "....mindset refers to how students perceive education: its value, what is and is not important, and the general approach of what to learn and how to learn it" (p. 980). For example, traditional students are primarily focused on getting high marks to move up in class ranking or move on to the next class; whereas, nontraditional students, while desirous of good grades, are more focused on how they can apply this new knowledge.

Challenges. There is an abundance of research dedicated to persistence and retention within higher education with the primary focus on first time full time traditional students. The National Center for Higher Education Management Systems Information Center published the United States retention rates for first time college freshmen attending a four-year public university to be $78.4 \%$ for 2010 . However, the attrition rates for adult learners are even higher with $27 \%$ of adult learners not returning to a four-year public institution after the first year. This places nontraditional students at a 73\% 
retention rate (Ruffalo Noel-Levitz, 2015). Based on the characteristics listed above for nontraditional students there is high likelihood they are burning the candle at both ends as they try to manage multiple roles. Many times the role of mother, wife, professional, and/or community leader can make it very difficult to make education a priority (RossGordon, 2011). Cross (1981) identified three areas that can impede adult learner success. Personal or situational challenges are fairly common with a vast number of nontraditional students. Most of the reasons fall into either a lack of time or a lack of money. An additional challenge is conceptual with respect to the perceived self-efficacy associated with returning to academia and the fear of failure. This fear of failure can be founded in past experiences or the simple fear of the unknown. The final category of challenges is institutional. Many institutions of higher education make it very difficult for the returning adult learner due to lack of flexibility with scheduling and student support services.

With all of the multiple roles, responsibilities, and challenges nontraditional students are faced with, one of the main reasons for such a high attrition rate is the integration into the higher education environment. Kenner and Weinerman (2001) identified three groups of adult learners that are entering college but require developmental or remedial instruction to assist them in their transition. The three groups are: (a) workers who lost their jobs due to the 2008 recession, (b) veterans returning from deployments who have delayed college entry, and (c) adults who have just completed their GED and want to continue their education. Addressing this issue falls solely on the faculty and staff of the institution. "By having an awareness of the different learning styles of adult learners, framing learning strategies in immediately useful ways, and using 
competition and repetition, the developmental educator can enhance the integration of the adult learner into the collegiate environment" (Kenner \& Weinerman, 2011, p. 90).

Educators who are placed in the role of assisting adult learners' transition to higher education should have an awareness of the type of student they are instructing. Understanding many adult students (not just those identified earlier) have had a gap in time between pursuing formal education can help with curriculum development and provide the nontraditional student with a better understanding of what is required. For example, veterans' writing skills are more closely aligned to technical writing, so having to learn how to prepare academic papers can be daunting. Being aware of the students' situation and putting into practice Knowles' (1973) adult learning theory, coupled with the understanding of SDT (Deci \& Ryan, 2000), the educator can not only enable the nontraditional students to learn a new skill but, more importantly, can do so without thwarting students' intrinsic motivation to succeed in higher education.

Framing learning strategies as Kenner and Weinerman (2011) suggested addresses another difference between traditional and nontraditional students. Because most nontraditional students are focused on the goal (completing college), the developmental educator must help the students understand how the current instruction will be of benefit to them in obtaining their goal. Keeping with the earlier example of veterans learning how to write academically, if students know there is a requirement to write a paper in most of their upcoming classes there is a strong possibility they will focus on learning how to prepare research papers.

Competition and repetition is the last strategy developmental educators could apply to assist the return of adult learners to academia. One of the primary concerns about 
adult learners is the gap in time from the last time the student had been in an academic environment and the tacit knowledge acquired. Nonaka and Konno (1998) described tacit knowledge as based on deeply personal ideas, thoughts, and experiences, which is further broken down into two areas: technical and cognitive. The technical focuses on an individual's know-how where the cognitive is about an individual's ideals, thoughts, and beliefs which are deeply rooted and frame our worldview. Kenner and Weinerman's (2011) concern for the nontraditional student was the possible incongruity between existing tacit knowledge, or learning strategies, and what is required for academia. If the student does, in fact, have ineffective learning strategies, it is incumbent upon the developmental educator to ensure the desired learning strategy is in direct competition with the student's current worldview. Kenner and Weinerman (2011) provided the example of reading and the different types of reading skills developed. Most individuals who are working read technical manuals or policy directions. This type of reading is completely different than reading a textbook; however, this is a skill an adult student must learn and is in direct conflict with what they know both from a technical and cognitive level. Since the prior knowledge is deeply rooted in the student's worldview, repetition is a must.

\section{Andragogy as Practice}

As stated earlier, Knowles (1973) developed four key assumptions in defining the adult learner as opposed to children. Over the years, two additional assumptions were included (Knowles, 1980). According to Knowles' adult learning framework, adult learners are presumed to

- learn best when they know "why" they should learn something, 
- excel in a learning environment that is autonomous and self-directed,

- bring varying levels of experience that should be considered in planning the learning experience,

- exhibit a readiness to learn,

- prefer a task- or problem-centered approach to learning, and

- possess a high degree of internal motivation.

While this framework addressed adult learner needs, it did not transcend the theoretical to practical application. Specifically, the assumptions did not allow for instruction to be developed because the assumptions did not address the specific needs, desires, or abilities of any adult learner group. To address this concern, Knowles, Holton, and Swanson (1998) developed the Andragogy in Practice model. This model placed the six assumptions developed earlier as the foundation and adds additional considerations that address the goals and purpose for learning and individual or situational differences.

Greer's (2013) study focused on off-ramping and the re-entry of women in the United States to the workforce. Using the Andragogy in Practice model as the framework Greer was able to construct a learner analysis (Holt, Swanson, \& Naguin, 2001). Greer's vision was to use the results from the learner analysis to influence opportunities for women returning to the workforce to receive the needed training and development necessary for a successful transition. After a comprehensive literature review Greer was able to identify themes addressing individual and situational differences as well as the goals and purposes for learning. As discussed earlier, it was the addition of these two areas that operationalized Knowles' adult learning theory. 
The Institute of Medicine's requirement to increase the number of baccalaureateprepared nurses to represent $80 \%$ of the nursing workforce by the year 2020 (IOM, 2011) created an opportunity for adult learning theory to be put into practice. Specifically, registered nurses returning to school meet all of the assumptions identified by Knowles (1973). Additionally, the goal and purpose of the adult learner group had been defined by the medical community's mandate. Leigh, Whitted, and Hamilton (2015) evaluated the effectiveness of the faculty-developed tool which incorporated the elements of Knowles' theory. The tool was called the Decisional Matrix for Preceptorship Experiences (DMPE). The DMPE was designed in response to student feedback as well as the realization that the current process was lacking with respect to needs assessment and individualized learning plans. Findings from the evaluation indicated "agreement/strong agreement that andragogical principles were evident" (p.15). Even more impressive was the higher level of course achievements with respect to student learning outcomes. While the students exceeded course standards before the development of the DMPE, there was a 4\% increase in overall achievement from an average of $94.4 \%$ before the DMPE to a 99.2\% and a $98.3 \%$ for the years 2012 and 2013 respectively.

Curran (2014), in the first of a two-part series, examined the teaching methods of nursing professional development (NPD) specialists in relation to the varying levels of academic preparation of NPD specialists and their understanding of adult learning theory. The academic classroom preparation of NPD specialists varies across a wide spectrum, from associate's degrees in nursing to graduate degrees in nursing education, nursing administration, health care administration, clinical specialties, 
and doctorates. Currently, there is no required level of academic preparations for NPD specialists. (p. 234)

Curran (2014), in the second part of the two-part series, examined the use of adult learning theory in curriculum development in relation to four variables: graduate degrees in nursing education, professional development training in adult learning theory, NPD specialist experience, and NPD certification. Curran hypothesized individuals with any of the four variables would incorporate higher levels of adult learning theory in their teaching practices to drive curriculum design than those without the attributes identified. Ultimately Curran's hypothesis was rejected. Of the 114 NPD specialists who participated in the research study, teacher-centered teaching was favored over the learnercentered.

Transformative Learning. While Csikszentmihalyi (2014) defined learning more from an information processing perspective, Mezirow (1994) addressed learning as a social process of understanding and adopting new meaning of one's experiences and acting accordingly. "Transformative learning theory is uniquely adult, abstract, idealized, and grounded in the nature of human communication. It seeks to explain how adults' expectations, framed within cultural assumptions and presuppositions, directly influence the meaning individuals derive from their experience" (Taylor, 2000, p. 1).

The label of transformation was first used by Mezirow (1978a) in his research on women re-entering the workforce or returning to college after a significant amount of time away. Mezirow conducted a qualitative study on factors that tend to support or obstruct women's re-entry into the workforce or higher education. After data analysis of the surveys collected, Mezirow (1978a) (1978b) and his research team concluded a 
personal transformation was evident and the 10 phases of transformative learning were developed. The basic construct for transformative learning begins with the concept that each individual has a unique frame of reference or lens through which they derive meaning. Mezirow (1994) identifies these frames of reference as meaning structures which consist of meaning perspectives and meaning scheme. Within the meaning perspectives there are predispositions developed based on assumptions. The three areas or "codes" that influence an individual's frame of reference are sociolinguistic, psychological, and epistemic codes.

The sociolinguistic codes come from an individual's ideologies and social norms. The psychological codes are personality traits or repressed parental prohibitions which block feelings and actions. The final code is epistemic. Examples of epistemic codes are learning styles and sensory learning preferences. An individual's frame of reference is also developed through meaning scheme. It is through this scheme that an individual's judgment, belief, and feelings on a particular situation or issue are shaped (Mezirow, 1994).

Mezirow's (1995) transformation learning process is comprised of three integral parts: the learner's experience, critical reflection, and discourse. To validate any process there has to be a starting point from which to evaluate. For transformative learning that point is the individual's experience or frame of reference which was discussed in detail above. While understanding the learner's experience is important, the most crucial point for a successful transformative learning experience is critical reflection. It is during this process the adult learner begins to question current beliefs and concepts. Couple the critical reflection component with discourse in an open, trusted environment, and new 
ideas begin to emerge, and questioning becomes the process instead of acceptance without inquiry.

Taylor (2000) reviewed 23 studies to discern how personal change was assisted in varying educational environments. The majority of the studies were qualitative in nature using interviews and observation as data collection methods. Taylor's research concluded:

- transformative learning theory has had a significant impact on adult higher education,

- despite all the interest there is a lack of research and understanding about the practice of transformative learning,

- teachers and learners who are willing to engage each other in open and safe group settings have the potential for a transformative learning experience,

- there is a need for more research,

- many adult educators are ill prepared for the task of engaging in transformative learning (p. 14).

Experiential Learning. While there are no doubt individuals learn from their experiences and those experiences can be assessed for college credit, experiential learning theory is more than just credit transfer and articulation of prior experiences. Internships, externships, study abroad, field placement, simulation exercises and many more experienced-based learning methods are being used in higher education. This type of learning environment has also become one of the preferred methods of learning for the nontraditional and underrepresented (Kolb, 2014). Similar to other learning theories, experiential learning theory (ELT) is not without its critics. Some identify ELT as just the latest fad in learning theory--all flash no substance. Kolb (2014) has answered the critics 
by providing guiding theory and principles as well as the understanding that ELT is "soundly based in intellectual traditions of social psychology, philosophy, and cognitive psychology" (Part I: Experience and Learning). To further support the legitimacy of ELT, Kolb (2014) provided a list of six experiential learning characteristics.

Learning as a process is one of the distinctive characteristics of ELT. This concept is contrary to other learning strategies that are based on behaviorist theories of learning with the prevalent theme of sameness. It is the idea of sameness that tends to lead educators into a more outcomes-based focus because sameness can be measured. ELT assumes ideas and thoughts are not fixed but formed and reformed through experience.

The second characteristic of ELT suggests learning is continuous and grounded in experience. The primary focus for this characteristic is the experience aspect in that everyone comes to the learning environment with experiences that need to be identified and considered. If experience is not considered, learning could be impeded. Students do not come to a class without any knowledge or experience with respect to the topic at hand. However, depending on the type of student experiences, the instructor may have to assist the students in reframing their perceptions (Kolb, 2014).

The third characteristic of ELT identified by Kolb (2014) stated the learning process requires conflict resolution between dialectically related modes of adaptation to the world. Specifically,

New knowledge, skills, or attitudes are achieved through confrontation among four modes of experiential learning. Learners, if they are to be effective, need four different kinds of abilities — concrete experience abilities (CE), reflective observation abilities (RO), abstract conceptualization abilities (AC), and active 
experimentation (AE) abilities. That is, they must be able to involve themselves fully, openly, and without bias in new experiences (CE). They must be able to reflect on and observe their experiences from many perspectives (RO). They must be able to create concepts that integrate their observations into logically sound theories (AC), and they must be able to use these theories to make decisions and solve problems (AE). (Part I, Section 2)

The fourth characteristic of ELT is learning as a holistic process of adaptation to the world. Kolb (2014) suggested learning is far reaching and is present in all aspects of life, not just the classroom. The fifth characteristic identifies the transactions between the person and the environment as learning. The traditional educational process seems to have removed the environment from the learning process, creating a learning experience that is primarily personal. This final characteristic identifies knowledge creation as a learning process.

\section{Prior Learning}

The three learning theories discussed above (adult, transformative, and experiential) all recognize nontraditional students bring with them a worldview that is based on past events which either impede or support new knowledge creation. Knowles' (1974) framework for adult learning theory addressed students' readiness to learn, their goal-centered or problem-centered learning preference, and their high level of intrinsic motivation. Kolb's (2014) description of experiential learning as a process which is grounded in experience also emphasizes and recognizes the impact of prior learning. However, the assessment of prior learning in higher education did not occur until World War II veterans returned home. The main reason for this new focus was to provide 
veterans greater access to higher education (Keeton, 2002). While access is still one of the hot button topics within higher education, of equal import or more is retention and persistence.

For public universities, reduced state funding and a sluggish economic recovery have driven retention concerns even higher. Retaining students equals revenue; revenue allows the doors of the university to remain open. Even more important than revenue is the loss of potential opportunities for students and the corresponding financial implications for not completing their degree. The University of Central Missouri's president, Dr. Charles Ambrose, addressed this vary issue when speaking with academic advisors about upcoming changes within the university. His point was as a university the focus needs to be on retaining our current students particularly during the current fiscal constraints for academic year 2019-2020. As a society, there is an additional economic loss because of the lack of skills and knowledge acquired (Crosling, Heagney, \& Thomas, 2009). From a global perspective, educators are placing particular emphasis on the need to increase the number of science, technology, engineering, and mathematics (STEM) degrees. President Obama's call for the United States to increase the number of Americans with degrees from $42 \%$ to $60 \%$ by the year 2020 (Kanter, 2011) was based in part on the financial impact as well as the fact the United States had dropped from first to ninth in the world with respect to the number of degree holding citizens (OECD's Education-At-A-Glance: 2010 report).

Based on census data, the number of traditional students available to attend college cannot meet President Obama's mandate for degree completion. Institutions of higher education must attract and retain adult learners who are re-entering college. 
Focusing on the aforementioned adult learning theories, what is necessary for institutions to increase their yield with respect to adult admissions? Finch (2016) identified programmatic areas exemplary institutions have incorporated to support the adult learner. A few of the more common programs are the implementation of competency-based education, flexible schedule, accelerated courses, online courses, interdisciplinary adult degree program, adult focused orientations and marketing campaigns, and prior learning assessment (PLA) which may lead to credit for prior learning. While there are no guarantees these programs will result in higher graduation rates or persistence they certainly address the needs and concerns of most nontraditional students. As mentioned earlier, attrition rates for returning adult learners is even higher than first-time full-time students; however, The Council for Adult and Experiential Learning (CAEL) 2010 study found adult students who received credit for prior learning had a higher graduation and persistence rate than adult learners without any credit for prior learning. "More than half (56\%) of PLA students earned a postsecondary degree within seven years, while only $21 \%$ of non-PLA students did so" (p. 7). The willingness of institutions of higher learning to consider prior learning not only reduces the time and cost for the student, it also adds value to the prior experiences of the adult learner. Prior learning assessment is not new; however, the types of learning assessments have expanded beyond exams to portfolios.

Advanced Placement Exams. Advanced Placement (AP) exams are administered through the College Board. The College Board is a nonprofit organization founded in 1900 to expand access to higher education. There are over 6,000 learning institutions that make up the College Board (www.collegeboard.org). In 1955, the College Board, which was called the College Entrance Examinations Board, started the AP program (Cargo, 
1982). The AP program was designed to allow students to earn college credit through advanced placement courses while still in high school. These courses are comparable to college level courses. To date, there are 34 subjects available and mastery of the material is determined through a rigorous exam. Course curriculum is approved by college and/or university faculty. This prior learning assessment is widely accepted with more than 3,300 institutions receiving AP scores in a year. "In May 2013, 2.2 million students representing more than 18,000 schools around the world, both public and nonpublic, took approximately 4 million AP Exams" (College Board Newsroom, 2014).

College Level Examination Program (CLEP). CLEP examinations are also administered through the College Board. The program was established in 1967 and continues to be one of the widest used examinations (Cargo, 1982). The Defense Activity for nontraditional Education Support (DANTES) covers the cost for military members to take CLEP examinations. There are 33 CLEP exams available to students; however, acceptance of the examination for college credit is dependent upon the institutions of higher learning policies. Fifteen to twenty faculty members who teach the equivalent college course are selected and determine the scoring process to ensure the scores given reflect mastery of the subject matter content (College Board, Setting Standards web page). "In a survey conducted by the College Board of more than 4,000 CLEP candidates, 91\% of CLEP test takers reported that CLEP made a difference in helping them complete their degrees" (College Board, Benefits-and-results web page).

Challenge Exams. This type of prior learning assessment allows the student to take a version of the course final exam to assess mastery of the student outcomes. Challenge exams are usually developed at the department level and, as such, there is little 
standardization in the process. The challenge exams can be used for the purpose of determining course credit. The exam may also be used to allow the student to test out of a lower, introductory level course (EAB, 2015, p. 87).

Evaluated Training, Certifications, and Licenses. Evaluated training is normally accomplished at the department or program coordinator level. Usually there is an internal review by a subject matter expert to determine if college credit is warranted. An example for an internal review would be the verification by an aviation faculty member that the private pilot license provided by the student should count for the course required in that degree program. There are also external organizations that provide evaluation services for prior training, certifications and licenses as well. The American Council on Education (ACE) provides credit recommendations for prior training. ACE has a large military focus and has been an important partner with institutions of higher learning, recognizing the training and experience of military members and veterans. The process used by ACE for credit evaluation involves a team of teaching faculty who travel to military bases to evaluate military training. Team members review all aspects of the training being provided to include syllabi, examinations, lesson plans, and textbooks. One unique aspect of the faculty evaluation is the interviews with service members in the course, supervisors, and subject matter experts. When the evaluation is completed, the team determines the credit recommendations. Institutions make the final determination on whether the credit recommended by ACE should, in fact, be applied (ACE, 2009).

The other outside agency that provides credit recommendations for prior training is the National College Credit Recommendation Service (NCCRS). NCCRS has more of 
a regional focus with approximately 1,500 member institutions. NCCRS has conducted a little over 5,000 evaluations (EAB, 2015).

Portfolio. This prior learning assessment process is the most time intensive, primarily for the student. The student is required to gather documentation that shows evidence of knowledge and skills acquired outside of a formal classroom. There is usually an extensive amount of writing required. EAB (2015) has identified the common portfolio elements which include resume, written narrative of prior learning as it applies to the specific course, demonstration of learning through an essay or project, and documentation of learning. "The thrust of the submission is not a demonstration of what has been done, but an exploration and explanation of what has been learned. In that sense, the portfolio becomes a presentation of self, albeit limited and shaped by the kinds of academic credits that are being sought" (Starr-Glass, 2016, p.7).

As stated above the portfolio is a presentation of oneself and requires critical reflection that can become a transformative learning experience. With this being the case, many institutions not only provide a course for the student to learn the process for creating the portfolio but also mentors to support the student experiencing a personal or educational transformative experience. While there is a limited amount of credit that comes from the portfolio process, it is this transformative learning environment that is most beneficial to the student.

\section{Summary}

This review began with the concept of learning and described different types of learning with the primary focus on adult and experiential learning theories. These learning theories were further reviewed with respect to prior learning assessment and the 
identification of college credit for prior learning. Additionally, this review identified the types of prior learning and the impact prior learning has on persistence and degree completion. 


\section{CHAPTER THREE \\ OVERVIEW OF THE STUDY}

The intent of this program evaluation on prior learning assessment (PLA) for the University of Central Missouri was to determine the effectiveness of the program with respect to faculty assessors' perceptions and understanding of the university's PLA program as well as to determine the impact PLA has on persistence and retention of our adult, nontraditional students. Through different data analyses from faculty, advisors, and administrators the strengths, weaknesses, opportunities, and challenges can be determined. With the PLA program administrator opting for a utilization focused program evaluation, there is a very real possibility for positive programmatic changes to increase student persistence and retention.

Students who are retained and persist through degree completion will substantially increase their lifelong earnings. The U.S. Bureau of Labor Statistics (2013) identified the unemployment rate for individuals with a high school diploma at $8.2 \%$ as compared to $4.5 \%$ for individuals with bachelors' degrees. Weekly earnings for an individual with a bachelor's degree are over four-hundred dollars more than an individual with a high school diploma. Education increases an individual's quality of life, while at the same time enhancing the overall economic outlook for the country. With that being the case, institutions of higher learning must focus their attention towards the group they have the most influence over - students currently enrolled.

Throughout this section of the research, many important questions are addressed to reassure participants and the general public that the research conducted meets the necessary protocols for a valid social science research project. The first area focused on 
the research topic. Specifically, why prior learning assessment is so important, the rationale for the selected research design, and a discussion on the participant sample.

The second area covered was data collection methodology. First and foremost, information is provided on what type of data collection methods were used for this research. Of equal import to data collection is data storage and protecting the identity of participants. Finally, the methods used to analyze the data collected are addressed. The last area covered focuses primarily on the validity, trustworthiness, and rigor placed throughout the research conducted during the program evaluation.

\section{Statement of the Problem}

Institutions of higher learning have focused recruiting, retention, and persistence efforts on the "traditional" student. In doing so, the retention and persistence rates of the fastest growing population in higher education (the adult student) are even lower than traditional students and needs to be addressed. Tinto (2012) described the relationship between the student and the institution as a moral contract in which the institution is obligated to provide an environment for success, particularly in the classroom, so those students who are willing can achieve their goals. Unfortunately, the lack of specific policy or recognition of adult learning in higher education has resulted in the breaking of this contract for many adult students. This is validated through their decision not to return. One way to improve adult student retention is through the recognition of their life/work experiences. While PLA provides this opportunity, the process is inconsistent within colleges and schools due to credit assessment based on faculty determinations. Understanding the rationale between departments will provide an informed dialog between the student, the processor of PLA, and the faculty member. 


\section{Purpose of the Study}

The purpose of this qualitative utilization focused evaluation was to determine the understanding, perceptions, and experiences with prior learning assessment at the University of Central Missouri (UCM). UCM has accepted many types of prior learning; however, there is an inconsistency within colleges and schools. There is also a need to determine the value faculty assessors place on adult students' prior learning experiences.

The CAEL (2010) study identified higher retention and persistence for adult learners who were awarded credit for prior learning. Specifically, graduation rates for adult students earning a bachelor's degree were $28 \%$ higher than adult students who did not receive prior learning credit. Adult students working towards an associate's degree graduated 7\% higher than their non-PLA counterparts (CAEL, 2010).

The University of Central Missouri is dedicated to student success with the goals of access, affordability, completion, and student success after degree obtainment. PLA can be a key contributor to the university's strategic governance (https://www.ucmo.edu/about/identity, n.d). Allowing prior learning to be considered reduces barriers for student access by recognizing the adult learners' contributions to the classroom and their desire to obtain a degree. PLA reduces the financial burden by allowing credit for past experiences and the CAEL (2010) study validated degree completion was higher when PLA was assigned. Understanding how the university's practices and acceptance of prior learning enhance/detract from the administration's student success model is a necessary part of this evaluation. 


\section{Research Questions}

This program evaluation examined the faculty assessor's understanding of PLA and the assessment processes developed to support UCM's strategic goals for student success. To accomplish this objective, the following research questions guided this study.

5. What do faculty assessors perceive as barriers to accepting credit for prior learning at UCM?

6. What type of processes do faculty assessors use to determine credit or noncredit for prior learning?

7. How recognizable is UCM's PLA program to faculty, administrators, and students?

8. How do administrators and faculty assessors perceive PLA to be in regards to retention and persistence efforts of adult learners?

\section{Design and Methods}

The approach used for this research is a utilization focused evaluation (UFE).

"Evaluation is the process of determining merit, worth and value of things, and evaluations are the products of that process" (Scriven, 1991, p. 1). Using the program evaluation construct, the effectiveness and merit of PLA can be researched. There are several types of program evaluation designs, UFE was selected primarily for its focus on the actual use of the research for program improvement. For this design method to be effective a relationship between researcher and the key stakeholder is a necessity. With the prior learning assessment program being relatively new to the department, the researcher and key stakeholder the purpose of this evaluation would be for "formative improvement and learning" (Patton, 2008, p. 139). Additionally, the key stakeholder 
worked with the researcher to determine participants, research questions, data collection methods used to accomplish this program evaluation. The key stakeholder was also made aware of the findings and the recommendations purposed by the researcher. Upon completion of this evaluation stakeholders will be given the opportunity to make program adjustments and improvements as identified by research participants.

Hatch (2002) provided novice researchers with characteristics that distinguish qualitative research from other approaches (i.e., quantitative, mixed methods). It is through his characterization of the qualities of qualitative research that the researcher was able to define her approach. Specifically, qualitative researchers seek to understand from the perspective of the participants. This program evaluation allows the perspectives of the participants to determine program effectiveness.

\section{Participants and Sampling Procedures}

The scope of this research was on the faculty assessors, advisors, staff, and administrator's perceptions of the impact PLA has on persistence. With such specificity designed into a program assessment, participants will be identified through a purposeful sampling of homogeneous participants (Hatch, 2002) associated with the University of

Central Missouri's prior learning assessment program. To determine the effectiveness of the program, the primary focus must be placed on individuals who have a direct impact on program success or failure. For this reason, the first group of participants is the faculty assessors. These 67 participants were identified and referred to as Group A, with respect to the data collection process.

The second group of participants, Group B, consisted of 11 academic advisors. This group of participants should provide significant insight into the visibility and 
importance of the prior learning assessment program. Advisors are in direct contact with nontraditional students routinely and have the opportunity to provide information and guidance with respect to the university's prior learning program.

Group $\mathrm{C}$ was the professional staff involved in the processing of credit for prior learning. This group of four individuals provided insight into the effectiveness, or lack thereof, with respect to program processes. Identifying best practices or areas for improvement will provide the additional supporting data on program support.

Finally, Group D included 15 department chairs. As leaders within their specific areas it will be valuable to determine if there is a consistency between faculty assessors and department chairs have similar perceptions about the importance of PLA and the barriers, if any, to implement a robust prior learning assessment program. It would be short-sighted to conduct research on a program and not look at the leadership responsible for program administration.

The first contact made for this program evaluation was with the primary stakeholder. This was accomplished through coordination with the office manager to set up a formal meeting time. While there have been many informal conversations and input from the program administrator, determining the perceptions and aspirations of and for the program provided invaluable information to this program evaluation (Patton, 2008).

Since this was an internal program evaluation, primary contact was through university electronic mail for all identified participants. While electronic mail is considered more of an informal communication, a formal letter was attached (Appendix A). This letter addressed the focus of the research with a request for their participation in the program evaluation. The letter also informed participants of a follow-up email that 
was sent approximately one week after receipt of the first formal request for support.

Initial contact with all groups was through email.

\section{Data Collection}

To effectively conduct a qualitative program assessment, multiple data collection methods were needed to provide the richness and depth of data needed to identify emerging themes or patterns. Creswell (2009) described the need for a codebook to help identify data sources and participants. This is particularly necessary with multiple groups of participants with several data collection methods.

Alphanumerical sequencing was used to identify the raw data collected for this research. Specifically, the first digit in the sequence was the type of data collection method: Surveys were identified with an "S", and archival data with an "A." The second digit identified participants, by assigning the appropriate group designation addressed earlier (i.e., Group A, B, C or D). Following the group designation was the numerical number of the participant. For example, SA1 = survey from a faculty member (Group A), who was the first to reply. Interview and focus group participants were given pseudonyms.

Data collection procedures. As stated above, surveys, interviews, focus groups and unobtrusive/archival data were collected and analyzed in this program evaluation. Sequentially, the first type of data collection was the review of archival data. These data were examined for trends in prior learning assessment participation and the impact on retention and persistence. Collecting unobtrusive/archival data, prior to any other data collection methods, provided an opportunity to address institutional policies and 
processes during interviews and focus groups. Before any interviews or focus groups were conducted, a survey was sent to participants in Group A: faculty (Appendix B).

The survey consisted of 19 qualitative, open ended questions, with some additional demographic information and took no more than 20 minutes to complete. Participants who responded to the survey were also requested to participate in an interview. If accepted, survey participants provided contact information for a follow-up conversation with the researcher.

The primary data collection method to be used for staff and university administrators (Groups C and D), was semi-structured interviews that were audiotaped and then transcribed. Interviews lasted no more than 45 minutes and only one interview per administrator was necessary. Interview protocols for Groups C and D can be found in Appendix C and D. With 27 departments and several staff members involved in the prior learning assessment program, there was a total of 19 interviews.

Finally, focus groups were conducted with academic advisors who are identified as participants in Groups B. With the number of advisors at the University of Central Missouri there were two focus groups. Each focus group had a minimum of one advisor from each of the four colleges. While there were only two focus groups, the single focus of the topic, prior learning assessment, allowed for adequate saturation of the subject (Kruger \& Casey, 2009). Each focus group lasted no longer than 90 minutes. See Appendix E for focus group protocol.

While this program evaluation had several data collection methods identified, there was no guarantee that a rich amount of data would be available for analysis. As 
Hatch (2002) stated, "participants are the ultimate gatekeepers. They determine whether and to what extent the researcher will have access to the information desired" (p. 51).

Human subjects' protection and other ethical considerations. Each participant was presented with an Informed Consent Form for them to review, and sign before participating. For this research, there were two informed consent forms, one for advisors (see Appendix F), and the other for professional staff and administrators (see Appendix G). The informed consent apprised participants on the type of data collection method and how the collection of data will be accomplished. When participants signed the informed consent, they were giving the researcher permission to collect data. Survey participants implied their consent through completion of the survey. Participation in this study was voluntary and there have not been any repercussions for choosing not to participate. However, willing research subjects were protected.

Confidentiality was maintained throughout the research project. Surveys were sent to participants through the use of Survey Monkey software, allowing the identity of participants to remain anonymous. All data were assigned an alphanumeric code prior to any data analysis. Applying an alphanumeric code serves two purposes. First, it removed the identity of the participant from any data being reviewed and secondly, assigning codes reduced the possibility of researcher bias during data analysis.

Confidentiality also required security. Raw data (i.e., audiotapes and transcripts), were stored electronically on one computer under password protection. Throughout the research process all data were stored in one of these two methods. Once the program review has been completed, all participant research data will be destroyed at the appropriate time, by shredding or deletion of electronic files. 


\section{Data Analysis}

Conducting a qualitative research study is an inductive process (Creswell, 2009; Hatch, 2002). Analysis began as soon as data were made available to the researcher. For example, information provided during the unobtrusive/archival data review and surveys will likely be used to modify the open-ended questions asked during the interviews and focus groups. This method of early analysis provided an opportunity to recognize a unique situation worth looking deeper into, as well as to capture the common themes among all the data collected.

A very important aspect of data analysis is the coding of themes. The traditional approach to coding "is to allow the codes to emerge" (Creswell, 2009, p. 187). This type of inductive analysis complements a program evaluation. The first step is open coding, which is the initial step in analysis. Open coding identifies broad commonalities, or the single stand out event. Once this coding has been completed, the data are reviewed again with a focus toward commonality (axial coding). The second type, axial coding, identifies broader categories or themes. Finally, selective coding is utilized to identify the emergence of a theme. All of the coding information will be annotated in the codebook (Creswell, 2009).

\section{Positionality}

Hatch (2009) described how an individual's view of the world affects the selection of data collection methods and research designs. A constructivist places a great deal of importance on the participants being researched. The products created by researchers with a constructivist view may be case studies, reconstructions, and narratives (Hatch, 2009). It is these types of characterizations that led the researcher to a 
constructivist positionality. This research is concerned with individual perceptions on the effectiveness of the prior learning assessment program. Obtaining an individual's perspective will require getting to know participants and understanding different viewpoints.

This program evaluation researched stakeholder perceptions of the effectiveness of the prior learning assessment program as it relates to adult student persistence and retention. While the researcher is currently employed with the University and functions as the prior learning assessment program monitor, the type of program evaluation, formative, poses limited risk to the participants and, as such, the role as researcher should not impact the validity of this evaluation.

\section{Trustworthiness}

To determine research validity, Denzin's (1978) methodological triangulation was the primary method used. This type of triangulation takes different methods of research (i.e., surveys, interviews, focus groups, and archival data) and compares the results. While time consuming, it does provide multiple opportunities to confirm the consistency or incongruities of the data collected. The survey was a cross-sectional design, administered once to selected participants (Fink, 2009). Participants were selected based on their stakeholder status within the program being evaluated (Patton, 2008). Before actual data collection, the survey questions were reviewed by the PLA administrator and pilot tested (Fink, 2009). The researcher's inclination to look at data from a methodological perspective assisted in identifying any inconsistences associated with personal interpretations. 


\section{Assumptions}

As stated earlier, using methodological triangulation (Denzin,1978) assisted in ensuring data verification. Multiple sources of data produced the same knowledge, mitigated the concern for broadness of the research topic. Additionally, a peer debriefing (Creswell, 2009) was used to ensure accuracy of coherence. With the amount of data anticipated there was an opportunity for the researcher to be very descriptive in reporting all aspects of the setting and varying perspectives. While there are limitations associated with any study, the practices listed above provided opportunities to reduce the effect on the research.

\section{Summary}

In 2009, President Obama described an educational system with over half of the students who attend an institution of higher learning failing to complete their degrees ("www.whitehouse.gov," n.d.). Finding out why students do not return is an important issue for administrators. There are many national level surveys and much quantitative research that address this issue, but little has changed with respect to persistence and retention.

This qualitative program evaluation looked at the perceived impact the prior learning assessment program at the University of Central Missouri has had on adult student persistence and retention. The sample survey consisted of a homogenous group, in that all participants were stakeholders in the PLA process. The faculty selected make the recommendations for credit transfer, the advisors have routine contact with students, the professional staff are key to the PLA process, and the administrators provide the leadership and guidance to faculty, advisors, and staff. Several data collection methods 
were used to ensure the breadth and depth of data necessary to identify anomalies or aggregate trends (Scriver, 1995).

With this program review utilizing Patton's (2008) Utilization Focused

Evaluation methodology there was a real possibility for increased understanding,

program improvements, and possibly increased persistence and retention of adult students at the University of Central Missouri. 


\section{CHAPTER FOUR}

\section{FINDINGS}

The purpose of this study was to conduct a utilization-focused program evaluation (Patton, 2008) of the University of Central Missouri's prior learning assessment for credit process. Through coordination with the primary stakeholder, key contributors were identified and contacted to determine program strengths, improvement areas, and the impact applying credit for prior learning has on student retention and persistence. The type of evaluation conducted was formative in nature through a lens toward improving the program (Patton, 2008). Key contributors were identified through the use of a logic map.

Table 4.1

Prior Learning Assessment for Credit Logic Map

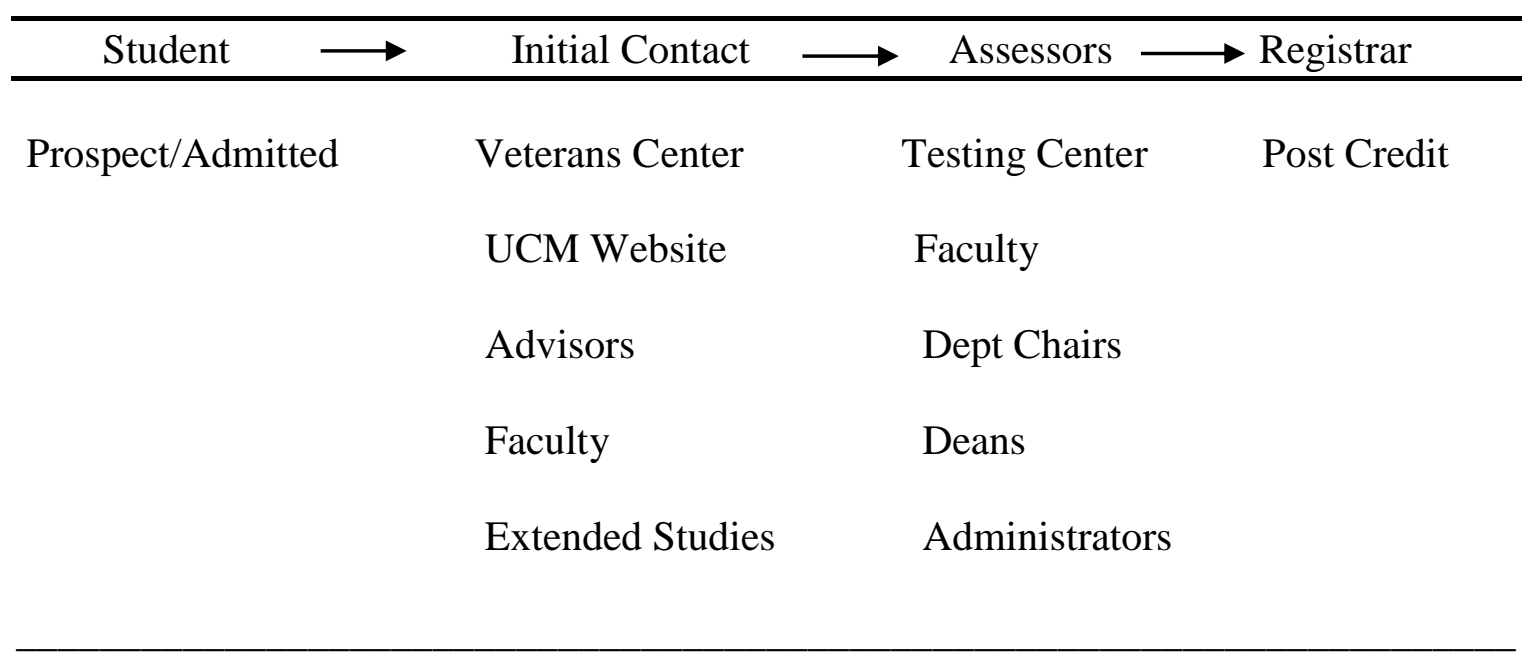

Note. This logic map identifies the process for prior learning credit to be considered and the various points of contact that may be involved in the assessment process.

Within Chapter Four is an overview of the design of the study, data collection methods, research questions, and analysis of data. Through the analysis of data gathered 
from surveys, focus groups, interviews, and archival records the emergence of common themes was evaluated.

\section{Design of Study}

A qualitative utilization focused program evaluation was applied to gain insight into the effectiveness of the prior learning assessment (PLA) for credit program at the University of Central Missouri. "Evaluation is the process of determining merit, worth and value of things, and evaluations are the products of that process" (Scriven, 1991, p. 1). Using the program evaluation construct, the effectiveness and merit of PLA can be researched. The intended purpose of this evaluation is "formative improvement and learning" (Patton, 2008, p. 139).

Hatch (2002) provided novice researchers with characteristics that distinguish qualitative research from other approaches (i.e., quantitative, mixed methods). It is through this characterization of the qualities of qualitative research that the researcher was able to define her approach. Specifically, qualitative researchers seek to understand from the perspective of the participants. This program evaluation allows the perspectives of the participants to determine program effectiveness.

\section{Data Collection Methods}

Before data collection began, the researcher requested permission from the university's Human Subjects Board for approval to begin data collection (see Appendix $\mathrm{H}$ for complete documentation). Survey and focus group questions were pilot tested with peers. This pilot testing resulted in an adjustment in the order of questions to be asked during the focus group and an additional set of questions for the faculty survey. Since the survey had some significant changes, the researcher was required to submit an 
amendment to previous Institutional Review Board (IRB) approval. Pilot testing provided the researcher with high confidence that the data collected would, in fact, answer the research questions. The researcher contacted the University of Missouri's Institutional Review Board to obtain approval to begin data collection and was informed that there was no need for their approval because the study is for program evaluation purposes only (Appendix I).

\section{Research Questions}

The following research questions guided this study:

1. What do faculty assessors perceive as barriers to accepting credit for prior learning at UCM?

2. What type of processes do faculty assessors use to determine credit or noncredit for prior learning?

3. How recognizable is UCM's PLA program to faculty, administrators, and staff?

4. How do administrators and faculty assessors perceive PLA to be in regards to retention and persistence efforts of nontraditional students?

\section{Conceptual Framework}

The conceptual framework for this research began with Knowles' (1973) adult learning theory. Through his work key differences were identified between the traditional and nontraditional student. Knowles' focus was on enhancing the learning environment for adult learners. One of the key aspects of his theory was the importance of the experiences nontraditional or adult learners bring with them to the classroom. 
Knowles' (1973) study of the adult learner has evolved into identifiable policies and practices within higher education. One specific area that has gained momentum over the years is prior learning assessment (PLA). In this data driven environment it is important for institutions of higher learning to determine program successes and vulnerabilities. To that end, this researcher, with the support of the PLA administrator, implemented a program review of the University of Central Missouri's PLA process with Patton's (2008) Utilization Focused Evaluation framework as the guide.

\section{Process of Data Analysis}

Conducting a qualitative research study is an inductive process (Creswell, 2009; Hatch, 2002). As such, analysis began as soon as data were made available to the researcher. This analysis was conducted through a constructivist lens (Hatch, 2009). With this study focused on a program evaluation the input from the participants was of particular importance. Constructivists place a great deal of importance on participants. Through the program evaluation it was the perceptions and recommendations of the stakeholders that enabled this researcher to conduct the assessment.

Analysis consisted of triangulation of data from archival documents, surveys, focus groups, and interviews (Creswell, 2009). Each document, survey participant, focus group member, or interviewee was assigned a code. Survey participants: SA-1 through SA-67; focus group participants: FGB1-1 through FGB1-4, FGB2-1 through FGB2-7; staff interview participants: IC-1 through IC-4; and administrative interviews ID-1 through ID-11. 


\section{Document Analysis}

With the assistance of the University of Central Missouri's Institutional Research, the researcher was able to collect information on UCM students who have received special credit (prior learning) for the last three academic years. Below is a breakdown of the information provided.

Table 4.2

Special Credit Awarded

\begin{tabular}{rrccr}
\hline Academic Year & \# of Students & \# of Hours Received & \# Persisted/Retained & $\%$ \\
\hline $2014-2015$ & 1,200 & 11,532 & 656 & 54.66 \\
$2015-2016$ & 1,248 & 11,867 & 879 & 70.44 \\
$2016-2017$ & 1,125 & 12,909 & 653 & 58.04 \\
& & & & \\
Cumulative Total & 3,573 & 36,308 & 2,188 & 61.23 \\
& & & & \\
\hline
\end{tabular}

Note. 3-year view of special credit awarded for prior learning including last semester attended and graduation semesters provided by UCM Institutional Research.

For those who received prior learning credit, the average amount of prior learning credit received for Academic Year (AY) 14-15 was 9.6 hours. AY 15-16 averages dropped by one-tenth of a percent to 9.5 hours of credit awarded. AY 16-17 saw an increase of credit hours awarded per student to $11.5 \%$. During this timeframe UCM's tuition rates remained relatively stable at $\$ 214.85$ per credit hour, reducing students out of pocket expenses between $\$ 2041.00$ and $\$ 2470.00$ dollars.

In addition to the internal data provided by Institutional Research, in March 2017 the University of Central Missouri participated in the Council for Adult and Experiential Learning (CAEL) survey to determine how the university compares to other institutions with respect to being an Adult Learning Focused Institution. Two surveys were 
conducted, the Adult Learning Inventory (ALI) which was completed by 166 undergraduate adult learners. This survey measured student perceptions of the university's adult-oriented services. The second survey was completed by university faculty, staff, and administration which provides a glimpse in time on what the university provides to adult learners. One of the areas addressed was prior learning. The demographics data on credit received from prior learning showed 39\% of the 166 students received credit for prior learning (Adult Learning Inventory, Noel-Levitz, 2017). However, students did identify receiving credit for prior learning as a challenge (UCM Internal Comparisons: ALFI Data, 2017).

\section{Participants}

For this program assessment, 330 faculty members were contacted through survey, with 67 respondents. Eleven academic advisors participated in focus groups, and 19 interviews were held with department chairs and staff directly involved in the prior learning assessment process. The selection of participants was discussed with the program administrator and agreed upon prior to contact. Each group of participants provided a unique perspective on the effectiveness of the prior learning assessment program.

\section{Survey Participants}

Institutional Research provided the researcher with a list of emails for tenuretrack and tenured faculty assigned to the university. Surveys did not go to adjunct or temporary faculty because they would not have been involved in reviewing documentation for special credit. The survey was created in Survey Monkey and was sent to 330 faculty members. A total of 67 responses were received, resulting in a $20.3 \%$ 
return rate. The answer to the first question pushed participants to specific questions within the survey. If participants were responsible for reviewing prior learning for credit they were directed to questions 2 through $14(n=30)$. If participants were not responsible for reviewing prior learning for credit they were directed to questions 15 through 19 $(n=37)$. Upon review of the participant responses, several of the participants skipped questions throughout the survey. Below is a breakdown of response rates per question (see appendix B for the complete survey).

Table 4.3

Survey Responses by Question

\begin{tabular}{cccc}
\hline Question \# & \# of Responses & \# of Participants & Response Rate by \% \\
\hline 2 & 23 & 30 & 76.67 \\
3 & 24 & 30 & 80.00 \\
4 & 17 & 30 & 56.67 \\
5 & 22 & 30 & 73.33 \\
6 & 21 & 30 & 70.00 \\
7 & 18 & 30 & 60.00 \\
8 & 18 & 30 & 60.00 \\
9 & 15 & 30 & 50.00 \\
10 & 17 & 30 & 56.67 \\
11 & 20 & 30 & 66.67 \\
12 & 20 & 30 & 66.67 \\
13 & 15 & 30 & 50.00 \\
14 & 8 & 30 & $26.67 *$ \\
15 & 24 & 37 & 64.86 \\
16 & 25 & 37 & 67.57 \\
17 & 24 & 37 & 64.86 \\
18 & 24 & 37 & 64.86 \\
19 & 21 & 37 & 56.75 \\
\end{tabular}

Note. Question 14 asked participants if they were interested in participating in an interview. 


\section{Focus Groups}

Two focus groups with academic advisors were conducted for this program evaluation. The first focus group had four participants and the second focus group had seven participants. Between the two groups the researcher was able to meet with at least one academic advisor from each of the four colleges at the University of Central Missouri. The focus groups lasted no longer than 60 minutes (see Appendix E for the interview protocol).

\section{Interviews}

Of the 19 interviews conducted, four were stakeholders directly involved with the credit for prior learning process and two were faculty who volunteered to be interviewed after taking the initial survey. The remaining 13 interviews were with department chairs. Contact was made with the interviewees through email. An initial email was sent letting the administration and staff know a request for an interview was forthcoming (see Appendices $\mathrm{C}$ and $\mathrm{D}$ for interview protocols). Approximately two weeks later the email requesting the actual interview was sent out. There was one follow-up email sent as a reminder. The email request for interview participants was sent to 25 department chairs and 13 participated for a 52\% response rate. Primary users, individuals directly involved in the prior learning process, all volunteered to be interviewed for a $100 \%$ response rate.

\section{Themes}

Through multiple participant data collection methods, the richness and depth of information provided the foundation for data synthetization resulting in the emergence of the following themes for this program evaluation: 1) Understanding Prior Learning, 2) Initiation of the PLA process, 3) Determining Credit Approval/Disapproval, 4) Impact on 
Student Success, 5) Program Barriers, and 6) The Future of PLA. These themes highlight key aspects of the Prior Learning Assessment for Credit program and addresses the research questions for the program evaluation.

\section{Understanding Prior Learning}

In this study, there was an overwhelming majority of individuals who did not know what was meant by the vernacular "prior learning," or the different types of prior learning considered for assessment. Of the 25 responses received for the survey question, "What do you know about prior learning assessment and credit for prior learning?" 11 responded with not much or nothing. Additional survey comments further validated the lack of understanding for the university prior learning assessment program. "In the past few months I began in a new position and to my knowledge, we do not accept prior learning that is not a specific class. Maybe I do not understand what is meant by prior learning assessment" (SA-2). However, survey participants were not the only group of participants who did not understand what prior learning was or encompassed.

Since one of the research questions was to determine the awareness of the prior learning assessment program at the University of Central Missouri it became clear that many of the department chairs who volunteered to participate in the program evaluation had very limited exposure to prior learning assessments or to the term. ID-4 stated, "We

don't have that term," and ID-5 acknowledged, "I gotta admit probably not much.” ID-14 summed it up in their statement, "By prior learning, prior to what?" are just a few of the statements given when asked about their experience and understanding about prior learning. Individuals involved in the prior learning approval process are only aware of a 
type of documentation they evaluate. Faculty assessors do not have the full understanding of what prior learning encompasses. IC-2 stated, I don't know how big the umbrella of prior learning is, but I would say my first experience in advising... and again, I don't know if it counts as prior learning, but when students would come in with an aptitude, like foreign language, they would take a higher level course and then would earn credit in the lower level courses. Or students who would get a lot of public speaking could go test out and prove their proficiency in public speaking with the department.

Once participants expressed a lack of experience or knowledge about prior learning assessment the researcher would describe the types of prior learning available for consideration. In some cases, describing the process and providing examples of the types of prior learning, participants who originally described their experience with prior learning assessments as "limited" or "none" began to realize they had been involved in the PLA process. ID-8 and ID-1 respectively stated, "You know, I had never thought about CLEP and AP as being part of prior learning" and "We do take AP credit" were common statements when participants were provided with the appropriate description of prior learning artifacts. Military credit also required some explanation to participants.

The University of Central Missouri transcribes military credit from the transcripts provided by the Community College of the Air Force (CCAF) or the American Council on Education (ACE). Because military credit is posted like other formal college transfer credit many participants did not think military ACE credit was actually considered prior learning credit. IC-2 stated, "My husband was military; he was Air Force. So, his stuff was transcripted. So, I don’t know if I would call that prior learning.” However, focus 
group participants were familiar with military ACE credit but the level of understanding varied based upon their exposure to different degree programs.

The University of Central Missouri is committed to supporting veterans. In 2017 UCM was ranked in the Top 10 of Military Friendly Schools (https://www.ucmo/edu/vets/team.cfm, undated) due, in part, to the acceptance of military credit identified through ACE. FGB2-2 commented,

I have some heavy military programs and so CDM and CJ both require a lot of free choice electives and so if I know any kind of military credit like JST, let's get these Joint Service Transcripts. So that's a common conversation I have with my students, the JST is a big one.

University policy allows for 60 credit hours of other credit which is divided between credit by examination (i.e., CLEP or AP). This is denoted as 'SC' on the student's degree audit, while special credit is denoted as 'CR' on the degree audit. CR credit is what the university uses to identify credit for prior learning. Students may have a maximum of 30 credit hours of 'SC' and 'CR' credit. Since military credit is transfer credit, it is not considered special credit, which allows military students to obtain a significant amount of credit depending on their major (UCM Undergraduate Catalog, 2017). Since the university created the military transfer coordinator position, the awareness of military prior learning has improved. IC-4 commented,

The students (military) are pretty good at bringing their transcripts to me, or that email...I send whenever they apply. I send that email out, "Hey, you applied to UCM," and they're pretty good at responding to that and letting me know they requested their transcript. 
Additionally, once a military member or anyone who is affiliated with the military applies to the University of Central Missouri an excel spreadsheet is created by someone in the admissions office sent out daily to the military coordinator. This product allows the coordinator to reach out to the applicants and let them know how military prior learning is evaluated at the university.

Based on the data collected, there is a lack of understanding or awareness of the university's prior learning assessment for credit process which spanned across all participant types. The awareness and understanding of PLA spanned the spectrum from knowing nothing to identifying transfer credit from other universities as prior learning. The only exception was prior learning for military members, but even that area had some misunderstandings with participants thinking military transfer credit was not considered prior learning.

\section{Initiation of the PLA Process}

During the 2016-2017 academic year, the Council for Adult and Experiential Learning (CAEL) surveyed students, faculty, staff, and administrators to determine how we compare as an Adult Learning Focused Institution. One of the reports provided to the university compared student surveys with the faculty, staff and administrators' inputs identifying strengths, challenges, and disconnects between the two groups and offered recommendations (CAEL, 2017). "One area of opportunity for UCMO...is to make prominent the variety of opportunities offered for credit for prior learning, or prior learning assessment (PLA)" (CAEL, 2017, p. 6). While the recommendation made by the CAEL report was not a surprise, the fact UCM has had over 1,100 students who each 
academic year have received credit for prior learning is surprising based on the passive management of the prior learning assessment process.

The theme of initiation emerged from the first theme of awareness and understanding of prior learning. As stated earlier, a majority of the participants had very little, if any, knowledge of what prior learning assessment entailed and, as such, opportunities to initiate the conversation about prior learning by faculty, staff, and administrators was missed. With the exception of military credit transfer, the university's prior learning process is initiated by the student. IC-3 stated, "We do a little advertising here and there, that sort of thing. But, for the most part, the students are coming to us." FGB1-3 mentioned, "I can't say that I mention a lot of the prior employment and stuff like that. It's usually student initiated." FGB1-4 followed with, "I'm the same way, it's all student-driven. I don't ask them.” Again, there was little difference in how each segmented group approached the initiation of the prior learning assessment process. One focus group participant, FGB2-4, recognized the opportunity to assist our adult students by stating, "I've never had that conversation; I should start." And then there was a totally different view from FGB2-2.

Normally we just don't have an avenue for that in the department, so if they want to bring it up I send them to the department, but it's not a conversation I start with them because chances are it's not going to get them anywhere anyway.

As stated earlier, the one exception is when participants engage with military. FGB2-7 noted, "We do have the conversation, it's not uncommon for a veteran to say, "Hey, I've got credit for this, can that be used?" Since the creation of the military transfer coordinator, military applicants are sent an email letting them know that their military 
training may very well transfer into their degree program. So, the military are getting the information sent to them and faculty and staff are also providing them with this information once their military status is known. There is no guarantee that military experience is going to accelerate degree completion or reduce their cost, the take-away is this particular group of students are being approached about prior learning, unlike our other adult learners. FGB2-6 commented,

We have the conversation up front when they want to know how long it's going to take and I'll say, "Well you can pick a major that aligns with your training and your background or if you want to do something completely different than you're basically starting over again.” (FGB2-6)

With students being the initiators of the prior learning assessment process there is the potential for missed opportunities and additional out of pocket expenses. If students are unaware of credit for prior learning, they may enroll in classes for which they could have received prior credit. Finding this information out after the fact is not only frustrating for the student, it does not put the university in a very good light. Students put in this situation are less likely to persist with the university.

\section{Determining Credit Approval/Disapproval}

This theme focused on several aspects from departmental policy for approving/disapproving prior learning credit to what factors drove the decision to approve or disapprove prior learning. With many of the participants having a limited view of the items that fall under prior learning assessment, the researcher was required to describe the types of prior learning and to ask more hypothetical questions versus actual decisions made. While the questions were more "what if," the information garnered was 
still of value to the study because the participant comments provided a view of their comfort level for each type of documentation that could be presented for their review in the future. Based on the vast amount of comments by the participants on this theme there was a need to further break down this theme into subcategories. The subcategories emerged as: philosophy, policy, procedures, and concerns.

Philosophy. Throughout interviews, focus groups, and surveys many participants provided their personal perspectives on the impact or merits of credit for prior learning. Student success was one of the areas that stood out to participants. IC-1 stated,

The big underlying thing, too, that we want to make sure is that those students are being successful. So, if they come in and bring in a bunch of prior learning, but like I said, it's dated or it doesn't align very well with the particular program, we don't want to jump into upper level classes or waive those upper level classes and send them out the door with a diploma if they're not prepared and familiar with those. We want them to be successful.

This thought process of ensuring student success is also closely related to university standards from the faculty perspective. The university learning experience is more than just obtaining a skill and, as such, faculty and administrators are concerned students will not receive the full benefit of their education if the learning experience is primarily training based. ID-3 shared this comment:

We are an institution of higher learning, and it's our job to teach the why, which is not necessarily skills-based. It is more knowledge-based and more abstract and understanding how things fit together and why persons operate the way they do and why police departments operate the way they do. No, that doesn't help you 
put the guy in the squad car, but it does help you understand why you're patrolling that particular area to get the guy to put him in the squad car.

And then there is the need to meet course objectives. While most participants did not define a specific grade percentage needed for prior learning credit to be awarded, there was a requirement for prior learning credit to match course objectives. One participant, ID-2 described a scenario that would never allow for prior learning credit.

A lot of the faculty's discomfort with giving prior learning for credit on the comm study side of the house, much of it is 16 weeks of concentrated study of a specific topic. Somebody says, "Well I've been a teacher for x amount of years. I know how to talk in public." Well, that's a different audience group when you're teaching. It's not the same as an audience group when you're doing public speaking. And secondly, they're working from prepared material like lesson plans with a specific objective. I haven't seen a single instance of somebody that has applied for credit for work experience or something like that, that would actually, legitimately, in our view, pedagogically, be a...yeah that counts.

While this viewpoint is not new, it does create a challenge for nontraditional students. Knowles (1974) identified key differences between the adult learner and the traditional college student. nontraditional or adult learners want their experience recognized and they do not want to sit in a class that they perceive to be of little value.

Policy. Without exception there is no written policy in any department with respect to how the review of prior learning is assessed for credit. There are common practices in several of the departments but the volume of requests for credit assessment has not warranted formal policy guidance. According to ID-6, "There's not a policy. 
Right now the practice has been just the Department Chair makes the decision on articulating courses." Other administrators/faculty had similar responses with respect to policy. ID-9 commented, "I would assume if someone presents themselves as wanting some (prior learning consideration), that you (the researcher) would send them to me." ID-11 shared, "It comes to the Department Chair, but with feedback from the areas."

While it is understandable, based on volume, that a written policy may not be necessary at this time for many of the departments, there is a concern for the student hoping to have their prior learning assessed. Specifically, if the departments are unaware of a policy a student could be told, incorrectly, that the university does not accept credit for prior learning. The fact that the vast majority of participants have little, if any, knowledge about the university's prior learning program it is possible students will miss out on an opportunity to reduce their time to degree completion and their debt.

Procedures. Survey participants were asked how they, assessors of prior learning, determine whether or not credit should be awarded. The majority of answers came down to comparing the experience with the course objectives and/or syllabus. Unfortunately, some of the survey responses were actually describing transfer credit. For example, "Based on course syllabus and course content including laboratory exercises/assignments (where applicable) from earlier institution." While the comment does define a procedure, it does not apply to assessing credit for prior learning. This survey participant comment also confirms the lack of understanding with respect to prior learning as identified earlier.

In the few cases, we decided on a case-by-case basis by looking at the syllabus for the class they have taken somewhere else and agreed it lined up with one of our class's objectives. Then we have given the student transfer credit for the course. 
Conceptually there seems to be a misunderstanding of what is prior learning. Transfer credit is knowledge and learning that has taken place in a classroom prior to attending a new university. Prior learning is focused on learning outside of a formal institution of higher learning.

There were a few survey participants who clearly understood what prior learning meant and had procedures in place for review, such as, this comment,

In $\mathrm{CJ}$ we have a fairly standardized way that we do things. For example: completion of a Law Enforcement Academy is worth a certain number of undergraduate hours. Completion of the U.S. Army's Military Police Career Captain's Course is worth a certain number of graduate hours.

Having set undergraduate and graduate hours for specific learning experiences as described above is an efficient way to provide students with timely feedback and ensures students do not enroll in any unnecessary courses. Even if a department does not have a set number of hours for a specific course, determining the procedures for review before a request is made for consideration helps reduce the amount of time required for a decision to be made. One survey participant commented,

I have not been involved in any cases where we have given credit for life experiences, although we have decided as a department that we will allow for that on a case-by-case basis, using the exams and projects we currently use in-class to assess a student's mastery of the objectives.

Developing these types of procedures eliminates confusion and provides for a consistent process, that while the outcome may be different, the procedure is repeatable. One participant, ID-14, addressed the department's procedure for reducing admission 
requirements based on prior experience. "At the graduate level, if they have four years of IT experience in a company that is listed, we waive their GRE requirement." While the recognition of prior learning in this form is not considered a type of prior learning, it does remove barriers, reduces admission costs, and recognizes the experience of the adult learner. Another area has become creative in applying prior learning concepts into their curriculum design by reducing the number of hours for the degree based on experience. ID-7 discussed,

So, we have a master program, specifically, that has option areas that they can get into and it's based on experience and education. So, we're not technically giving them course credit, but we're reducing course requirements based on a set of information of what they already have coming in.

Concerns. Ensuring the student who is requesting credit is the individual who earned the credit was recognized by faculty participants in both the survey and in interviews. "Concern about the authenticity of documents submitted" was one of the comments submitted in the faculty survey as a reason why credit was not considered. This concern is very similar to the challenges faculty have with online course delivery. While there are mechanisms to reduce online cheating, it is more difficult to assess authenticity for prior learning, as suggested by IC-1,

The issue that's come up, too, is how do I know you're the one that completed that? Or we've run into, in my past experience in the industry certifications and trainings, it's a weekend workshop and you go through there and you sit through a presentation and you get a certificate. Not all of them (certification programs), but some are. 
In addition to authenticity of documentation, there is a strong concern for meeting the rigor required to award credit. Survey participants were asked to provide reasons why they had disapproved prior learning credit in the past and the following comments validate the faculty concern for rigor. "They were asking for a course to be counted for one of our required courses" and "Content not equivalent to course to be replaced" It appears there is little flexibility when considering prior learning for credit if the experience does not match exactly to the course being considered or it is a required course. Part of the concern comes from awarding academic credit for a skill, as noted by ID-3.

Training for credit is probably the one (prior learning) that's probably the most contentious, because as a department we have some people who lean more theoretical and people who lean more practical. And so the people who lean theoretical are quite hesitant to give credit for such things.

Students would have a better understanding of the reasons either for or against accepting prior learning if there were a standard established within the departments or at the university level to state how comparable the prior learning should be to the course being considered. For instance, one department chair thought if courses were reviewed in a way to breakdown the course objectives into theoretical and skills based, then the departments could determine what percentages were needed for credit to be awarded. Being able to provide some clarity would be beneficial to both faculty and students.

This concept of theoretical versus skills is also seen as a concern for faculty. There seems to be more acceptance of prior learning when tied to a technical skill. ID-2 stated, "I do see the value in it (prior learning) and I think some of it is probably 
more...lends itself more readily to the technical side of learning, the technical skills." Assessing prior learning with respect to technical skills is certainly less ambiguous. Many students have documentation such as certifications or licenses from very reputable companies. There are ways for students to provide evidence of prior learning for the more theoretical courses through the use of the portfolio, however, the concern for authenticity becomes a concern.

\section{Impact on Student Success}

The researcher asked focus groups and interviewees their opinion about the impact awarding credit for prior learning had on persistence and retention. The reason for this question was to determine what participants knew about the impact prior learning can have on the student and the institution. There were comments based on the limited amount of prior learning credit assessments that the participants did not feel they could make an informed decision on persistence/retention. ID-3 stated, "I don't have any real data on that," followed by ID-7's comment, "I don't know how it would impact retention." ID-14 simply stated, "I don't have the data for that." While the majority of the participants have had limited exposure to assessing credit for prior learning, they did feel comfortable providing an opinion. ID-10 acknowledged,

I am not really that familiar, but I hope there is, because there will be a motivation I guess, if we give them credit because of previous learning or something like that, they will continue and try to finish their program.

Most of the comments about the impact PLA has on persistence and retention recognized a positive relationship between the two. The idea students were receiving recognition for past experience and reducing their time to degree were motivational 
factors for persistence. FGB1-4 described, "I think it always gives them this feeling of, I have accomplished something. My past has meant something and I'm being recognized for what I can do. Even it's as little as one class to fifteen classes." While not all experiences should be considered for credit, recognizing an individual's prior learning can have a significant impact. ID-4 commented,

If any student who is here and we can find a way to legitimately give them credit for a course where they didn't have to spend the money or the time to complete that course, I think that would only increase their incentive to stay. And to continue to stay in the department and get their degree with us, because they see us working with them, not as a collection of data, but as a person sitting across the table pleading their case, showing us their resume.

Another aspect slightly outside of student success identified during the data gathering about retention and persistence was the concept of prior learning as a recruitment tool. It is true students have many options and they are shopping for the best fit. Being able to tell a future student how many credit hours they would receive from prior learning is certainly a recruitment tool. FGB2-6 commented,

I think recruitment more than retention, because we're competing, for me personally, with the $\mathrm{AU} A B C$ schools who take 100 percent of what they have and be like $50 \%$ of the way done so the more you can work with them by giving them credit for what they have learned helps.

And ID-2 also shared,

I would see PLA as more of having more value as a recruitment tool, especially if you start talking about people coming back...people who are 20 hours away from 
graduating, they've got a lot of credit hours, they just never got the degree. Wow, what a piece of bait to throw on the hook. I hate to characterize it that way, but it could be a great hook to say, "Look, we can give you x amount of credit for your experience and that puts you further down the road to getting your degree."

While these examples show PLA has value as a recruitment tool, once the student chooses an institution they are more likely to persist and complete their degree (CAEL, 2010).

There were a couple of participants who focused on the process of awarding military prior learning credit and how the current process could reduce morale and possibly hinder persistence and retention. IC-2 noted, "I actually think prior learning credit hinders some students. For example, if credit is posted in excess, I don't know how financial aid separates that from other credit for their awarding of financial aid." The reason this is a concern for military prior learning is because all of the student's credit comes in as transfer credit and if there are too many hours towards a degree financial aid can be withheld. Additionally, the amount of transfer credit received by the military student can also be confusing and misleading. FGB1-1 commented, "Sometimes the students think they're halfway through to graduation when, really, they still have three semesters left because they have all these major courses that their military work did not apply to." While these are real concerns, advisors are in the position to explain this to the students at the onset to avoid any misunderstandings.

\section{Barriers}

The primary purpose of this study is to evaluate the Prior Learning Program at the University of Central Missouri. To determine how effective the program actually is the 
researcher needed to identify the barriers so improvements can be made. With this in mind, all participants were asked to identify improvement areas within the program. Through participant inputs, three key barriers or improvement areas became clear: communication, the process, and external obstacles. The process focused on areas from automation to having a systematic process.

Communication. The limited knowledge and exposure to the prior learning program at the University of Central Missouri by the participants made the emergence of communication as a barrier obvious. If participants do not know about the program, there must be a lack of communication. ID- 8 mentioned, "I think there needs to be knowledge about it" while FGB1-4 stated, "I kind of feel a lack of knowledge, because I don't know if everybody knows you do prior learning assessment." The lack of knowledge comments was not just focused on institution personnel but also students. FGB2-7 shared, Well I would say first of all communication because I don't think the students realize there's a possibility and unless they sit down with us and have a conversation there's a lot of students floating around there that maybe not end up in an advisor's office and then like Michelle (pseudonym) said the process gets hung up sometimes and so between communication and the process I think there's some things that could be improved.

FGB2-7 continued the thought by stating,

I just wish that some of this information was more readily accessible, not just to the students but to us as well and that maybe with the website redesign over the next year maybe something can be done there to get that information to make it easier to find the Special Credit Certification form for credit. 
One focus group participant's (FGB1-3) comment about the lack of knowledge not only addressed concerns, but how the lack of knowledge affected students.

I feel like it's a very hidden process. The whole thing is very hidden. As a staff member, I feel very unknowledgeable about the entire thing, so when students even ask about it, I feel like I have very little knowledge that I can share with them.

This theme was certainly prevalent. ID-3 captured it when stating, "more information and better communication, I'm sure you've hear that a million times." As stated earlier, the limited knowledge and exposure to the prior learning assessment process made this barrier inevitable. However, the researcher was not aware of just how prevalent the lack of communication and knowledge was until initiating this program evaluation.

Process. While the process was discussed earlier, the focus of that theme was on approving and disapproving credit for prior learning. This theme is more focused on how the process is impeding the prior learning assessment program. One of the items that came up was the actual processing of the paperwork. IC-1 pointed out the process. Currently, there is a form called the Special Credit Certification Form which is used to request special credit for prior learning. This form is required to go from the student, to the department, to the dean, to the Vice Provost for final approval. The challenge with this process is there is not any way to determine where the form is in the approval process. Many times the form has gotten lost in the approval process because the form is sent via snail mail. "It can be a long, slow 
process to get some feedback. Some (students) are patient and some wait and some do not".

Some participants suggested an automated process to help with tracking and for decreasing the time it takes for approval/disapproval. IC-1 went on to explain "It would be nice to have some system in place kind of like we do an approval process where it's automated and you can see it and get reminders." Certainly, the amount of time it takes to conduct a review can have an impact on the student. Students may take a class unnecessarily or miss an opportunity to take a class that is only offered one semester an academic year. FGB1-1 would also be in favor of an electronic process.

One of my biggest flaws in the system now is it's the paper form. You never know where it is in the process and so the student is constantly asking and rightfully because they'd like an update, because its taking a while, you know, they've initiated their part, but then we never know where it is until the credit is posted. So, I think that that process, I don't know if it could be electronic or something.

Another concern is the length of time it takes to process routine forms for special credit in the aviation department. FGB2-2 stated,

I think the process that needs probably the most work in my mind would be the evaluation of licenses and certificates. I think it could be smoother and faster. I mean, it takes weeks to do something that, I mean we do it standard. Our private rating is a standard like process, it shouldn't take a month to get posted in my opinion. 
ID-12 not only addressed the delay but also the lack of feedback throughout the process unless the form is returned:

It just takes a while for the paperwork to get through. I've learned my lesson to make duplicate copies of everything, cause (sic) we've had a couple where I've submitted them, several months go by and the student doesn't hear anything. I don't hear anything.

As discussed earlier, survey participants were split between faculty who assess prior learning for credit and faculty who are not responsible for the assessment. The faculty who are not responsible for prior learning credit assessment were asked where they would send a student for information about credit for prior learning. While a majority of them identified their department chair or an advisor, $21.7 \%$ said they did not know. This is a serious concern and certainly a barrier in the process. This presents a missed opportunity to inform nontraditional, adult learners of the potential to reduce cost and time pursuing their degree. One survey respondent stated, "I'm not sure, I don't know what office handles this sort of thing." Because faculty are unaware of the prior learning assessment process, students who are looking for assistance are on their own. The majority of faculty participants saw the need for a more standardized process for the review of prior learning credit. Some saw the lack of formal processes as a concern for future accreditations. IC-1 noted,

I think formalizing that process and us as an institution having a better understanding and handle on that probably falls on my lap to try and define what some of those things are and learn more about what is required." 
And ID-5 also commented, "as long as we kind of have some procedures in place, once those procedures are in place, then it's easy for me to say yes, no, yes, no" are representative of the overall theme for improving the processes to reduce barriers for faculty assessors.

External Obstacles. In addition to internal barriers already discussed, the external accrediting agencies have a significant impact on the amount of prior learning credit that can be awarded. While this situation was only addressed by a few participants it certainly is representative of a trend that can impact the adult learner from receiving recognition for past experience. FGB1-2 related, "Previous teacher education program were allowed to do that (award credit for prior learning) for the first aid and CPR...But DESE doesn't allow that anymore." A survey participant also mentioned DESE. "I have never awarded this type of credit (special credit). I'm in the college of education and I am not sure we are allowed to substitute teaching experience for credit. I do not think DESE would allow it." Accreditation is necessary for many programs to be successful, but not allowing prior learning consideration may have the unintended consequence of fewer majors.

\section{The Future of PLA}

Participants were asked their opinion of the future of assessing prior learning for credit. The question was asked by the researcher to determine participants' understanding of the impact prior learning has on the student. All the participants envisioned an increase in prior learning considerations. Participants provided several reasons for why they believed the increase was going to occur: student type, cost, and perception of higher education. IC-4 shared, 
I see it growing. I think a lot of it is just educating the university about the different pieces, it is looking at the population of students. If more nontraditional students who do have that work experience or prior learning, I think that is an area that can really grow.

In addition to the student demographics, there is also a competition for the nontraditional student, as noted by ID-6,

The university is looking for more students. I am assuming they're going to be pushing more into the adult learning population. And I think when they do that, there is going to be that competition of how much are you going to give credit for special learning experiences?

The University of Central Missouri has always provided a quality education at a reasonable cost but, as state appropriations continue to shrink, finding ways to reduce the cost for students is necessary. Prior learning credit can be an avenue for reducing student cost. IC-2 mentioned, "I think as a nation, it'll just keep growing. With the cost of higher education, I see it only growing." With reducing costs for the student there is also a need to expedite the learning experience, as shared by ID-11. "Well I would guess that probably there's going to be more emphasis on those kind of things (prior learning). Because there is a push, I know, to get students out sooner."

Another consideration for why prior learning will continue to increase in the future is the general public's perception of higher education. IC-2 stated, "In general the public is looking for us to be efficient." One participant, ID-7, described the type of education society is expecting from higher education as career focused. "I think as a society, I hate say people don't value education, I think they do. They value productive 
education. I just think the general public doesn't want to pay for enrichment. They want to pay for a career." The idea of society wanting efficient, career focused programming for higher learning institutions is not new. However, as noted by IC-1, it is not just the general public it is the business sector as well.

I think it's going to continue to increase. We keep hearing discussions from industries and companies that are not finding employees that they need and they don't really care how they get the experience and the knowledge that they want. They just want them to have that and be able to perform the duties and tasks that they need done. So, I think we're going to start seeing more of it. It's going to be a slow kind of process.

The themes represent stakeholders' understanding of the prior learning assessment process, the barriers to assessing prior learning credit, and the future of prior learning. The researcher was interested in the effectiveness of the university's prior learning assessment program to work with the program administrator to improve the process for faculty, staff and most importantly the student.

\section{Summary}

The study design, data collection methods, research questions, conceptual framework, and the process of data analysis have been discussed in Chapter Four. There were 330 faculty assessors contacted through a survey with 67 responses. Eleven academic advisors participated in two focus groups with 19 interviews conducted with department chairs and staff involved in the prior learning assessment program. Additionally, a logic map was provided to identify key stakeholders and the process used for assessing prior learning. With the framework of this study being a utilization focused 
evaluation, the researcher has remained in contact with the key stakeholder of the prior learning assessment program.

Presented in Chapter Five are the findings and recommendations presented to the primary stakeholder for consideration. Additionally, discussed in Chapter Five are the limitations of this study, implications for practice, and recommendations for further study. 


\section{CHAPTER FIVE}

\section{SUMMARY, RECOMMENDATIONS, AND CONCLUSIONS}

This qualitative, utilization focused evaluation was conducted to determine the understanding, perceptions, and experience with the University of Central Missouri's prior learning assessment program. The scope of this program evaluation was for “formative improvement and learning" (Patton, 2008, p. 139). A utilization focused evaluation requires input from the primary stakeholder to ensure the evaluation meets their needs. With the stakeholder involved throughout the process there is a high probability that the recommendations will be implemented.

During this program evaluation, the primary stakeholder has been involved throughout the process from providing guidance on the research questions, to the type of data collection used for each group of participants. As data were collected and themes emerged the primary stakeholder was briefed on the findings and has been informed of the recommendations provided in this chapter. To ensure validity of the research Denzin's (1978) methodological triangulation was used. This type of triangulation takes different methods of data collection (i.e., surveys, interviews, focus groups, and archival data) and compares the results.

To ensure credibility, the researcher used peer debriefing and reviews, which allowed a disinterested party to provide feedback on the research concept and data collection methods (Creswell, 2009). Through data analysis six themes emerged with several subthemes: 1) Understanding Prior Learning Assessment, 2) Initiation of Prior Learning, 3) Process of Approving/Disapproving Prior Learning Credit, 4) Impact on Student Success, 5) Barriers, and 6) the Future of Prior Learning. Discussed within this 
chapter is a summary of the findings and recommendations that are based on the analyzed data. Additionally, presented are implications for practice and recommendation for future evaluations.

\section{Summary of Findings}

The findings of this evaluation examined the Prior Learning Assessment program at the University of Central Missouri with a focus on stakeholders' understanding, perceptions, and experiences with prior learning assessment as it relates to student persistence and retention. The conceptual theory of adult learning provided the framework and lens for data analysis. Knowles (1973) study of the adult learner has evolved into identifiable policies and practices within higher education. One of the key aspects of his theory was the importance of the experiences the nontraditional or adult learner brings with them to the classroom. Understanding the importance of experience is at the core of prior learning assessment. It is through this lens the following research questions served as a guide for this program evaluation.

1. What do faculty assessors perceive as barriers to accepting credit for prior learning at UCM?

2. What type of processes do faculty assessors use to determine credit or noncredit for prior learning?

3. How recognizable is UCM's PLA program to faculty, administrators, and staff?

4. How do administrators and faculty assessors perceive PLA to be in regards to retention and persistence efforts of nontraditional students? 
A summary of the major themes and subthemes were presented in Chapter Four. Below is the researcher's analysis of how the data applies to the study's research questions.

\section{What do faculty assessors perceive as barriers to accepting credit for prior learning at UCM?}

From a broad perspective, the barriers to accepting credit can be an institutional process. Starr-Glass (2016) described an environment whereby faculty are inserted into the process merely as subject-matter experts or administrators over the approval process. Presently, the review of prior learning to faculty is just another task at hand and it does not allow for faculty to develop an appreciation for the life experiences, challenges, and desires that are tied to the student's learning experiences.

In addition to this institutional barrier there is the reluctance from faculty to accept prior learning. "Often, the reluctance to accept and recognize credit for prior learning is strongest within the faculty" (Starr-Glass, 2016). Because of this reluctance many institutions only offer limited PLA options for students. There has been some suggestion that the resistance to embrace PLA is a holdover from the past where higher education identified itself as having the corner on knowledge production, as well as, the only entity to determine what is considered knowledge (Starr-Glass, 2016). ID-2 expressed concern:

A lot of the faculty's discomfort with giving prior learning credit on the comm study side of the house, much of it is 16 weeks of concentrated study of a specific topic. Somebody says, "Well I've been a teacher for x amount of years. I know how to talk in public." Well, that's a different audience group when you're teaching. It's not the same as an audience group when you're doing public 
speaking. And secondly, they're working from prepared material like lesson plans with a specific objective. I haven't seen a single instance of somebody that has applied for credit for work experience or something like that, that would actually, legitimately, in our view, pedagogically, be a yeah that counts.

In addition to the example above, this evaluation identified a slightly different twist with respect to faculty reluctance to accept prior learning credit. Participants by and large accepted the concept of PLA and its value but not in their area. ID-2 also stated, "I do see the value in it and I think some of it is probably more...lends itself more readily to the technical side of learning, the technical skills as opposed to what I'm going to characterize as soft skills." A focus group participant, FGB1-2, described the challenges of awarding credit for prior learning more of a programmatic concern. "I think the biggest challenge is the variety of programs we have, some programs just can't work for it (prior learning), some might lend themselves beautifully for it." The idea that PLA is only a good fit for certain programs or skills was also reported in the form of theoretical vs practical when ID-3 stated,

Training for credit is probably the one (type of PLA) that's probably the most contentious, because as a department we have some people who lean more theoretical and people who lean more practical. And so the people who lean theoretical are quite hesitant to give credit for such things.

In addition to institutional and perceptional barriers to approving prior learning for credit, participants focused on the need for prior learning to match course objectives. Survey participants were asked to provide their top three reasons for not awarding credit for prior learning and the majority of responses were focused on course incompatibility 
and standards, including survey comments such as, "The student's previous coursework did not match the objectives in our courses" and "The content did not fit a course that is offered."

Another barrier that became clear during data analysis was the lack of understanding of what was Prior Learning Assessment. This lack of understanding created an unknown barrier to the faculty. This was also made clear with the survey responses to why they did not award credit for prior learning. Participants considered institutional transfer credit as prior learning. It is understandable how it can be confusing since students bringing institutional credit did in fact learn the information prior to attending UCM. Survey comments such as, "Institution not accredited," "Student wanted credit for course in which "D" was received" and, an "Unaccredited source" described the lack of understanding of what separates prior learning credit from transfer credit. One survey participant wrote: "Not academic study (e.g., submitted time served in work experience)." From an adult learning perspective and assessing prior learning for credit, work experience should be considered. This lack of understanding was not limited to only one participant group. In fact, all participant groups expressed a lack of understanding or knowledge about the university's prior learning assessment program.

Not understanding what constitutes prior learning has certainly caused a barrier to credit approval. If there is a lack of knowledge, how can individuals make informed decisions? ID-5 commented, "So, I'm getting a little more familiar with that ACE acronym that you mentioned. It is one of these things that if you're not in that environment, it's just something we don't know." Hypothetically, if this participant were presented with an ACE transcript to review and evaluate for academic credit there would 
be a high probability the request would be denied mainly because the participant did not know who evaluated the course for credit.

In addition to the barriers discussed to awarding credit, participants identified frustrations that would make the process for evaluating credit smoother. There were two areas that stood out: the form used for processing special credit and the posting of AP and CLEP examinations from the testing center. IC-1 suggested, "It'd be nice to have some system in place kind of like we do an approval process where it's automated and you can see it and get reminders." The current process is paper-based and requires several reviewers and approval signatures with no idea where the documentation is within the approval process. FGB1-1 shared,

One of my biggest flaws in the system now is it's that paper form and you never know where it is in the process and... because they'd like an update, because it's taking a while. You know, they've initiated their part, but then we never know where it is until the credit is posted. So, I think that the process, I don't know if it could be electronic or something.

In addition to the time it takes for the approval process, there is the lack of feedback on the process. As described earlier, faculty just wait for the credit to be posted. ID-12 summed it up: "I think the main issue are two things, the paperwork trail and knowing where things are at in the process and getting feedback from above. Cause the only time I would ever get feedback was when they kicked it back." As an institution if the paperwork cannot be processed quickly, there is a real possibility that the student may take an unnecessary course. This is possible because advisors review the student's degree 
audit when making recommendations or placing students in classes. This is the same concern expressed about the posting of AP and CLEP examinations.

Participant responses with respect to the posting of AP and CLEP examinations varied and there was a disconnect between participants. FGB1-1 shared,

A downfall, in my opinion, is the testing services office and posting credit for accelerated mechanisms, because it does not happen very quickly, sometimes, and if you need it as a prerequisite to another course for the student to progress in that major, that can sometimes be difficult.

In contrast, the testing center felt other participants were aware of the process and had the ability to obtain the information without it having to be posted in the degree audit. IC-3 stated,

I can't post anything until they're actually officially a student here. I don't have even permission to do it until they've actually been accepted and they're a student here. These scores go in banner. Their scores are loaded as soon as we get them, and as soon as they have a 700 number and can be matched. The advisors have all of our policies, so they know, and the scores in banner will show, for the most, if it's passing or not. So, they know that they're going to get credit.

While this situation and the processing of the approval form do not impede faculty from approving credit for prior learning, it does highlight a less than optimal process for approving and posting credit for prior learning. The barriers identified for faculty to approve credit for prior learning stem from institutional procedures, perceptions about prior learning credit, the concerns over standards, and the ability to 
validate documentation provided. Additionally, the limited amount of exposure and knowledge about PLA can certainly have an effect on approving credit for prior learning.

\section{What Type of Process do Faculty Assessors Use to Determine Credit or Noncredit for Prior Learning?}

The process used varied between departments, but one thing was consistent throughout the data: there was not any written policy on how the evaluation of prior learning credit was to be evaluated. However, when participants were asked what could be improved with the prior learning program many suggested a need for a policy or standardized process. IC-1 commented, "We need to make sure as an institution we have guidelines set in place," and ID-10 stated, "I think the whole university needs to come on board and try to adopt or establish a policy for providing credit for this type of experience."

While participants spoke out about wanting a policy at the university level many of the assessments were determined by the department chairs. ID-6 shared, "Usually I would just make the decision" while ID-11 commented, "It comes to the Department Chair, but with feedback from the areas." A survey respondent stated, "I compare content described with content that we cover in a given course. In difficult cases, I email the colleagues in my discipline asking for their opinion." As discussed earlier, this approach to reviewing credit for prior learning puts faculty, including department chairs, in the role of a subject matter expert which limits their view and understanding of the prior learning process (Starr-Glass, 2016).

In addition to participants having a limited view and lack of understanding of the university's prior learning program, many participants had no exposure to the prior 
learning assessment process. This lack of exposure required the researcher to explain in detail the different types of prior learning that can be evaluated. This made it very difficult for the researcher to determine if there were a type of prior learning that was preferred over others. To compensate for this lack of experience with prior learning assessments the research described the type of prior learning and then posed the question "which type of prior learning would you be most/least comfortable considering for credit?" While this was not ideal, it was still valuable in that the researcher was able to determine participants' comfort levels for the types of prior learning.

One of the types of prior learning credit that drew some concerns was the portfolio. IC-4 shared concern, "Yeah because it just seems more aloof (portfolios). How do you have the verification that you actually completed this." ID-6 expressed concern by stating,

I think probably the military and the portfolio. Just because it would be, I think for us, the most difficult thing for us is going to be lining something up that doesn't fit with our particular credit hours and course curriculum.

Additionally, survey participants where asked how likely they were to award credit for a student's portfolio and $41 \%$ responded they were highly unlikely to award credit. The primary reason, as stated above, is the validity of the documentation. IC-1 provided additional comments about the portfolio, "The issue that's come up, too, is how do I know you're the one that completed that?"

While many of the processes for approving or disapproving prior learning are fluid, military credit for prior learning is fairly well recognized throughout the university. If a military member identifies themselves as an active duty or veteran when applying for 
admission to the university, they are contacted even before acceptance into the university. The military are the one group of nontraditional, adult learners who are aware of prior learning credit. IC-4 recognized this by commenting,

It seems like a lot of people don't have any idea what it is (prior learning) or who to go to, but the students (military) are pretty good at bringing their transcripts to me, or that email that I send out, I send whenever they apply. I send that email out, "Hey, you applied to UCM." They're pretty good at responding to that and letting me know that they've requested their transcript and to let them know after I receive it. So that piece is good.

In addition to providing the student with information about the prior learning assessment process, there seems to be an acceptance of credit for military prior learning based on the documentation provided in the military transcript. ID-10 shared,

That's a little different (military credit) because most of the requests that I get, and I get several I guess, come from courses, might be correspondence courses that military people have taken before they come to Central. In that case, I see that transcript and I see the description and then I just approve. But that's a little bit different because that's an actual course, I guess.

Military credit is the most approved prior learning for credit type, outside of standardized testing such as AP and CLEP, for several reasons: the students are aware of the program and provide the necessary information, key stakeholders are familiar with military credit and can assist the student, and faculty assessors are more familiar with the documentation and understand the contents. ID-14 also commented, 
We have done that ACE for military and whenever someone says, "Okay, we have done these kinds of things." And the reason I have done that, and we like it is that they're structured. They tell you exactly the 10 things or whatever they have learned in that. So, it's been easy to do that.

In addition to the types of prior learning approved/disapproved, the researcher also asked participants what impact accreditation agencies had on the evaluation process. Accreditation drives policies and procedures at every level within higher education. The University of Central Missouri is accredited by the Higher Learning Commission. There are also accrediting agencies at the department level depending on the discipline. While there were only a couple of comments with respect to accreditation, the comments were significant. The Missouri Department of Elementary and Secondary Education (DESE) establishes guidelines for K-12 teacher education programs and it appears prior learning is not authorized. A survey response included "I'm in the college of education and I am not sure we are allowed to substitute teaching experience for credit. I do not think DESE would allow it." FGB1-2 acknowledged that while limited credit was once given in teacher education, it is no longer allowed by DESE. "Previous Teacher Ed programs were allowed to do that for the first aid and CPR, you're reminding me of that, but DESE doesn't allow that anymore." This decision to not accept any prior learning, not even CPR, seems to be a step back for one of the largest colleges on the campus. While this situation is outside the realm of this program evaluation it would be interesting to see if there have been any unintended consequences from this change in policy. 
In summary, the processes used by participants for approval/disapproval of prior learning credit were varied and no one had any formal procedures. Participants believed there should be some standardized processes and policies at the university level. Additionally, the researcher recognized the participants had a limited amount of exposure to, or knowledge of, the prior learning program which made it difficult to address processes. The exception to this was military prior learning for credit. While the military credit process was fairly standardized and accepted, DESE has opted not to accept any prior learning for their K-12 Teacher Education Degree programs.

\section{How recognizable is UCM's PLA program to faculty, administrators, and staff?}

While the researcher and the primary stakeholder anticipated a need for improvement, the researcher was surprised at how little the participants knew about prior learning, which ties directly to visibility. This lack of knowledge was seen in all participant groups. Survey responses indicated 15 participants out of 25 responses which equates to $60 \%$ identified their knowledge of PLA from very little to nothing. Focus groups and interviewees were similar. ID-6 stated, “I don't think I know what it is” along with comments of "I don't, we don't have that term," and "By prior learning, prior to what?" from ID-4 and ID-14 respectively. These are just a few of the comments made when asked what they know about prior learning assessment for credit. If the participants do not have a general awareness of the program, then it would be fair to say there is limited visibility at best. The only deviation from this trend was with the focus group and that was dependent upon what programs they supported. FGB2-2 commented,

I have some heavy military programs and so CDM and CJ both require a lot of free choice electives and so if I know any kind of military like JST let's get these 
Joint Service Transcripts. So that's a common conversation I have with my students, the JST is a big one.

FGB1-3 also stated,

I feel like it's a very hidden process. The whole thing is very hidden. As a staff member, I feel very unknowledgeable about the entire thing, so when students even ask about it, I feel like I have very little knowledge that I can share with them.

As FGB1-3 mentioned, the staff's lack of knowledge has an impact on the student. With limited knowledge on the university program how can the student find out about the program? In the 2016-2017 academic year the university, in collaboration with the Council for Adult and Experiential Learning (CAEL), assessed UCM's adult oriented services. Faculty and staff evaluated the services and 166 adult students completed a survey to identify the university's strengths, challenges and disconnects as an Adult Learning Focused Institution. Nine areas were assessed with prior learning being addressed within this assessment.

One area of opportunity for UCMO that can improve performance in the Principles of Transitions, Technology, and Assessment of Learning Outcomes is to make prominent the variety of opportunities offered for credit for prior learning, or prior learning assessment (PLA). (CAEL, 2017, p.6)

This assessment of the lack of prominence of the university's PLA program further validates the participant's comments. With participants having a limited knowledge of the program, how does that affect the students? There could be a significant impact on the student because the student is not aware of the university policies, and the university faculty and staff may know a little bit about the prior learning 
process, but they are not initiating a conversation with the student. The university is missing an opportunity to reduce student debt and time to graduation rates because no one is talking about prior learning assessment. FGB1-3 stated, "I can't say that I mention a lot of the prior employment and stuff like that. It's usually student initiated." FGB1-2 confirmed that by stating, "only when students email me questions." FGB2-3 also commented, "if they bring it up." This is a concern because the student may not be aware of the process and so the conversation never happens. Survey participants, who were not faculty assessors, were asked to whom they would they send a student wanting information on credit for prior learning. Of the 23 responses, $21.7 \%$ said they did not know. These are lost opportunities for the university to provide quality student services to nontraditional, adult learner students.

\section{How important do administrators and faculty assessors perceive PLA in regards to}

\section{retention and persistence efforts of nontraditional students?}

Twenty-one survey participants answered this question and overwhelmingly believed credit for prior learning had an impact on retention and persistence. Of the responses, $81 \%$ believed PLA was somewhat significant to extremely significant with respect to persistence and retention. It was interesting that $14 \%$ thought PLA had no impact on student retention/persistence. This response may be two-fold based on the other participant groups.

First, there were a few interviewees that believed, with their limited exposure to prior learning assessments in general, they did not have enough data to provide an answer. Survey respondents made statements such as "I don't have any real data on that," "I don't have the data for that," and "I don't have the good sense of whether it would help 
with retention or not." Since the participants are academics it makes sense their answers would be measured without data.

The other reason survey respondents might have identified no impact for PLA on persistence/retention is they may have identified PLA as more of a recruitment tool. ID-2 shared, "Candidly, I don't see it having a whole lot to do with retention and persistence. I see it more to do with recruitment" and FGB2-2 stated, "I definitely agree on the recruitment and kind of a morale piece when they're in your office and your like, 'Oh this will count for a free choice elective.' They just kind of light up.” FGB2-6 also commented:

I think recruitment more than retention, because we're competing for me personally with the $\mathrm{AU} \mathrm{ABC}$ schools who take 100 percent of what they have and be like 50 percent of the way done so the more you can work with them by giving them credit for what they have learned the better.

This competition is particularly true with the amount of choices students have when it comes to choosing a university. As one of the stakeholders, IC-2, put it: "I think students are getting more savvy as higher education becomes more consumerism based." While it has been documented that students who receive credit for prior learning do persist and graduate sooner than non-PLA students (CAEL, 2016), the university must first get them to apply for admission. Providing students with an estimate of how many credit hours they can receive for prior learning may have an impact on their choice of university.

However, there were several participants, who believed PLA had an impact on retention and persistence. Knowles' (1973) description of andragogy addressed the 
importance for adult learner experiences to be recognized and the need for the courses taken to be relevant and necessary for goal attainment. PLA addresses many of these concerns through eliminating prerequisite courses, reducing entrance requirements or credit hours for a degree based on experience. All of these examples also impact persistence and retention. IC-4 stated, "I see persistence, because usually they're the students who are just hardcore, I want this credit, and those are the ones that they have the drive to just push through." There is also the fact nontraditional students have many priorities and while school may be one, institutions need to understand the challenges facing these students and how providing credit can help them and keep them there. IC-1 made that point:

They're trying to get through the programs as efficiently as they can or they're working full-time and raising a family. So, if it means you can finish your degree a semester, or a year, or more earlier I think that's huge and very beneficial to those students.

As noted earlier, participants mentioned how they support experience in their programs and while they did not think it was PLA their programs do, in fact, save students time and money. One of the programs reduces the entrance requirements into the program based on student experience. ID-14 commented, "So for example, at the graduate level, if they have four years of IT experience in a company that is listed we waive their GRE requirement.” Reducing acceptance requirements eliminates additional out-of-pocket expenses and allows for students to enroll sooner. 
Another graduate program has considered experience prior to enrolling and accepting students into the program. So, experience is not eliminating any of the degree requirements; however, it is reducing the overall course requirements. ID-7 shared, So, we have a masters program, specifically, that has option areas that they can get into and it's based on experience and education. So, we're not technically giving them course credit, but we're reducing course requirements based on a set of information of what they have coming in.

Assessing credit for prior learning is a personal process and, depending on the type of PLA being considered, it may require the student to meet with faculty and administrators to demonstrate competency. Students may develop a sense of loyalty to the school and commitment to degree completion all because of the effort made by the departments to support the student request. ID-4 commented,

I think this is tied to economics. If any student who is here and we can find a way to legitimately give them credit for a course where they didn't have to spend the money or the time to complete that course, I think that would only increase their incentive to stay. And to continue to stay in the department and get their degree with us, because they see us working with them, not as a collection of data, but as a person sitting across the table pleading their case, showing us their resume. In conclusion, most participants perceive PLA as having an impact on persistence and retention with several recognizing PLA as a recruitment tool. Because many of the participants have had limited exposure to the PLA process and a lack of data to support their answer, they were not comfortable answering the question about the impact PLA has on retention and persistence. Finally, examples were provided of how the essence of 
PLA has been incorporated into a couple of the graduate programs offered which supports the needs of our nontraditional adult student learners.

\section{Conclusions}

A qualitative study was the best method for conducting a program evaluation focused on improving and learning the effectiveness of the university's prior learning assessment program (Patton, 2008). Hatch (2002) provided researchers with characteristics that distinguish qualitative research from other approaches (i.e., quantitative, mixed methods). Specifically, qualitative researchers seek to understand from the perspective of the participants. This program evaluation allowed the perspectives of the participants to determine program improvements. The concept of evaluating prior learning for credit is not new to the university; however, the onus for program success was placed on the primary stakeholder within the last two years. As such, the primary stakeholder wanted to determine where improvements can be made. With most students requesting prior learning consideration being nontraditional, also known as adult learners, the program coordinator initiated the Adult Learning Focused Institution (ALFI) evaluation during the 2016-2017 academic year (CAEL, 2017). This evaluation focused on many areas with prior learning assessment being recognized as an opportunity for improvement. The ALFI evaluation became the catalyst for this utilization focused program evaluation (Patton, 2008).

The primary stakeholder, in collaboration with the researcher, developed research questions to identify program effectiveness. The researcher met with the program coordinator throughout the data collection method and discussed findings and recommendations. The program coordinator also reviewed participant questions for the 
survey, focus groups, and interviews. As stated earlier, qualitative research is an inductive process which results in the development of themes (Creswell, 2009). During this program evaluation six themes and subthemes emerged. With the use of triangulation (Denzen, 1978) the data analysis was validated through multiple data collection methods and multiple participant groups. The participant groups consisted of faculty, administrators, and staff. Through the emergent themes and research question findings, the following recommendations are presented for the purpose of improving the university’s prior learning program. On a larger scale, recognizing nontraditional students' prior experiences enhances their overall learning experience. Knowles' (1974) suggested as individuals mature their experiences increase. These experiences allow for a richer learning experience and provide a broader focus for new learning to occur.

\section{Recommendations}

Recommendations are based on the emergent themes that provided answers to the four research questions developed by the researcher and key stakeholder. With the use of triangulation (Denzin, 1978) the multiple forms of data collected provided the validation of participants' comments. Recommendations were discussed with the key stakeholder.

\section{Understanding Prior Learning}

This theme provided insight into research question one, barriers to accepting credit, and research question three, the visibility of the PLA program. Through data analysis the researcher identified barriers that impacted faculty assessment. The lack of knowledge about and the limited exposure to the prior learning assessment program from the participants is a concern. A survey participant stated, "In the past few months I began in a new position and to my knowledge we do not accept prior learning that is not a 
specific class. Maybe I do not understand what is meant by prior learning." As discussed earlier, many of the participants grouped institutional credit with prior learning. While this is understandable, these comments validate a need to educate stakeholders. In addition to not discerning prior learning for transfer credit, there were participants who were, in fact, participating and recognizing prior learning but did not recognize the process as prior learning. FGB1-4 noted, 'I guess I wasn't thinking accelerated mechanisms would count for prior learning." It should be mentioned that while the research participants demonstrated limited knowledge or understanding with respect to prior learning, the archival data identified prior learning is being considered for credit. The data provided by Institutional Research identified 3,573 students who received prior learning credit between the 2014/15 and 2016/17 academic years for a total of 36,308 college credits. With that being the case, the researcher and program coordinator believe there is a need for education across the university.

Starr-Glass (2016) suggested one of the challenges with getting prior learning credit awarded is based on the situation the faculty assessors are placed in with respect to the approval process. The idea faculty assessors are only subject matter experts who are called upon to approve/disapprove credit considerations limits faculty exposure to the student and the type of documentation being presented. Survey participants, identified as faculty assessors, were asked to identify how likely they would be to award credit for the different types of prior learning. The military transcript provided by the American Council on Education (ACE) was the most likely to receive credit, with $44.4 \%$ being likely or highly likely to give credit. However, only $26.6 \%$ would give credit for civilian prior learning with transcripts from ACE. 


\section{Initiation of the PLA Process}

Data analysis found that other than military credit, the student is the initiator of the prior learning process, usually without any assistance from faculty or staff. This situation is partly due to the limited amount of exposure to prior learning and the missed opportunities by advisors, faculty, and administrators to start the conversation with newly admitted students. Two focus group participants shared these thoughts, "I can't say that I mention a lot of the prior employment and stuff like that. It's usually student initiated" (FGB1-3). "I'm the same way, it's all student-driven. I don't ask them" (FGB1-4). The process for AP and CLEP processing is also student initiated. IC-3 stated, "Right now, our policy always says it's up to the student to make sure we get the score reports and that their advisor knows." While it is understandable the process should be student driven, there is a need for student support through information sharing. Specifically, there is a real possibility that students are not aware that the university accepts credit for prior learning and, as such, students may be taking unnecessary courses increasing time to degree completion and expenses.

\section{Determining Credit Approval/Disapproval}

This theme is directly connected to the second research question which addresses the process faculty assessors use to approve/disapprove prior learning credit. During data analysis this theme required the addition of subthemes which addressed participants' philosophy, policies, procedures, and concerns. With the different participant groups this theme addressed the administrative processes as well as the faculty assessors' role as approver. 
The student experience and success were key aspects of the participant's philosophy towards prior learning credit. ID-11 stated, "My other concern would be that I think so much of education is the hidden curriculum and the pieces that happen organically in the classroom that sometimes are missed. Creating community, you know? Those kind of things." Setting the student up for success is a central theme for all faculty, staff, and administrators at the university. IC-1 also commented,

The big underlying thing, too, that we want to make sure is that those students are being successful. So, if they come in and bring in a bunch of prior learning, but like I said, it's dated or it doesn't align very well with the particular program, we don't want to jump into upper level classes or waive those upper level classes and send them out the door with a diploma if they're not prepared and familiar with those. We want them to be successful.

We want the students to be successful, but we also want our diploma to mean something. The intention of prior learning is not to carelessly provide credit to students for experiences that are not of educational value. Kolb (2014) recognized this as well, suggesting not all experiences should be considered for credit; however, recognizing an individual's prior learning can have a significant impact. So how does the university ensure a consistent process for awarding credit for prior learning? While the vast majority of participants had limited experience with prior learning it became clear across all groups that there was no written policy at the assessor level. ID-6 noted, "Usually, I would just make the decision" and ID-10's comment of "no, we don't" were common remarks for interview participants. This makes sense with the limited number of requests participants have been asked to review. However, many participants requested a policy at 
the university level. ID-10 said, "I think the whole university needs to come on board and try to adopt a policy or establish a policy for providing credit for this type of experience."

In addition to university policies to assist faculty assessors, participants identified procedures that could be improved. There seems to be some dissatisfaction with the approval process with respect to the administrative process. FGB1-1 stated, "One of my biggest flaws in the system now is that paper form and you never know where it is in the process." FGB1-1 also addressed the posting of examination credit as a concern. "A downfall, in my opinion, is that testing services office and posting credit for accelerated mechanisms, because it does not happen very quickly, sometimes."

\section{Impact on Student Success}

This theme addressed the importance participants placed on PLA with respect to persistence and retention. While most of the participants believed PLA had a positive impact on persistence and retention, there were a few who believed the focus of PLA was more as a recruiting tool, as evidenced by this comment by ID-7.

I don't know how it would impact retention. I would think it might if they've got a good start. I think it would impact getting them here to begin with. I think that would be a big draw if you're willing to take something that other places won't and you're a reputable university.

If the university does a good job recruiting a student, then there is a likelihood the student will persist and finish with the university. This is the case primarily because awarding credit for prior learning is not an automatic impersonal process. Students, processes, and faculty must work together to determine the value of the experience from an academic perspective. ID-4 stated, 
Oh, listen if any student, and I think this is tied to economics, if any student who is here and we can find a way to legitimately give them credit for a course where they didn't have to spend the money or the time to complete that course, I think that would only increase their incentive to stay. And to continue to stay in the department and get their degree with us, because they see us working with them, not as a collection of data, but as a person sitting across the table pleading their case, showing us their resume.

Additionally, participants believed they could not adequately answer the question about the impact PLA has on persistence or retention because they did not believe they had enough data to have an informed opinion. While the researcher understands this from the participants' limited personal experience with assessing prior learning for credit, there is a great deal of research on the correlation between PLA and retention, persistence, and the adult learner. The CAEL (2010) study collected data from over 62,000 students at 48 institutions and found persistence and retention rates were in fact higher for PLA students when compared to non-PLA students.

\section{The Future of PLA}

While this theme was not tied to the research questions, the researcher asked this question to determine participants understanding of the impact prior learning has on the student. All participants envisioned an increase in prior learning assessments. Reasons for this response was student type, cost, and the perception of higher education. From a research perspective, the fact the participants see prior learning increasing there is hope that they personally will be asked to participate more often and obtain a better 
understanding of the process and the importance of recognizing the experiences of nontraditional, adult learners.

\section{Limitations}

Conducting qualitative research in and of itself is a limitation. The reason for this is twofold. First, a single researcher normally conducts qualitative researcher. Secondly this researcher is a novice.

Qualitative research is a means for exploring and understanding the meaning individuals or groups ascribe to a social or human problem. The process of research involves emerging questions and procedures, data typically collected in the participant's setting, data analysis inductively building from particulars to general themes, and the researcher making interpretations of the meaning of the data. (Creswell, 2009, p. 4)

There is a possibility that with the lack of experience, the researcher missed key themes or made incorrect interpretations of the data presented during analysis. While the triangulation of data should have mitigated this possibility, there is no guarantee.

Researcher bias is also a limitation. While the researcher made every effort to minimize bias, the fact the researcher has a significant role in the assessment for prior learning program could influence the interpretation of the data collected. This limitation was lessened through personal reflection and communication with the primary stakeholder throughout the evaluation process.

While the participants were purposefully selected because of their role or potential role in the prior learning assessment process, the majority of volunteers had limited exposure and experience to assessing prior learning for credit. There is the 
possibility that the data analysis may have produced different themes or findings had participants been more actively involved in the program. Additionally, with this research being a program evaluation all the participants are from the University of Central Missouri. Individuals may have felt pressured to be less than candid for fear of being recognized in the evaluation. Every effort has been made to reduce this concern through using group designations and pseudonyms as necessary.

\section{Implications for Practice}

The findings suggested opportunities for program improvement and much was learned from the evaluation. This program evaluation identified barriers impeding program improvement. Specifically, the lack of program visibility has limited the opportunity for students to request consideration for prior learning. Participants had limited exposure to the program and survey participants who were not faculty assessors did not know where to send students. In fact, of the 23 responses to the question, "where would you send a student wanting information on PLA," $21.7 \%$ did not know where to send them. These are potential missed opportunities for the student and the university.

For faculty assessors to obtain a better understanding of the process it is recommended that the key stakeholder initiate a purposeful information campaign providing university policy and procedures. There has already been some improvement in this area with the updating the undergraduate catalog to define prior learning and the possible acceptance of ACE recommended credit. However, there is more to be accomplished. For example, faculty assessors are not aware of the process used by the American Council on Education when determining recommended credit or the qualifications of the faculty members making credit recommendations. This lack of 
understanding may have resulted in the disapproval of credit for prior learning. This is clear from the data in which military credit is considered more likely than civilian work experience even though the transcripts are coming from the same source.

There are opportunities within the university structure to provide policy and general guidance. It is recommended, information about the prior learning process be placed in the monthly nontraditional newsletter, as well as UCM Daily (a daily email to the faculty and staff), and the University’s Muleskinner newspaper. This recommendation requires no cost and can have an immediate impact on providing the visibility necessary for faculty, staff, and students. Also, a formal presentation should be made to the Faculty Senate. Faculty Senate should then provide information about the prior learning process to the faculty. This will provide faculty with information without having to take any additional time out of their schedule. To ensure new faculty are made aware of the university's prior learning assessment program, it is recommended that the PLA program be addressed at the new faculty orientation each semester.

Additionally, the primary stakeholder and researcher have discussed inviting individuals from the American Council on Education (ACE) to visit the university to provide a forum for faculty and staff to address the ACE review process and faculty concerns. This forum could also assist in bringing down the barriers identified by the perceptions of prior learning requests not meeting university standards by the faculty assessors. Additionally, the university holds a faculty "Day of Learning" each semester. A breakout session on PLA could provide important information to faculty and staff.

As the ALFI (2017) assessment suggested, there is an opportunity to improve the visibility of the Prior Learning Assessment program on the UCM webpage. Following the 
ALFI recommendation, the webpage has been updated with the central focus being on the types of prior learning considered and whom individuals should contact for information on each type of documentation. Additionally, the program coordinator has moved forward with the new webpage architecture to have the information for prior learning be prominent when new applicants identify themselves as transfer students. This decision will assist in identifying prior learning assessment opportunities at admission, not after the student takes a class unnecessarily.

In addition to the changes already addressed there is still an opportunity to further ensure awareness of the program. It is suggested that the PLA coordinator meet with advisors prior to each enrollment cycle to remind them of the experiences and possible credit their students may have brought with them when they decided to commit to the University of Central Missouri for their educational goals. Advisors should be reminded to ask the student what they are bringing to the table and help discern if there is an opportunity for credit. Additionally, advisors should also remind students that there is an opportunity through CLEP to reduce their time and expense if they feel they have the knowledge to test out of a general education course. The most important thing for advisors to do is to just have a conversation about prior learning in general. This is a recommendation for all advisors regardless of the degree program because many times students change majors and, possibly, what was once not an option (prior learning) is now available.

First and foremost, recommendations must be confined to the primary stakeholder's circle of influence. Requiring academic departments to adopt procedures or policies is outside of the scope of this evaluation. As such, with the participants 
requesting a university policy it is recommended that a committee be established to address faculty, staff, and administrator concerns. It is recommended that the program coordinator work with the Vice Provost of Academic Programs and Services to identify key constituents to participate on this committee. It is also the recommendation of the researcher to include nontraditional students with all the rights and responsibilities as other members. This is critical to obtain full buy-in from the students.

In addition to the establishment of the committee, an electronic process should be developed for the approval of special credit. There is an opportunity to discuss the posting of examination credit (i.e., AP or CLEP) in the student record. Consideration should be given to posting credit in the student record in a timelier manner.

Opportunities to improve the examination process should be explored. The researcher and program administrator are not responsible for this process; however, based on participant comments there is an opportunity for process improvement or an opportunity to explain the process to others.

The participants' limited knowledge of PLA is a concern in that the subject is connected to the nontraditional, adult learner. As discussed earlier, this population of students is becoming the new traditional student and yet our primary focus remains on the freshman straight out of high school. Our faculty, staff, and administers need to understand the impact nontraditional students have on the university and the correlation between them and PLA. To support this objective, it is recommended that the program coordinator brief the faculty and staff during the two learning day sessions offered each academic year. While there is a selection process for briefings, the more visible the program becomes the more likely the nontraditional student topic will become attractive 
to the selection committee. Additionally, there needs to be a recognition of the impact accepting PLA has on our students. There is a monetary cost savings that should be identified and highlighted. To make this possible the program coordinator should, with the assistance of institutional research, provide senior leadership with the data on savings to the student. We need to show our students and the public in general that we are good stewards of our students' money and time.

There is a need to validate the opinions of the participants with respect to the increase in prior learning. The program administrator should, with the assistance of Institutional Research, evaluate the amount of special credit that is being awarded each academic year. Again, this is a story that needs to be told and told loudly and often.

\section{Recommendations for Future Studies}

This program evaluation provided a rich and thick narrative of participants understanding of the prior learning program and their perceptions of the programs impact on persistence and retention for the nontraditional student. With the purpose of the program evaluation being for "formative improvement and learning," (Patton, 2008, p.139) the primary concern is implementation of recommendations. Implementation is the responsibility of the primary stakeholder. Future studies would include a student survey to determine the effectiveness of the university's PLA program from the students' perspective.

\section{Concluding Overview}

The purpose of this study was to conduct a program evaluation of the prior learning assessment program and its perceived impact on adult student persistence and retention at the University of Central Missouri. With Patton's (2008) design being used 
for this qualitative analysis, subjects selected to participate in this evaluation were all stakeholders or potential stakeholders in the prior learning assessment program. Utilizing adult learning theory (Knowles, 1973) and a constructivist lens, the researcher's analysis process consisted of triangulation of data from surveys, focus groups, and interviews to identify themes. This process resulted in six themes and subthemes with all them fitting primarily under the overarching theme of program visibility. Program visibility will improve faculty assessors' concerns about standards and rigor with respect to the request for prior learning considerations for credit. Visibility will also make it easier for current and future students to locate information about the program which will help as a recruiting tool. Highlighting the prior learning assessment program impacts with respect to student success and the reduced cost and time to graduation is a story that needs to be told. Based on the comments provided by participants, prior learning credit consideration is not going away, in fact, all the participants believed requests for prior learning will increase in the future. The University of Central Missouri can improve upon the program and provide our students every opportunity to be successful in obtaining their education goals. 


\section{REFERENCES}

ACE (American Council on Education). (2009, March). A transfer guide: Understanding your military transcript and ACE credit recommendations. p. 5.

Adamson, D. W., \& Bailie, J. W. (2012). Education versus learning: Restorative practices in higher education, Journal of Transformative Education, 10(3), 139-156. doi: $10.1177 / 1541344612463264$

Anderson, L. W., \& Krathwohl, D. R. (eds.). (2001). A taxonomy for learning, teaching, and assession: A revision of Bloom's Taxonomy of educational objectives: Complete edition, New York: Longman.

Argyris, C. \& Schön, D. A. (1978). Organizational learning. Reading, MA: AddisonWesley.

Bandura, A. (1986). The explanatory and predictive scope of self-efficacy theory, Journal of Clinical and Social Psychology, 4, 359-373.

Bloom, B. S., \& Krathwohl, D. R. (1956). Taxonomy of educational objectives: The classification of educational goals, by a committee of college and university examiners. Handbook 1: Cognitive domain. New York: Longman.

CAEL (Council for Adult and Experiential Learning). (2010, March). Fueling the race to postsecondary success: A 48-institution study of prior learning assessment and adult student outcomes. Research Brief. Retrieved from $\underline{\text { www.cael.org/pla/publication/fueling-the-race-to-postsecondary-success }}$

CAEL (2016). Experiential learning and assessment for today's learner: The link between theory and practice. 2016 CAEL Forum and News. 
CAEL (2017, March). University of Central Missouri. Internal Comparisons: ALFI Data Cargo, R. (1982). You deserve the credit: A guide to receiving credit for non-college learning. Columbia, MD: Council for the Advancement of Experiential Learning.

CLEP College Board. Retrieved from https://clep.collegeboard.org/benefits-and-results

CLEP College Board. Retrieved from https://clep.collegeboard.org/about-clep/setting$\underline{\text { standards }}$

Corbin, J. \& Strauss, A. (2008). Basics of qualitative research (3rd ed.). Thousand Oaks, CA: Sage.

Csikszentmihalyi, M. 2014. Learning, "flow," and happiness. Applications of flow in human development and education (pp.153-172). doi: 10.10007/978-94-0179094-9_7

Creswell, J. W. (2009). Research design: Qualitative, quantitative, and mixed methods approaches. Thousand Oaks, CA: SAGE Publications, Inc.

Crosling, G., Heagney, M., \& Thomas, L. (2009). Improving student retention in higher education. Australian Universities Review, 51(2), 9-18.

Cross, K. P. (1981). Adults as learners. San Francisco, CA: Jossey-Bass Publishers.

Curran, M. K. (2014). Examination of the teaching styles of nursing professional development specialists, Part I: Best practices in adult learning theory, curriculum development, and knowledge transfer. The Journal of Continuing Education in Nursing. 45(5), 233-240.

Curran, M. K. (2014). Examination of the teaching styles of nursing professional development specialists, Part II: Correlational study on teaching styles and use of 
adult learning theory. The Journal of Continuing Education in Nursing, 45(8), 353-359.

Deci, E. L. \& Ryan, R. M. (2000). The "what" and "why" of goal pursuits: Human needs and the self-determination of behavior, Psychological Inquiry, 11(4), 227-268

Denzin, N. K. (1978). The research act: A theoretical introduction to sociological methods. New York, NY: McGraw-Hill.

Dewey, J. (1938). Experience \& education. New York, NY: Free Press.

EAB (Education Advisory Board). (2015). The CBE and PLA playbook tools for alternative credit programs. Research Brief, p. 87.

Finch, W. (2016). The adult learner: A critical ally for state economic development. The Council of State Government's Book of States 2016, 468- 472.

Fink, A. (2009). How to conduct surveys: A step-by-step guide (4th ed.). Thousand Oaks, CA: Sage.

Fisher, C. D. (1978). The effects of personal control, competence, and extrinsic reward systems on intrinsic motivation. Organizational Behavior and Human Performance, 21, 273-288.

Forehand, M. (2005). Bloom's taxonomy: Original and revised. In M. Orey (Ed.), Emerging perspectives on learning, teaching, and technology. Retrieved from http://epltt.coe.uga.edu/

Glynn, S. M., Aultman, L. P., \& Owen, A. M. (2005). Motivation to learn in general education programs, The Journal of General Education, 54(2), 150-170. doi: $10.1353 /$ jge.2005.0021 
Greer, T. W. (2013). Facilitating successful re-entries in the United States: Training and development for women returners. New Horizons in Adult Education \& Human Resource Development, 25(3), 41-61.

Hess, K. K., Jones, B. S, Carlock, D., \& Walkup, J. R. (2009). Cognitive rigor: Blending the strengths of Bloom's Taxonomy and Webb's Depth of Knowledge to enhance classroom-level processes. Retrieved from ERIC database. (ED517804)

Holton, E.F., III, Swanson, R. A., \& Naquin, S. S. (2001). Andragogy in practice: Clarifying the andragogical model of adult learning. Performance Improvement Quarterly, 14, 118-143.

Huddleston, M. W. (n.d.). An update on our challenges and opportunities. Retrieved from University of New Hampshire, Office of the President website: http://www.unh.edu/president/update-our-challenges-and-opportunities

Illeris, K. (2015). The development of a comprehensive and coherent theory of learning, European Journal of Education, 50(1). doi: 10.1111/ejed.12103

Institute of Medicine (2011). The future of nursing: Leading change, advancing health. Washington, DC: The National Academies Press.

Jinkens, R. C. (2009). Nontraditional students: Who are they? College Student Journal, 43(4), 979-987.

Kanter, M. J. (2011). American higher education: 'First in the world'. Change, 43(3), 719. doi: $10.1080 / 00091383.2011 .568896$

Kenner, C. \& Weinerman, J. (2011). Adult learning theory: Applications to nontraditional college students. Journal of College Reading and Learning, 41(2), 87-96.

Klein-Collins, R. (2011). ALFI, What's it all about? Strategies for colleges and universities to become adult learning focused institutions. The Catalyst, 40(2), 30- 
33. Retrieved from

https://login.cyrano.ucmo.edu/login?url=http://search.proquest.com/docview/8788

97896?accountid $=6143$

Knowles, M. (1973). The adult learner: A neglected species. Houston, TX: Gulf Publishing Company.

Knowles, M. S. (1980). The modern practice of adult education: From pedagogy to andragogy. Wilton, CN: Association Press.

Knowles, M. S., Holton, E. F., III, \& Swanson, R. A. (1998). The adult learner (5 ${ }^{\text {th }}$ ed.). Houston, TX: Gulf Publishing.

Keeton, M. (2002). Forward. In T. Flint, P. Zakos, \& R. Frey (Eds.), Best practices in adult learning: A self-evaluation workbook for colleges and universities (pp. vix). Dubuque, IA: Kendall/Hunt Publishing.

Kolb, D. A. (2014). Experiential learning: Experience as the source of learning and development ( $2^{\text {nd }}$ ed.). Upper Saddle River, NJ: Pearson Education, Inc. Retrieved from

http://proquestcombo.safaribooksonline.com.cyrano.ucmo.edu:2048/book/socialsciences/9780133892512

Leigh, K., Whitted, K., \& Hamilton, B. (2015). Integration of andragogy into preceptorship. Journal of Adult Education, 42(1), 9-17.

Mezirow, J. (1978a). Education for perspective transformation: Women's re-entry programs in community colleges. New York, NY: Centre for Adult Education, Teachers College, Columbia University.

Mezirow, J. (1978b). Perspective transformation. Adult Education, 28, 100-110. 
Mezirow, J. (1994). Understanding transformation theory. Adult Education Quarterly, 44(4), 222-232.

Mezirow, J. (1995). Transformation theory of adult learning. In M. R. Welton (Ed.), In defense of the life-world, (pp. 39-70). New York, NY: State University of New York Press.

Military and Veteran Services Team. Retrieved from https://www.ucmo.edu/vets/team.cfm

Mosca, J. B., Agacer, G., Flaming, L., \& Buzza, J. (2011). The assurance of learning process components and the effects of engaging students in the learning, American Journal of Business Education, 4(9), 43-56.

National Center for Higher Education Management Systems Information Center for Higher Education Policymaking and Analysis. Retrieved from $\underline{\text { www.higheredinfo.org/dbrowser/?level=nation } \& \text { mode }=\text { map } \& \text { state }=0 \& \text { submeasur }}$ $\underline{\mathrm{e}=224}$

Nonaka, I., \& Konno, N. (1998). The concept of "Ba": Building a foundation for knowledge creation. California Management Review, 40(3), 40-54. doi: $10.2307 / 41165942$

Obama, B. (2009, Feb) Address to Joint Session of Congress. Remarks of President Barack Obama - as prepared for delivery. Retrieved from http://www.whitehouse.gov/the_press_office/Remarks-of-President-Barack-Obama$\underline{\text { Address-to-Joint-Session-of-Congress }}$

Oliff, P., Palacios, V., Johnson, I., \& Leachman, M. (2013). Recent deep state higher education cuts may harm students and the economy for years to come. Retrieved 
from Center on Budget and Policy Priorities website:

http://www.cbpp.org/cms/?fa=view\&id=3927

Organisations for Economic Co-operation and Development. (2010). Education at a glance 2010. OECD Indicators. Retrieved from http://www.oecd.org

Paige, D.D., Sizemore, J. M., \& Neace, W. P., (2013). Working inside the box: Exploring the relationship between student engagement and cognitive rigor. NASSP Bulletin 97(2), 105-123. doi: 10.1177/0192636512473505

Rose, A. D. (2008). AAACE: Where are we going and where have we been? The future of AACE in light of its past. Adult Learning, 19.1(2), 34-36.

Ross-Gordon, J. M. (2011). Research on adult learners: Supporting the needs of a student population that is no longer nontraditional, Peer Review, 13(1). Retrieved from https://www.aacu.org/publications-research/periodicals/research-adult-learnerssupporting-needs-student-population-no

Ruffalo Noel Levitz (2015). Student retention indicators benchmark report. Cedar Rapids, Iowa: Ruffalo Noel Levitz. Retrieved from www.RuffaloNL.com/BenchmarkReports.

Ruffalo Noel Levitz (2016). 2016 Report: Motivation of adult learners for completing a college degree. Cedar Rapids, Iowa: Ruffalo Noel Levitz. Retrieved from www.RuffaloNL.com/Motivation.

Ruffalo Noel Levitz (2017). University of Central Missouri: Adult learner inventory. 02/2017. 
Ryan, R. M. (1982). Control and information in the intrapersonal sphere: An extension of cognitive evaluation theory. Journal of Personality and Social Psychology, 43, $450-461$.

Scriven, M. (1991). Evaluation thesaurus. (4 ${ }^{\text {th }}$ Ed.). Newbury Park, CA: Sage.

Starr-Glass, D. (2016). The thoughtful assessment of prior learning: hastening, ensuring and enhancing graduation. PLAIO Prior Learning Assessment Inside Out, 5, 1-17.

Stake, R. E. (1995). The art of case study research. Thousand Oaks, CA: Sage.

State Higher Education Executive Officers, State of Higher Finance (2012). Retrieved from http://www.sheeo.org/sites/default/files/publications/SHEF\%20FY\%201220130322rev.pdf

Taylor, E. (2000). Fostering Mezirow's transformative learning theory in the adult education classroom: A critical review. The Canadian Journal for the Study of Adult Education, 14(2), 1-28. Retrieved from https://login.cyrano.ucmo.edu/login?url=http://search.proquest.com/docview/2031 $\underline{55608}$ ? accountid $=6143$

The College Board. Retrieved from https://www.collegeboard.org/about

The College Board. (2014). 10 years of advanced placement exam data show significant gains in access and success; Areas for improvement. Retrieved from https://www.collegeboard.org/releases/2014/class-2013-advanced-placement$\underline{\text { results-announced }}$

Tinto, V. (2012). Completing college rethinking institutional action. Chicago, IL: The University of Chicago Press.

University of California, The facts:UC budget basics. (2011). Retrieved from http://budget.universityofcalifornia.edu/files/2011/12/Budget_fact_11.29.11.pdf 
University of Central Missouri, Undergraduate catalog. (2017). Retrieved from http://catalog.ucmo.edu/

University of Nevada-Las Vegas, Budget Cuts Continue at UNLV. (2010). Retrieved from https://www.unlv.edu/news/article/budget-cuts-continue-unlv

U.S. Department of Labor, Bureau of Labor Statistics, News Release, USDL-16-2025 (2016). Retrieved from https://www.bls.gov/news.release/pdf/wkyeng.pdf

US Bureau of Labor and Statistics. Employment status of the civilian population 25 years and over by educational attainment. Retrieved from https://www.bls.gov/news.release/empsit.t04.htm

Webb, N. (1997). Research Monograph Number 6: “Criteria for alignment of expectations and assessments on mathematics and science education." Washington, DC: CCSSO.

Webb, N. (1999). Research Monograph No. 18: "Alignment of science and mathematics standards and assessments in four states." Washington, DC: CCSSO.

Yadin, A., \& Or-Bach, R. (2010). The importance of emphasizing individual learning in the "collaborative learning era", Journal of Information Systems Education, 21(2), 185-194.

Zepke, N., \& Leach, L. (2010). Improving student engagement: Ten proposals for action, Active Learning in Higher Education, 11(3), 167-177. doi:

$10.1177 / 1469787410379680$ 


\section{Appendix A}

\section{Electronic Letters to Participant Groups}

\section{Letter to Group A}

Dear <Name of Faculty Assessor>,

I would like to request your participation in a study, entitled: The Process of Prior Learning Assessment for Credit at the University of Central Missouri-A Program Evaluation. This study is a requirement of the dissertation research for a doctoral degree in Educational Leadership and Policy Analysis from the University of MissouriColumbia.

The intention of this research is primarily information gathering to determine program effectiveness and organizational awareness of the prior learning assessment process. In the near future I will be contacting you to assist me in my data gathering efforts through a survey. Participation in this survey is completely voluntary. This survey should not take more than 20 minutes. Your participation will be confidential and remain anonymous in the reporting of results.

Please contact me if you have any questions or concerns about this request either by phone at (660) 543-8926 (office), (660) 441-8195 (cell) or by electronic mail at orcutt@ucmo.edu

Thank you in advance for your time and support.

Respectfully,

Vicki M. Orcutt

Doctoral Candidate 


\section{Electronic Letter to Group B, C and D}

Dear <Advisor, Staff Personnel, and Administrators>,

I would like to request your participation in a study, entitled: The Process of Prior Learning Assessment for Credit at the University of Central Missouri-A Program Evaluation. This study is a requirement of the dissertation research for a doctoral degree in Educational Leadership and Policy Analysis from the University of MissouriColumbia.

The intention of this research is primarily information gathering to determine program effectiveness and organizational awareness of the prior learning assessment process. In the near future I will be contacting you to assist me in my data gathering efforts through a $<$ focus group, interview>. Participation is completely voluntary. This <focus group, interview $>$ should not take more than $\langle 90,60\rangle$ minutes. Risk for this study is minimal, all audio tapes and transcripts will remain confidential, anonymous, and separate from any identifying information.

Please contact me if you have any questions or concerns about this request either by phone at (660) 543-8926 (office), (660) 441-8195 (cell) or by electronic mail at orcutt@ucmo.edu

Thank you in advance for your time and support.

Respectfully,

Vicki M. Orcutt

Doctoral Candidate 


\section{Appendix B}

\section{Prior Learning Program Evaluation Survey}

This survey is being conducted by Vicki Orcutt, a doctoral student at the University of Missouri-Columbia in Educational Leadership and Policy Analysis. My dissertation research is on the University of Central Missouri's Prior Learning Assessment (PLA) program.

I will use your feedback to assist in determining the PLA program effectiveness. This information, compiled with data received from archival documentation, interviews and focus groups will provide the breath of data necessary to complete a thorough programmatic review.

Participation in this program evaluation is voluntary. At any time you may withdraw from survey participation with no consequences, or you may simply choose not to answer particular questions. In addition, I am working under the direction of Dr. Sandy Hutchinson, of the University of Central Missouri (UCM). You may contact her if there are any concerns related to the process or results of this interview. Her number is: (660) 543-4720. Completion of this survey infers consent to participate. The survey will last no longer than 20 minutes.

1. Have you ever been asked to review documentation of prior learning for credit consideration?
a. Yes
b. No

If no, survey skip logic takes participants to questions 15 through 19.

2. What category of prior learning assessment have you evaluated for credit consideration?
a. Undergraduate
b. Graduate
c. Both

3. How long have you been a faculty member at UCM?
a. Less than 2 years
b. 2 to 5 years
c. 6 to 10 years
d. Over 10 years

4. What type of prior learning have you accepted for credit in the past? Check all that apply:

a. Standardized Tests (CLEP, AP, DSST)

b. Military Transcripts provided by the American Council on Education (ACE)

c. Civilian ACE transcripts

d. Challenge exams

e. Department developed examinations 


\section{f. Student portfolios}

5. In your role as a faculty assessor of Prior Learning Assessment (PLA), how do you determine whether credit should be awarded?

6. On average how much time is required for you to review PLA documentation for credit consideration?
a. Less than 2 hours
b. 2-3 hours
c. 4-5 hours
d. Over 5 hours

7. If/When credit was not awarded what were the top 3 reasons why?

\#1 reason:

\#2 reason:

\#3 reason:

8. How likely are you to give credit for prior learning for military with ACE transcripts?
a. Highly likely
b. Likely
c. Somewhat likely
d. Unlikely
e. Highly unlikely

Please provide rationale for answer.

9. How likely are you to give credit for prior learning to civilians with ACE transcripts?
a. Highly likely
b. Likely
c. Somewhat likely
d. Unlikely
e. Highly unlikely

10. How likely are you to give credit for a student's portfolio of prior learning? (Note: A portfolio describes how the student has applied their learning in relation to the credit being sought)
a. Highly likely
b. Likely
c. Somewhat likely 

d. Unlikely
e. Highly unlikely

11. Does your department allow students to take challenge exams to demonstrate proficiency of course objectives? (Note: Challenge exams are normally used to bypass a prereq course or to move up to a more advanced course).
a. Yes
b. No

12. In your assessment of prior learning, please rank the type of credit awarded with 1 being the most awarded and 5 being the least awarded credit.
a. General Education Credit
b. Major courses (upper level)
c. Core courses (lower level)
d. Electives approved as part of degree
e. Free electives or fall through credit

13. What is the impact of prior learning on persistence and retention?
a. Not at All
b. Slight
c. Somewhat Significant
d. Significant
e. Extremely Significant

14. If you are willing to be interviewed please provide your name, email, and phone number.

Remaining questions were asked to participants who did not evaluate prior learning for credit.

15. When meeting with nontraditional students is transfer credit discussed?
a. Not at All
b. Sometimes
c. Frequently
d. Almost Always
e. Always

16. What do you know about prior learning assessment and credit for prior learning?

17. When meeting with nontraditional students is prior learning (CLEP, ACE Military and Civilian Credit, Departmental exams or Portfolios) discussed?
a. Never
b. Rarely 

c. Sometimes
d. Frequently
e. Almost Always
f. Always

18. Where would you send a student wanting information on credit for prior learning?

19. What is the impact of prior learning on persistence and retention?
a. Not at All
b. Slight
c. Somewhat Significant
d. Significant
e. Extremely Significant 


\section{Appendix C}

Processing Staff Interview Protocol

Date:

Start Time:

Introduction:

Good morning/afternoon. Thank you for taking the time to answer my questions about your experiences with the University of Central Missouri's Prior Learning Assessment (PLA) program. The purpose of today's discussion is to gather information from you about the effectiveness of the university's PLA program. My name is Vicki Orcutt, and I will be conducting the interview. In order to ensure accuracy, I will be audio taping the interview.

Remember, there is no right or wrong answers. If you want to follow-up on a question or give an example, feel free to do so. I want this to be more of a conversation between professionals. Our session will last about 45-60 minutes and we will not be taking a formal break. Please let me know if you need to leave for any reason. Before we begin with the interview, please look over and sign the Informed Consent form for this interview.

\begin{tabular}{|l|l|}
\hline Questions & Information \\
\hline $\begin{array}{l}\text { 1. Please tell me your name and the role your } \\
\text { position serves on campus. }\end{array}$ & $\begin{array}{l}\text { Learn about the Participant. Establish a } \\
\text { connection. }\end{array}$ \\
\hline $\begin{array}{l}\text { 2. What has been your experience with prior } \\
\text { learning assessments? }\end{array}$ & Research Question 3 \\
\hline $\begin{array}{l}\text { 3. What has been the success, if any, of UCMs } \\
\text { PLA process? }\end{array}$ & Research Question 1 \\
\hline $\begin{array}{l}\text { 4. In your opinion, how important is } \\
\text { recognizing prior learning with respect to } \\
\text { retention and persistence? }\end{array}$ & Research Question 4. \\
\hline $\begin{array}{l}\text { 5. Is there anything the University could be } \\
\text { doing to improve the process for reviewing } \\
\text { prior learning credit? }\end{array}$ & Research Question 1 and 3 \\
\hline $\begin{array}{l}\text { 6. What is your impression of the future of } \\
\text { prior learning assessments and credit for prior } \\
\text { learning? }\end{array}$ & Research Question 4 \\
\hline $\begin{array}{l}\text { 7. Is there anything else you would like to } \\
\text { share with me that I have not asked? }\end{array}$ & Research Question 2, 3, 4, 5, 6 \\
\hline
\end{tabular}

Thank you for your time and participation. 


\section{Appendix D}

\section{Administration Interview Protocol}

Date:

Start Time:

Introduction:

Good morning/afternoon. Thank you for taking the time to answer my questions about your experiences with the University of Central Missouri's Prior Learning Assessment (PLA) program. The purpose of today's discussion is to gather information from you about the effectiveness of the university's PLA program. My name is Vicki Orcutt, and I will be conducting the interview. In order to ensure accuracy, I will be audio taping the interview.

Remember, there is no right or wrong answers. If you want to follow-up on a question or give an example, feel free to do so. I want this to be more of a conversation between professionals. Our session will last about 45-60 minutes and we will not be taking a formal break. Please let me know if you need to leave for any reason. Before we begin with the interview, please look over and sign the Informed Consent form for this interview.

\begin{tabular}{|l|l|}
\hline Questions & Information \\
\hline $\begin{array}{l}\text { 1. Please tell me your name and the role your } \\
\text { position serves on campus. }\end{array}$ & $\begin{array}{l}\text { Learn about the Participant. Establish a } \\
\text { connection. }\end{array}$ \\
\hline $\begin{array}{l}\text { 2. What has been your experience with prior } \\
\text { learning assessments? }\end{array}$ & Research Question 3 \\
\hline $\begin{array}{l}\text { 3. There are several forms of prior learning to } \\
\text { be considered for credit. Specifically, CLEP, } \\
\text { ACE-Military, ACE-Credit (Civilian), } \\
\text { Challenge Exams, departmentally developed } \\
\text { exams, and portfolios. Of the types of PLA } \\
\text { described what have you had the most } \\
\text { experience with? }\end{array}$ & \\
$\begin{array}{l}\text { Probe: Of the types described are there any } \\
\text { forms of prior learning you would be hesitant } \\
\text { to award credit? If so, why }\end{array}$ & \\
\hline $\begin{array}{l}\text { 4. Does your college/department have a policy } \\
\text { with respect to prior learning assessment for } \\
\text { credit? }\end{array}$ & Research Question 2. \\
\hline $\begin{array}{l}\text { 5. Do you see any correlation between } \\
\text { awarding credit for prior learning and } \\
\text { persistence? Please explain. }\end{array}$ & \\
\hline $\begin{array}{l}\text { 6. Is there anything the University could be } \\
\text { doing to improve the process for reviewing } \\
\text { prior learning credit? }\end{array}$ & Research Question 1 \\
\hline $\begin{array}{l}\text { 7. What is your impression of the future of } \\
\text { prior learning assessments and credit for prior } \\
\text { learning? }\end{array}$ & Research Question 4 \\
\hline
\end{tabular}


8. Is there anything else you would like to

Research Question 2, 3, 4, 5, 6 share with me that I have not asked?

Thank you for your time and participation. 


\section{Appendix E}

\section{Focus Group Protocol}

Date:

Start Time:

Introduction:

Good morning/afternoon. Thank you for taking the time to participate in this focus group to discuss the University of Missouri's prior learning assessment program. My name is Vicki Orcutt, and I will serve as the moderator for today's discussion. In order to ensure accuracy, I will be audio taping the focus group.

Remember, there are no right or wrong answers rather differing points of view. Please feel free to share your point of view even if it differs from what others have said. If you want to follow-up on something that someone has said, you want to agree, disagree or give an example, feel free to do so. I want this to be more of a conversation between professionals. Our session will last about 90 minutes and we will not be taking a formal break, however, let me know if you need to leave for any reason.

While the nature of a focus group makes it impossible to provide complete anonymity, your confidentiality will be maintained by the evaluator during future reporting. No names will be included in any reports. Before we begin with the focus group, please look over and sign the Informed Consent form. Let's start this focus group with introductions.

\begin{tabular}{|l|l|}
\hline Questions & Information \\
\hline $\begin{array}{l}\text { 1. Please tell me your name, how long you } \\
\text { have been an advisor, and the students you } \\
\text { serve. }\end{array}$ & $\begin{array}{l}\text { Learn about the Participant. Helps establish the } \\
\text { level of contact with the PLA process. }\end{array}$ \\
\hline $\begin{array}{l}\text { 2. What do you know about prior learning } \\
\text { assessment and credit for prior learning? }\end{array}$ & Research Question 3 \\
\hline $\begin{array}{l}\text { 3. In your advising sessions is prior learning } \\
\text { assessment addressed? }\end{array}$ & Research Question 3 \\
\hline $\begin{array}{l}\text { 4. Based on your interaction with and/or } \\
\text { knowledge of prior learning assessments what } \\
\text { would you consider to be UCMs challenges } \\
\text { with the process? }\end{array}$ & Research Question 1 \\
\hline $\begin{array}{l}\text { 5. What would you consider to be a success } \\
\text { with the university's prior learning assessment } \\
\text { program? }\end{array}$ & Research Question 1 \\
\hline $\begin{array}{l}\text { 6. There are several types of prior learning. } \\
\text { What types are you aware of? }\end{array}$ & Research Question 3 \\
\hline $\begin{array}{l}\text { 7. Is there anything else you would like to } \\
\text { share with me that I have not asked? }\end{array}$ & Research Question 2, 3, 4, 5, 6 \\
\hline
\end{tabular}

Thank you for your time and participation. 


\section{Appendix F}

\section{INFORMED CONSENT FORM - Academic Advisors}

Identification of Researchers: This research project is being conducted by Vicki Orcutt, supervised by Dr. Sandy Hutchinson. I am a doctoral student with the Department of Educational Leadership and Policy Analysis at the University Missouri.

Purpose of the Study: The purpose of this study is to explore the impact of prior learning assessment for credit on the retention and persistence of nontraditional students at the University of Central Missouri (UCM).

Request for Participation: I am requesting your participation in a focus group on UCMs prior learning assessment program. It is up to you whether you would like to participate. If you decide not to participate, you will not be penalized in any way. You can also decide to stop at any time without penalty. If you do not wish to answer any of the questions, you may simply skip them. You may withdraw your data at the end of the study.

Exclusions: You must be an academic advisor with the University of Central Missouri. .

Description of Research Method: This study involves participating in a focus group. The focus group will consist of open-ended questions and will take no more than two hours to complete. The focus group will be audiotaped and transcribed. You will have a chance to ask questions.

Privacy: All of the information collected will be confidential. Data collected will be coded to ensure no personally identifying information will be revealed within the completed program evaluation. Data will be stored on a password protected computer or in a locked file cabinet stored in a secure office. Upon completion of the program evaluation, the information will remain secured until it is destroyed by shredding and/or deletion of all electronic files.

Explanation of Risks: The risks associated with participating in this study are similar to the risks of everyday life. There will be no compensation or incentives for participation.

Explanation of Benefits: As a participant in educational research you will benefit from participating in this study by providing important information of benefit to students.

Questions: If you have any questions about this study, please contact Dr. Sandy Hutchinson. She can be reached at (660) 543-4720. If you have any questions about your rights as a research participant, please contact the Human Subjects Protection Program at (660) 543-4621 or the University of Missouri at (573) 882-3181 
If you would like to participate, please sign a copy of this letter and return it. The other copy is for you to keep.

I have read this letter and agree to participate.

Signature:

Date 


\section{Appendix G \\ INFORMED CONSENT FORM - Administrators and Staff}

Identification of Researchers: This research project is being conducted by Vicki Orcutt, supervised by Dr. Sandy Hutchinson. I am a doctoral student with the Department of Educational Leadership and Policy Analysis at the University Missouri.

Purpose of the Study: The purpose of this study will be to explore the impact of prior learning assessment for credit on the retention and persistence of nontraditional students at the University of Central Missouri.

Request for Participation: I am requesting your participation in a semi-structured interview on UCMs prior learning assessment program. It is up to you whether you would like to participate. If you decide not to participate, you will not be penalized in any way. You can also decide to stop at any time without penalty. If you do not wish to answer any of the questions, you may simply skip them. You may withdraw your data at the end of the study.

Exclusions: You must be a stake holder in the prior learning assessment program at the University of Central Missouri.

Description of Research Method: Interviews will be conducted with administrators and staff. The interview will be audiotaped and transcribed and will take no more than 60 minutes.

Privacy: All information collected will be confidential. Data collected will be coded to ensure no personally identifying information will be revealed within the completed program evaluation. Data will be stored on a password protected computer or in a locked file cabinet in a secure office. Upon completion of the program evaluation, the information will remain secured until it is destroyed by shredding and/or deletion of all electronic files.

Explanation of Risks: The risks associated with participating in this study are similar to the risks of everyday life. There will be no compensation or incentives for participation.

Explanation of Benefits: As a participant in educational research you will benefit from participating in this study by providing important information of benefit to students.

Questions: If you have any questions about this study, please contact Dr. Sandy Hutchinson. She can be reached at (660) 543-4720. If you have any questions about your rights as a research participant, please contact the Human Subjects Protection Program at (660) 543-4621 or the University of Missouri at (573) 882-3181. 
If you would like to participate, please sign a copy of this letter and return it. The other copy is for you to keep.

I have read this letter and agree to participate.

Signature:

Date 


\section{Appendix H}

\section{Human Subject Approval to Collect Research}

Amendment

8/14/2017

\section{Protocol Number: 836}

Dear Vicki Orcutt:

Your request to amend your research project, 'The Process of Prior Learning Assessment for Credit at the University of Central Missouri-A Program Evaluation', was approved by the University of Central Missouri Human Subjects Review Committee on $8 / 14 / 2017$. You may collect data for this project until 6/16/2018. Your informed consent is also approved until 6/16/2018.

If an adverse event (such as harm to a research participant) occurs during your project, you must IMMEDIATELY stop the research unless stopping the research would cause more harm to the participant. If an adverse event occurs during your project, notify the committee IMMEDIATELY at researchreview@ucmo.edu.

The following will help to guide you. Please refer to this letter often during your project.

- If you wish to make changes to your study, submit an "Amendment" through Blackboard under the "Amendment and Renewals" tab. You may not implement changes to your study without prior approval of the UCM Human Subjects Review Committee.

- If the nature or status of the risks of participating in this research project change, submit an "Amendment" through Blackboard under the "Amendment and Renewals" tab. You may not implement changes to your study without prior approval of the UCM Human Subjects Review Committee.

- If you are nearing the expiration date for collecting data for this project

$(6 / 16 / 2018)$ and you have not finished collecting data:

1. submit your project application via Blackboard under the "Amendment and Renewals" tab (include any revisions and/or amendments approved since you submitted your application initially)

\section{AND}

2. submit a "Renewal Report" through Blackboard under the "Final/Renewal Report" tab.

- When you have completed your collection of data, please submit the "Final Report" found on Blackboard under the "Final/Renewal Report" tab. 
If you have any questions, please feel free to contact me at researchreview@ucmo.edu.

\section{Sincerely,}

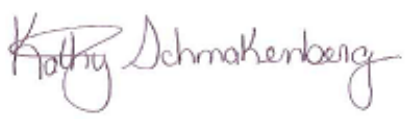

Kathy Schnakenberg

Program Administrator/Research Compliance Officer Office of Sponsored Programs and Research Integrity University of Central Missouri 


\section{Appendix I}

\section{University of Missouri IRB Review}

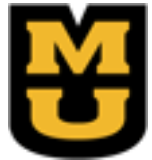

\section{Institutional Review Board University of Missouri-Columbia}

190 Galena Hall; Dc074.00

Columbia MO 65212

573-882-3181

irb@missouri.edu

Dear Vicki Orcutt,

The IRB reviewed your project entitled The Process of Prior Learning Assessment for Credit at the University of Central Missouri - A Program Evaluation and made the following determination:

Per your confirmation, this study is for program evaluation purposes only and does not require IRB approval.

If you have any questions regarding this determination, please feel free to contact our office at 573-882-3181, irb@missouri.edu, or by replying to this notification.

Note Regarding Publications: It is appropriate to disseminate and replicate QI/program evaluation successes, including sharing the information external to an organization. This may include presentations and publications. The mere intent to publish the findings does not require IRB review as long as the publication does not refer to the activity as research.

Thank you,

MU Institutional Review Board 
VITA

Vicki Orcutt was born on August 6, 1959 in Miami, Florida to Patricia and Kevin Gordon. After graduating from Miami Norland Senior High School, she joined the United States Air Force in March 1978. Ms. Orcutt spent 30 years in the Air Force culminating her career as the Command Chief Master Sergeant for the $509^{\text {th }}$ Bomb Wing, Whiteman Air Force Base, Missouri. As the Command Chief, she was responsible for the morale, welfare, and training of 3,000 enlisted personnel.

In 2007, Ms. Orcutt retired from the military. Ms. Orcutt began her second career as the office professional for the Aviation Department at the University of Central Missouri. She has worked at the University of Central Missouri for the last ten years. Since January 2016 she has been the Director for Academic Outreach in Extended Studies.

Her primary focus as the Director of Academic Outreach is the adult learner with emphasis on non-credit industry recognized credentials and professional development. Ms. Orcutt is the coordinator for prior learning assessment for credit. This prompted her to conduct a program evaluation for her dissertation.

Vicki Orcutt has been married to John Orcutt for 30 years and they have three daughters: Samantha, Danielle, and Taylor. The also have four grandsons: David, Noah, Ezekiel, and Clay. 